EXPLORING SUPPORT PERSONS' NARRATIVE ACCOUNTS OF WAITING FOR LUNG

TRANSPLANT

by

Linda Liu,

BScN, Ryerson University, Toronto, 2013

BSc, University of Toronto, Toronto, 2007

\author{
A thesis \\ presented to Ryerson University \\ in partial fulfillment of the \\ requirements for the degree of \\ Master of Nursing \\ in the Program of \\ Nursing
}

Toronto, Ontario, Canada, 2015

(C) Linda Liu 2015 


\section{AUTHOR'S DECLARATION FOR ELECTRONIC SUBMISSION OF A THESIS}

I hereby declare that I am the sole author of this thesis. This is a true copy of the thesis, including any required final revisions, as accepted by my examiners. I authorize Ryerson University to lend this thesis to other institutions or individuals for the purpose of scholarly research I further authorize Ryerson University to reproduce this thesis by photocopying or by other means, in total or in part, at the request of other institutions or individuals for the purpose of scholarly research. I understand that my thesis may be made electronically available to the public. 


\title{
EXPLORING SUPPORT PERSONS' NARRATIVE ACCOUNTS OF WAITING FOR LUNG
}

\section{TRANSPLANT}

\author{
ABSTRACT \\ Linda Liu \\ Master of Nursing Program \\ Ryerson University, Toronto, 2015
}

Patients must have one designated support person (e.g., family member) provide constant care during the waiting period for lung transplant - this may involve relocation to be within 2.5 hours from the transplant site. There is little research concerning support persons' experiences of waiting for transplant. This narrative study involving interviews and journaling, framed by the concept of liminality was conducted to explore support persons' accounts of waiting for lung transplant. Findings indicate that support persons entered into a liminal space where they became focused upon and confined to patients' routines and needs. The uncertainty of waiting was interwoven with emotions of hope, fear, and isolation. Implications include the need to identify the support person as a care recipient and implement supportive and counselling interventions responsive to their needs. This research also advances the theoretical concept of liminality in illness and provides direction for future research, policy and education. 


\section{ACKNOWLEDGEMENTS}

The past two years was an overwhelming, challenging and fulfilling journey. As I had been immersed in the world of narratives, please indulge me to use one more metaphor. My thesis experience was like treading in deep waters. The waters were murky, the waves were unpredictable, and my sense of direction was unsure. Yet, with the help of wonderful friends, mentors and families, I persisted and emerged from the deep waters stronger, more courageous, and more convicted in the importance of uncovering liminal spaces and persons.

To my wonderful thesis committee: thank you for your unwavering support and guidance! Dr. Heather Beanlands, you instilled a sense of steadfastness with your calm demeanor, which brought clarity to the murky waters and quelled my anxieties. Dr. Oona St-Amant, your passion and critical lens raised thought-provoking gaps in our discussions and brought warmth into the deep waters. And to my thesis supervisor and dear friend Dr. Jennifer Lapum, who was my lifeguard. You knew when I needed to push and keep treading, but you also knew when to hand me a life jacket. Especially when I was grieving for my loss, your kindness and compassionate encouragement gave me strength to find healing in my work. I hate to boast, but I really do think I have the best thesis committee. I must also thank all my instructors and mentors within the Ryerson Nursing program, who have continued to invest their knowledge, time and smiles to help me grow. And to my thesis support group: I am glad we found comfort in our shared "suffering." Be strong! It will be over before you soon know it.

To my mother, thank you for the comfort of good food so I didn't become a starving writer. To my sister Cindy, who believed that all of life's problems could be solved with a fresh coat of nail polish. It turns out that you were right most of the time. I give thanks for my church family who continued to pray for me and cheer me on. And, to my wonderful husband Austin, 
my rock and my comfort. You are a dream and a true embodiment of resilience because you have to endure and put up with me! Even when you would return home from work and find me dishevelled and incoherently staring at a blank screen, you still claimed I was beautiful. Thank you, I love you so much.

Last, to my Heavenly Father, I hope that my thesis work bears witness to your character and love. Thank You for the strength and opportunity to listen, to bear, and to share these rich and heartfelt stories.

Whatever you do, work at it with all your heart, as working for the Lord, not for human masters, since you know you will receive an inheritance from the Lord as a reward. It is the Lord Christ you are serving. (Colossians 3:23-24) 


\section{DEDICATION}

I dedicate my thesis to all the wonderful storytellers and characters in my personal stories. To Caitlin, Matthew, Dianne and Roger, these are of course not your real names, but you know who you are. Thank you for the privilege of listening to your stories, and for allowing me to share in your liminal spaces.

I also dedicate my thesis to my grandfather. When I was a child and had to write about my favourite family member, I wrote about you. I am glad for the chance to pay homage to your legacy and character. I miss you very much. 


\section{TABLE OF CONTENTS}

Page

AUTHOR'S DECLARATION ...................................................................................... ii

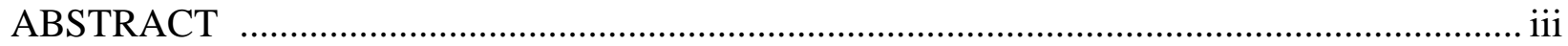

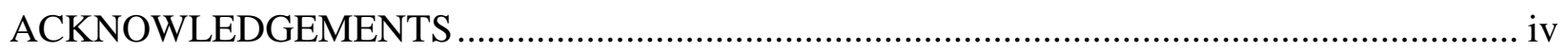

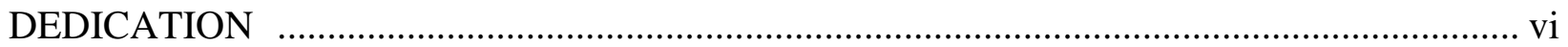

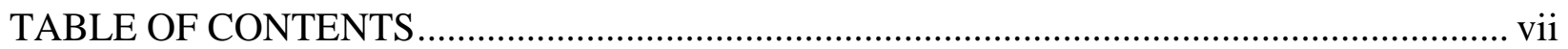

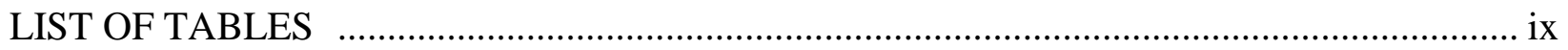

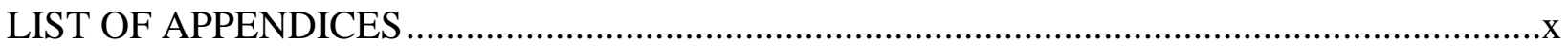

CHAPTER 1 PROLOGUE: MY STORIES OF WAITING ................................................ 1

CHAPTER 2 INTRODUCTION: WAITING FOR LUNG TRANSPLANT .......................... 13

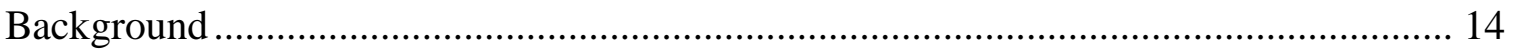

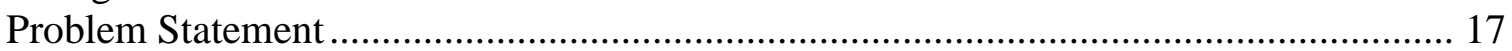

Research Purpose and Questions .......................................................................18

Significance to Policy, Practice and Education ............................................................ 19

CHAPTER 3 THEORETICAL LENS OF LIMINALITY ............................................. 21

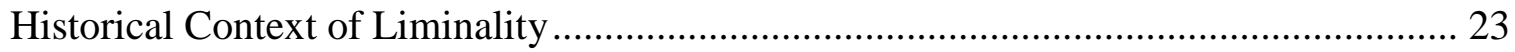

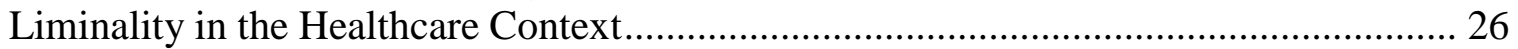

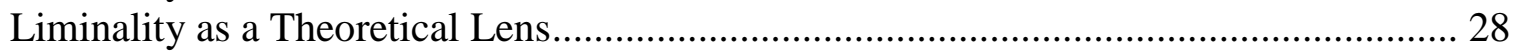

CHAPTER 4 LITERATURE SYNTHESIS AND CRITIQUE .......................................... 30

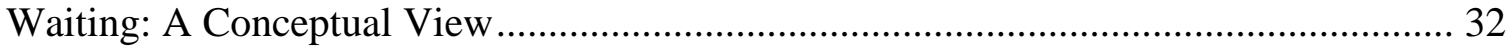

Shared Experiences of Waiting for Lung Transplant ................................................ 34

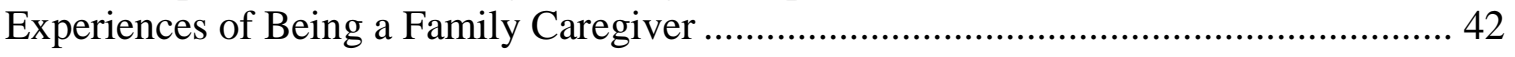

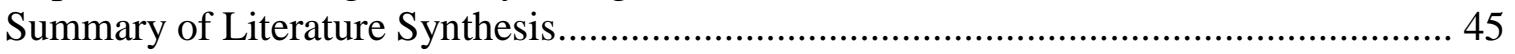

CHAPTER 5 RESEARCH METHODOLOGY AND METHODS.......................................47

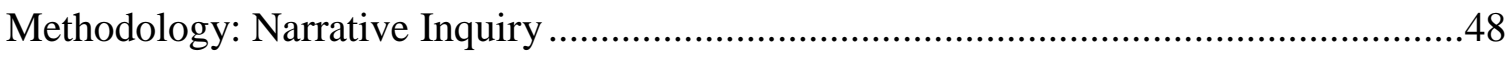

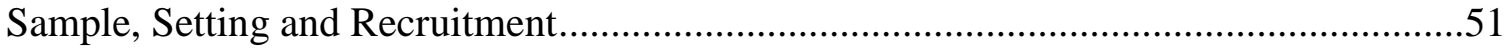

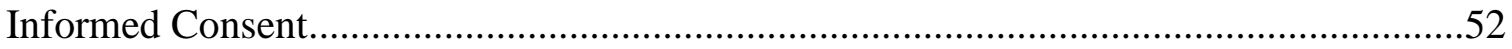

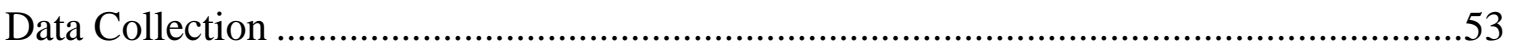




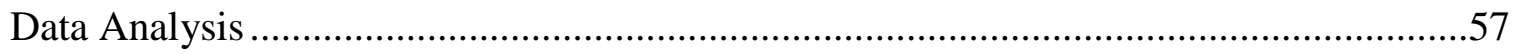

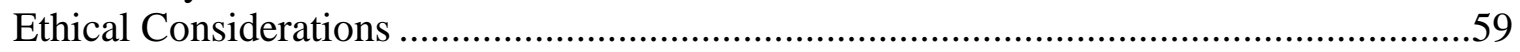

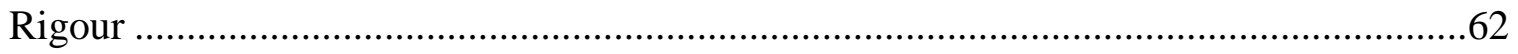

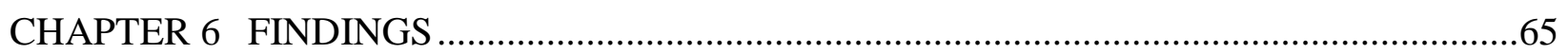

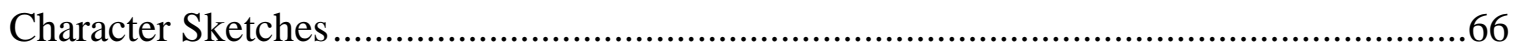

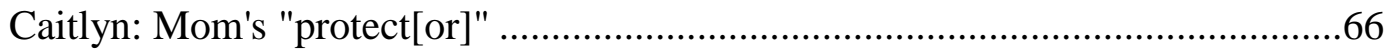

Matthew: Being prepared for the "waiting game" ............................................68

Dianne: The "interminable wait" ...................................................................68

Roger: "Fish out of water"-Transitioning into the world of waiting ..................69

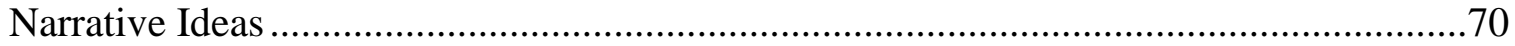

The physical and social space of waiting ..................................................... 71

The patient as the focal point ...................................................................... 80

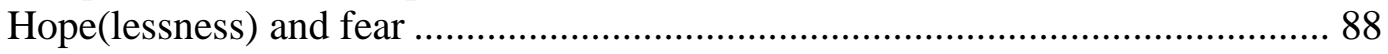

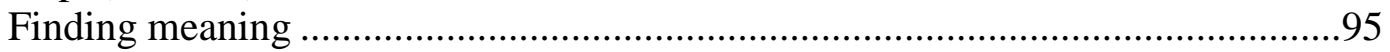

The (un)support of the support person.................................................97

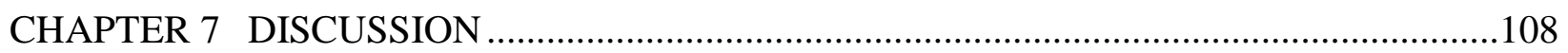

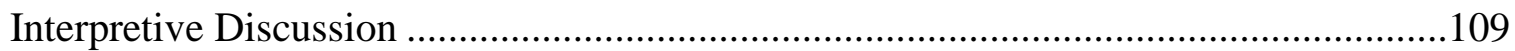

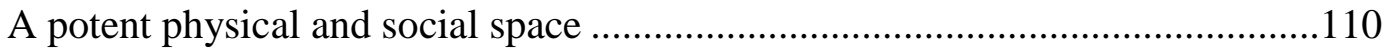

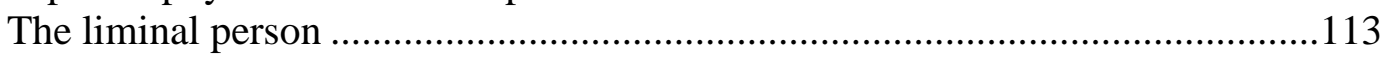

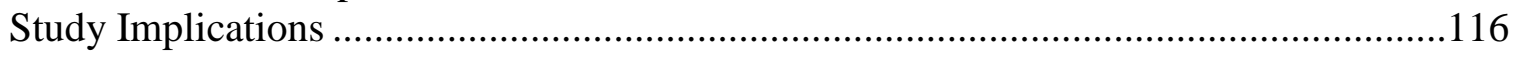

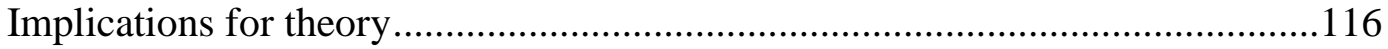

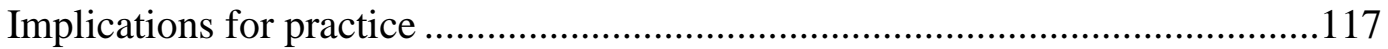

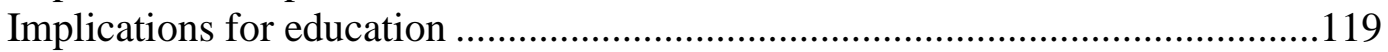

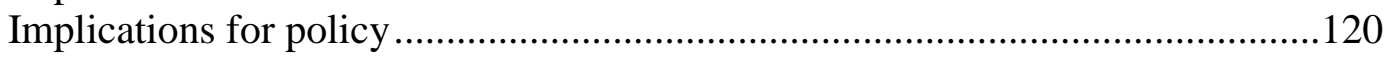

Implications for research................................................................. 121

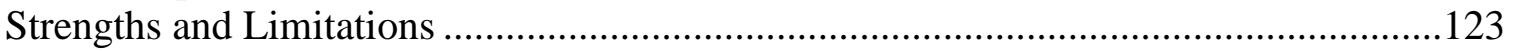

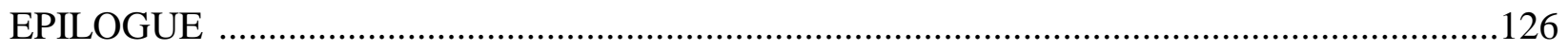

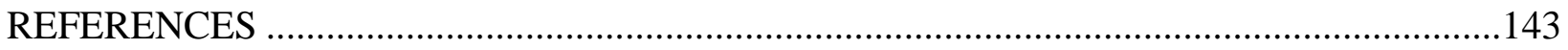




\section{LIST OF TABLES}

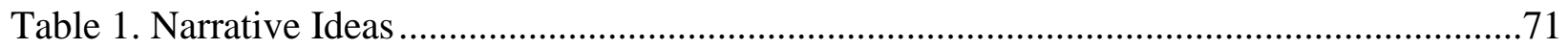




\section{TABLE OF APPENDICES}

APPENDIX A: RECRUITMENT POSTER

APPENDIX B: CONSENT FORM

APPENDIX C: DEMOGRAPHIC FORM

APPENDIX D: RECRUITMENT AND DATA COLLECTION PROCEDURE

APPENDIX E: INTERVIEW GUIDE I

APPENDIX F: JOURNALING GUIDE 


\section{CHAPTER 1}

PROLOGUE: MY STORIES OF WAITING 
But do not forget this one thing, dear friends: With the Lord a day is like a thousand years, and a thousand years are like a day. The Lord is not slow in keeping his promise, as some understand slowness. (II Peter 3:8-9)

When I was a young child, I was always struck and perhaps, a little indignant by this Bible scripture. I marveled at the omnipotence of God, who was able to pass time in a blink of an eye, or stretch a day into a thousand years; but at times when I was impatient, I felt it to be unfair that God kept His powers to Himself. I later came to understand that this passage was referring to the waiting period between the present time and the day of the Lord Jesus Christ's Second Coming. In my Christian faith, the Second Coming signals a judgement period and an end to all suffering. As we wait for this day to come, I as a Christian am esteemed with the task of transforming my character to be more Christ-like that I may serve as a living witness of God's unconditional love. II Peter 3:8-9 indicates that only God alone will know when the Second Coming is, but this waiting period for Christians is also a time for hope that we may bring more people to know Christ and be saved through His salvation. While I do not know when this moment will take place, and it may not even arrive during my lifetime, it is a moment I constantly wait for.

While I carry the hope through waiting, others who do not share my faith may find waiting to be an arduous experience, especially the patients whom I have met in my nursing practice. Waiting can take on a different character when interwoven with illness, suffering and thoughts of mortality. As will be shown, the phenomenon of waiting is a key focus of my narrative study. To preface this research, I begin with my own personal and professional narratives of waiting because these reflective accounts are the departure point of my work and help explicate my own positionality as a researcher (Lapum, 2008). As I recount these stories, 
different voices and my own reflective self-talk are represented through different italicized fonts so they are distinguished from the rest of my story.

\section{Personal Narratives of Waiting}

Waiting is an everyday occurrence in life. I wait for the microwave to beep, I wait for the bus to come, I wait in line at the theatre, I sit in the waiting area for my doctor's appointment. If I am not running late, I usually do not mind standing in the waiting queue. However, if I am in a hurry, I can feel my frustration and anxiety rising. In our North American digital age, we have learned to overcome waiting through multi-tasking. I find myself turning on my cell phone, checking my email or current news to fill the void of waiting. By engaging in chats with friends, ordering products online, and responding to correspondence while waiting, I feel more accomplished that seconds were not wasted. My understanding of wasted time stems from the need to remain occupied or productive as time passes, whereby waiting in queue or waiting in the doctor's office appears to be a waste even though it is necessary to reach my objective (i.e. paying for groceries or seeing the doctor). My perception on the movement of time also changes given the context of waiting. When I was waiting outside the church on my wedding day, I felt

like the clock had stopped as I was teeming with anticipation to walk down the aisle. Conversely, when I was sitting in a packed conference room waiting to give my presentation, I felt as if the hands on the clock were racing as I anticipated my struggle to keep within the time limit. For me, waiting is as if the sands in an hourglass are not subject to gravity. They can rush through the opening, or remain suspended in space.

Waiting as a patient or family member in a healthcare context is a complex and nuanced experience. Previously, as a novice nursing student, I was irritated with my own family when we moved our grandfather into a long-term care facility due to end-stage Parkinson's disease. I 
never wanted my grandfather to go to a long-term care facility, because I believed those were not his wishes. I knew he would not receive timely care. My family members were constantly upset that they had to wait for his medications, wait for bathroom assistance, wait for feeding. I wanted to scream to them, Well, what did you expect? Could they not see that there were nine residents to one Personal Care Assistant (PCA)? That there was one Registered Practical Nurse giving medications to over 30 residents? I tried to relay to them the extent of a healthcare professional's workload, only to have my family retort that I did not care for my grandfather's best interests, that I should have pushed harder to advocate for him, filed more complaints to the nursing home administrators. I was angry at their insinuations and felt helpless when being pressed by my family members because I believed that we were being unreasonable; and yet, I felt equally powerless when some of my grandfather's PCAs gave me exasperated looks upon my call bell or verbal requests for assistance. I took your grandfather to the bathroom this morning before breakfast. I can't take him to the bathroom all day long.

I watched my grandfather's rapid decline with mounting frustration and grief. He grimaced in pain and embarrassment from needing help to complete bodily functions like toileting, daily activities that he had mastered for the majority of his lifetime. His embarrassment and frustration would heighten when he was unable to hold out on the wait for assistance, ashamed of his incontinence and powerlessness. It hurt me to see him become increasingly agitated and distressed when waiting for help. In these moments, every waiting second was an excruciating second, knotted with anxiety and frustration for him and family members, including me. In these moments of waiting, my family and I had no patience, we had no understanding of others' needs, only my grandfather's immediate concerns. We attempted to fill the gap of care. We transferred him to the bathroom alone when two-person assists were recommended, we 
shamelessly chased down PCAs in the hallway, we took over his feeding. But when my grandfather continued to deteriorate, and his care became more complex, we became once again at the mercy of the long wait before healthcare professionals responded to our requests for care assistance. Once again, I became helpless standing over his call bell. Waiting created tensions, friction over mismatched expectations particularly between us (family) and them (healthcare professionals). My family would bemoan, Those workers are so lazy. My grandmother unfortunately heard a nursing home staff member comment This family is so demanding. For us, waiting closed off communication and created a barrier to mutual understanding among family members and healthcare professionals. Even though I cognitively knew that healthcare professionals were busy, as a family member, my grandfather's needs superseded this understanding. Every time I stepped foot into the nursing home, I felt strained, anticipating that I would have to engage in a standoff with those who provided direct care for my grandfather. Since when did waiting for care become so tension-filled? Or, am I just becoming more aware of the experience of waiting because I am now the one waiting?

The emotions of waiting can become even more exacerbated when there is an unknown about the outcome, which can have a potentially devastating consequence. This occurred for me when I was waiting in the emergency department at midnight, and my mother-in-law was doubling over in pain. What started as a week of abdominal discomfort and reduced appetite had grown into an unrelenting pain, to the point that my mother-in-law, a woman known for her stoicism, was hunched over and moaning continuously. There were no inpatient beds or emergency stretchers available that night as my mother-in-law was slumped over in a hard triage chair, waiting, to be assessed. The nurses kept apologizing: I'm sorry, we are maxed out on beds tonight. After your blood tests and CT [contrast tomography] scan, you'll have to wait in the triage area until 
we have a bed available for you. No, l'm sorry we can't give you pain medications, as the physician doesn't know where the pain is originating from.

Exhausted and numb, we continued to sit in frustration while waiting for a bed, waiting for answers. When we received a stretcher bed by 4:00 a.m., the emergency physician pulled us away from her: Your mother has a bowel obstruction. Due to a colon mass. We think it is colon cancer. The hours of waiting did not prepare us for this devastating blow, which took only seconds to deliver. We're sorry, we do not have any more answers. The surgeon can explain more to you when he arrives to see her. We did not know how to tell my mother-in-law. My husband was in shock. I pulled myself together to seek out more answers. Please show me where the mass is on the CT scan. What is the next step? When is surgery? What other diagnostic tests are pending? How can her pain be relieved? Our frustration now gave way to fear. We only explained the bowel obstruction to our mother and nothing more. We told her we did not know enough and we must wait for answers. Perhaps we did not want to tell her because we were unsure of the facts ourselves; or, maybe we were hoping that there would be an alternate explanation. Anything was preferable to cancer.

The emergency department is a terrible place for waiting. Everybody had a need in the packed ward. My mother-in-law did not receive intravenous access and pain medications for another two hours. She did not receive a naso-gastric tube insertion for gastric decompression to relieve her abdominal pain for another six hours. I forced my husband to go home to rest for an hour before heading back at 7:00am to catch the surgeon. The surgeon confirmed the diagnosis and outlined the schedule for her: We should have an OR [operating room] by the end of the day. She may need a colostomy depending on the actual size of the tumour. That was another blow to our system. I had to explain what a colostomy was to my husband as we 
were fighting to stay focused despite our exhaustion. There were still no patient beds available. Our mother remained on the stretcher until she was transferred for surgery. By the time she was sent to the operating room, it was 22 hours since we arrived at the hospital. I know this timeline was a pretty remarkable feat, but emotionally, the entire waiting process leading up to surgery just felt long, scary and hard.

In reflecting about my mother-in-law's experience, waiting for diagnostic news and finding out information was probably the hardest aspect. The process of gaining more information or asking for assistance in care was complicated by the surgeons', nurses' and other healthcare professionals' respective scopes of practice. Since I was a nursing student at the time, I had a bit more insight into the system. I knew that we should approach the nurses regarding symptom management, like pain and intravenous infusions, but it was not within their scope of practice to offer information regarding pathology results. I knew we had to wait to find out when the surgeon was completing shift assessments in order to catch him for information relating to the tumour, surgery and possible discharge planning. However, aside from these small moments of communication, my husband and I felt in the dark and constantly anxious about missing these important opportunities to seek out information. We needed information to plan out our lives: Do we book off the morning or afternoon in order to catch the surgical team? How many postoperative appointments would she have? Who is the oncologist? What would be the treatment course for her? While my mother-in-law was the recipient of care, it was important for my husband, my sister-in-law and I to also be well informed so that we could facilitate her care, such as taking time off for her appointments. It was frustrating to receive conflicting information from various healthcare professionals. Our family tried to make sense of everything that everyone was saying. She will probably be discharged in a few days, her primary nurse offered. The 
surgical resident countered, Really, they said that? I don't see why she has to stay for this long. The surgeon stated, The five-year survival rate when completing chemotherapy is $60 \%$ for Stage III tumours. Then, the oncologist said, Well, surgeons tend to be more conservative, but from my perspective, I think the five-year survival rate would be closer to 75 $80 \%$ if you complete chemotherapy. What was true? What was relevant?

Although waiting is a universal experience, the narratives I have shared thus far have been from my perspective as a family caregiver. In major illness encounters, uncertainty over the unknown can pervade the experience. Even as you are waiting, you are not at a standstill; rather, it is like a fast-flowing stream in which you are pulled by the currents and trying to grasp for some sort of anchor. My mother-in-law's tumour would keep growing as she waited for surgery. My grandfather would become incontinent of stool and urine if he was not transferred to the toilet in time. The world around us keeps moving as we wait.

\section{Professional Narratives of Waiting}

As a staff Registered Nurse practicing on a busy multi-organ transplant unit at an urban hospital centre, I see people waiting every day. I recall one middle-aged patient who was several years post kidney transplant and otherwise in very good health, except for his Polycystic Kidney disease which caused cysts in his native kidney to rupture. He became increasingly frustrated over the need to be hospitalized for a few weeks in order to wait for a nephrectomy. This meant that he had to be separated from his family and take leave from work in order to just wait in a hospital bed, even though he was in no immediate health danger. I recall another patient whose transplanted liver was failing after suffering a severe infection. He shared that he was tired of waiting in his hospital bed to receive a peripherally inserted central catheter so he could go home with intravenous antibiotics. This patient needed to have his infection resolved before he could 
be re-listed for another liver transplant. This patient's condition later became worse, to the point where re-transplantation was no longer a viable option for him. At this point, while the healthcare team was trying to arrange for palliative care, he forced himself off his bed and laid prostrate on the floor, refusing to get up until he was allowed to go home to die. He did not want to spend any remaining time of his life in a hospital. I admired his strength and courage in making his voice heard. Although he knew he was facing impending death, he made sure that he got to decide where and how he was going to wait for death.

Even in my position as a nurse, I find myself impatient and anxious in waiting for news or for responses to my patient inquiries, so that I may facilitate the flow of information between the patient and interdisciplinary team, or initiate the required treatment needed to stabilize the patient's condition. Anxiety often builds in me as I page one practitioner after another. Have you seen the patient's blood work yet? Would you recommend a course of action based on the results? What is the plan of care for this patient? You told the patient that he could return home today, can you confirm this with written orders? The patient is not doing well at all; it will take you another 30 minutes before you can come to assess her? Given that the nursing role often involves that of mediating conversations and facilitating the patient's care plan, I often felt stranded in a limbo, straining to be understood, straining to understand, struggling as I wait.

\section{Drowning while Waiting}

In my nursing student placement on a multi-organ transplant program, I was able to gain insight into the experiences of patients who were waiting for lung transplant. Patients waiting for lung transplant rely heavily on extensive oxygen therapy for their daily activities. Everyday tasks such as getting out of bed, getting dressed, taking a shower, can become laborious. Patients' work lives, family lives and social lives are impacted from the inability to do the one activity that 
our brains are hardwired to perform without any effort - breathe. Waiting for lung transplant for the patient and family, is a complex experience. Both literally and metaphorically, it can feel like drowning. The shortness of breath that these patients experience is often likened to feelings of drowning. Many of the lung transplant patients I met often experienced a significant amount of anxiety related to their breathing functions and oxygen equipment. End-stage lung disease is progressive leading to deteriorating lung function and mobility, and eventually death. I tried to imagine being in their position: struggling with every breath I take, not knowing if this breath would be my last breath.

During my clinical placement, I observed a monthly support group for lung transplant support persons. The support group was packed with tired looking spouses and adult children. I could see the strain in their weary eyes as they trickled in one by one. But they seemed glad to see one another. Pleasantries were exchanged, each eager to share their experiences. The support group opened with formal introductions, and participants shared how long their loved one had been waiting. We have been listed for 6 weeks. A collective sigh of joy was shared. We have been waiting for 4 months ... 6 months for us ... 13 long months ... it has been 19 months. A collective sigh of sympathy was expressed. The support group session was unstructured and the topic naturally flitted to everyone's relocation experience. The majority of caregivers who attended this session were from the Eastern provinces, since Toronto and Montreal are the only lung transplant programs in Eastern Canada (Canadian Institute for Health Information [CIHI], 2014). There was a myriad of conversations going on: Where are you living? Oh, that's quite expensive, have you tried "__ " residences? I know, they're very difficult to get into. I think it is ridiculous why there are no housing arrangements for us! As the conversations carried on, I noted the similar experiences that each support person recounted: the added stress of relocation 
while being overloaded with information regarding transplantation; adapting to a new city; and of course, learning how to manage their loved one's illness. How many litres are you on? Oh, that's not so bad. When we were driving down to rehab, the oxygen tank started beeping in the car. I was so afraid that [my husband] would stop breathing. I know, me too, I am constantly afraid that we would run out of oxygen. It appeared that with relocation, support persons were primarily accountable for the management of their loved one's illness and their daily livelihood.

Participants began to probe into deeper issues. They shared what it was like to be called in for a potential transplant, only to find that the lungs were not viable or they were not a good match. Oh, we've received three false alarms already. The first time, all our children flew out to be here with us. Well, believe me, we learned our lesson. It was just so heartbreaking to hear that surgery wasn't going to happen. We felt so foolish. The next two times, I told them to stay put. Who knows what will happen? As the waiting time lengthens for patients, their condition begins to deteriorate. They gradually lose the ability to work, to socialize, to dress themselves, to breath. We just don't see anyone anymore. There isn't time for any of that! Support persons were attuned to their loved one's proximity to mortality and at times they felt like helpless spectators. My wife hasn't been able to even get up the past two days. Does that mean the end is near for her? I don't know what to do, nothing I can do to help her. She's just lying there and I'm not sure who to call? Like, where do I go from here? Where is that point? That point, when you know it's not going to happen. I...I....can anybody tell me how the end will look? This spouse's vulnerable admission made me acutely aware that he was watching his wife die in front of his eyes, and he was scared. I was scared for him. His comment made me realize that lung transplant patients hover over a line of life and death. To receive a transplant would signal a possible second chance of life. The longer they wait though, 
the closer they are to approaching death; and their support person, that constant caregiver, is most privy to this process.

\section{Summary - Waiting}

I was deeply impacted by support persons' struggles and their vulnerability during the wait for transplant. I learned that hope can be mingled with despair, where one's ecstatic joy can quickly recede into disappointment and grief. More importantly, as support persons shared about the social withdrawal associated with waiting, there was a collective indignation that outsiders could not and did not relate to their experiences. I am so frustrated that our experiences are not being acknowledged. Like others are looking at us and thinking, 'Well, he looks pretty good, he doesn't look as bad.' They don't know the struggles we go through, the hardships we have.

Waiting for transplant is a complex experience, where support persons also experience similar turbulent emotions as patients. I imagine that being a support person is a long and solitary journey during the transplant waiting period. My personal and professional stories peaked my interest on waiting in general, but also waiting for lung transplant. In this thesis work, I aimed to shed light on the experience of waiting for lung transplant, from the perspective of the support person. I elaborate on my research focus in the following chapter with a formalized introduction. 
CHAPTER 2

INTRODUCTION: WAITING FOR LUNG TRANSPLANT 
"For a while" is a phrase whose length can't be measured.

At least by the person who's waiting.

(Haruki Murakami, South of the Border, West of the Sun, 1998)

This quote can be applied to patients and their loved ones who are waiting for lung

transplant, where the time period is indeterminate. Waiting for transplant is interwoven with a myriad of feelings including fear, despair, frustration, anger, joy and hope. Alongside the patient, the family is also anxiously waiting and sharing in this experience with their loved one. In fact, a family member is often the patient's support person when placed on a lung transplant list (Kurz, 2002; Stubblefield \& Murray, 2002). And together, they wait. There are multiple terms used in the literature to refer to the support person including primary/spousal/family caregivers (e.g. Claar et al., 2005; Lefaiver, Keough, Letizia, \& Lanuza, 2009; Rodrigue \& Baz, 2007) and carers (Monterosso, Young, \& Morey, 2003). For the purpose of this study, I employed the term support person as this was the label advanced in the recruitment transplant site and the term I was exposed to in my dialogues with transplant coordinators and in the support group. However, these individuals are referred to in the literature with terms such as family caregiver, spousal caregiver, parental caregiver or informal caregivers. Hence, I used the aforementioned terms that corresponded with the body of literature being cited. In this chapter, I provide a brief background to the study phenomenon, the problem statement, the research purpose and questions, and the significance of the study.

\section{Background}

In 2015, there were 1,651 people on the organ transplant waiting list in Ontario, Canada and 75 of these individuals were waiting for lungs (Trillium Gift of Life, 2015). Although the overall number of transplant surgeries performed each year is increasing in Canada (Trillium 
Gift of Life, 2015), donor rates are significantly outpaced by the number of patients being waitlisted (CIHI, 2014). When considering national statistics for lung transplantation, the number of lung transplants completed annually increased from 133 in 2004 to 247 in 2013 (CIHI, 2014). However, the number of wait-listed patients also increased from 181 in 2004 to 314 in 2013 (CIHI, 2014). In 2013, 52 patients died while waiting for lung transplant (CIHI, 2014). While average waiting times are not captured by statistics due to the fact that wait times vary according to disease acuity, blood type and lung size, Cystic Fibrosis Canada (2011) estimates that the average wait is $18-24$ months in Canada.

There are stringent criteria to qualify for a lung transplant wait-listing, with slight variations from province to province. Patients are referred for a lung transplant assessment when their lung function has decreased to less than $30 \%$ of that of normal functioning lungs (Belkin et al., 2006). The most common primary diagnoses leading to transplant referral include cystic fibrosis, chronic obstructive pulmonary disease, and idiopathic pulmonary fibrosis (CIHI, 2014). Upon referral, there is a rigorous transplant work-up consultation completed by an interdisciplinary team. Patients undergo pulmonary function tests, blood gas profiles, electrocardiograms, coronary angiograms, and bone density tests, all for the purpose of ensuring that they can tolerate the transplant surgery itself. In order to qualify to be wait-listed, these tests must reveal that the patient's physical functioning is within the "transplant window" (Belkin et al., 2006, p. 659); that is, these patients are ill enough to require lung transplant, but must be sufficiently healthy to withstand the surgery and recovery process. In addition to these physiological evaluations, patients must also complete several assessment interviews with various members of the interdisciplinary team (University Health Network, 2010). Assessments based on these interviews determine whether patients have the necessary coping skills and 
resilience to manage the waiting period, post-operative recovery and anti-rejection medication regimens. Another important criterion that patients must agree to before being listed for transplant is to commit to pre-transplant physiotherapy sessions with a rehabilitation facility that is affiliated with the transplant site. They are required to attend physiotherapy three times a week, and may also work with a dietician towards either gaining or losing weight in order to obtain and maintain an optimal state of physical functioning prior to transplant.

Meetings are held among the interdisciplinary transplant team to evaluate all physical and psychosocial findings in patients' pre-transplant assessments to determine whether they are eligible for the lung transplant wait-list. If a patient is not initially considered suitable, dialogue can be initiated to work on areas to support them for transplant candidacy (U. Dignard, personal communication, October 2012). This may involve working in conjunction with a team of healthcare professionals to resolve any underlying medical issues that prevent patients from waitlisting.

In order to qualify for the wait-list, the patient is required to have a designated support person who can provide full time care and companionship to the patient during the entire waiting period. As previously noted this person is usually a family member, such as a spouse, parent or adult child (The Lung Association Alberta \& NWT, 2009; University Health Network, 2010). Support persons have significant responsibilities that are focused on managing the patient's daily activities, such as: ensuring sufficient oxygen supply; driving the patient to pre-transplant physiotherapy sessions; relaying important information between patients and healthcare professionals, as patients experience memory issues due to their reliance on oxygen machines; and assisting with routines such as grooming and meal preparation (Lefaiver et al., 2009; C. J. Whytehead, Davies, \& Bolden, 2012). Due to the fact that live organs are only viable for a short 
amount of time after being extracted, transplant patients and their support persons must relocate to be within a 2.5 hour drive from the transplant site/hospital (The Lung Association Alberta \& NWT, 2009; University Health Network, 2010). Within my clinical practice, patients have shared that they were eligible for relocation stipends ranging from $\$ 650$ to $\$ 2,000$ per month, depending on which province they relocated from. However, these stipends often only partially cover their accommodation costs, and many support persons must also continue to manage their affairs back home.

\section{Problem Statement}

During the waiting period, support persons are indispensable in supporting patients with their daily activities as well as facilitating the optimization of their physical abilities for transplant, all while their respiratory functions are declining. And yet when I first began this study, there was a paucity of research specifically about the support person's waiting experience. There was some qualitative research about family caregivers' waiting experiences (Kurz, 2002; Stubblefield \& Murray, 2002) and information needs (Ivarsson, Ekmehag, \& Sjöberg, 2014), but most of these studies stemmed from over a decade ago and none originated in the Canadian context. This was important to consider because of Canada's care delivery model as well as the minimal number of transplant sites, which thus, usually requires relocation when patients are wait-listed. A few quantitative studies used different measurements to examine caregiver stress and burden among family caregivers waiting for transplant (Lefaiver et al., 2009; Meltzer \& Rodrigue, 2001; Rodrigue \& Baz, 2007; Catherine J. Whytehead, 2006). However, there were mixed findings related to family caregivers' wellbeing and quality of life (QOL) scores during waiting. Kurz as well as Stubblefield and Murray revealed that family caregivers reported many stressors during the waiting period for lung transplant. However, Whytehead measured caregiver 
burden in relation to relocation for lung transplant using the Caregiver Reaction Assessment (CRA) tool and found no significant changes in burden scores, with exception of those who had high scores for depression. Lefaiver et al. sought to explore family caregivers' experiences through concurrently measuring QOL, general health, mood and caregiver burden. While they found that family caregivers reported generally positive QOL scores and moderate CRA scores, analysis of sub-scores revealed that their fatigue and mental health scores were significantly worse than the normative population, and there was a significant negative correlation between depression and QOL. Moreover, only two studies explored the impact of relocation on family caregivers' experiences of waiting for lung transplant (Stubblefield \& Murray, 2002; Whytehead, 2006); although the former revealed themes of stress and burden in family caregivers' experiences of relocation using a qualitative approach, the latter reported no significant changes in caregiver burden during relocation in their pilot study. Also, while Stubblefield and Murray elicited experiences from parent caregivers of children who required lung transplant, Whytehead surveyed caregivers of adult patients. Moreover, Whytehead noted that her study utilized a small convenience sample, which might not have allowed for sufficient power to detect significant differences in caregiver CRA scores. The incongruence between findings in the literature suggested that not all aspects of waiting for transplant were adequately understood in the Canadian adult population. Thus, it was essential to gain a clearer picture of support persons' experiences of waiting for transplant.

\section{Research Purpose and Question}

The purpose of this study was to explore support persons' narrative accounts of waiting for lung transplant. Waiting was defined as the period from when a patient is placed on the lung transplant wait-list until the day that they undergo transplant surgery (or they are removed from 
the wait-list due to complications or death). The research questions were: What are support persons' experiences of waiting for lung transplant and how do they narrate these accounts? How does the role of being a support person appear in these accounts?

\section{Significance to Practice, Policy and Education}

In reverting back to my stories in Chapter 1 , I recall sitting in the support group and feeling an utter sense of amazement about the strength of these support persons. Most of these individuals did not possess any medical training, but were required to actively manage their loved ones' health issues and navigate the healthcare system. While waiting for mundane things may be insignificant and perhaps only mildly frustrating, waiting for transplant can have mortal consequences for the patient, and the support person is integral during this period. Healthcare professionals can assess for risk and provide resources, but when the appointment is over, support persons are left to their own devices to continue their daily lives while waiting. It became imperative for me to better understand the support person's experience of waiting. Narratives contain a potent empathic quality to transport the reader into the shoes of the storyteller (Lieblich, Tuval-mashiach, \& Zilber, 1998), such that the reader can almost travel in the same steps, smell the same odours, hear the same sounds, see the same sights, and embody the same emotions.

The narratives of support persons in this study provided an intimate look into the experiences of waiting, the support person's needs, and identification of resources to be allocated to them during their waiting period. Furthermore, from an educational standpoint, these narratives provided crucial insight into understanding the complexities of waiting from the support person's viewpoint. Thus, this research aimed to inform practice, education and policies concerning the wait-listing period and how to better support the support person. 
In the next chapter, I provide an overview of the theoretical lens of liminality that informed my study. 


\section{CHAPTER 3}

THEORETICAL LENS OF LIMINALITY 
I am in limbo and in limbo there are no races, no prizes, no changes, no chances. There are merely degrees of endurance, and endurance was never my strong point.

(Keri Hulme, The Bone People, 1984)

In Hulme's novel (1984), the protagonist felt a sense of limbo as she reflected on her isolation from past events and relationships. As she was running away from a past family trauma, she entered into a space in which there was no direction or belonging, a space of non-being, an existential void. Lacking of purpose, this limbo was a transitional space that was tension-filled, until the protagonist found reconciliation with her family at the end of the novel. Similarly, support persons may find themselves in limbo as their lives are suspended during the wait for lung transplant.

While the patient is waiting for lung transplant, support persons are also present in this limbo. With only five lung transplant programs in Canada, patients likely have to leave their homes and lives during the waiting period (CIHI, 2014; The Lung Association Alberta \& NWT, 2009; University Health Network, 2010). Given that support persons must accompany the patient, they too uproot their lives and relocate to a temporary new home and a whole new space. Both patients and support persons enter a new routine filled with non-stop assessments, continuous waiting and uncertainty (Kurz, 2002; Naef \& Bournes, 2009; Stubblefield \& Murray, 2002). They enter into a liminal phase that is transitional, carrying the hope of receiving a transplant.

At the outset of my research, I considered a number nursing theories or models to frame my study, including but not limited to the shifting perspectives model in chronic illness (Paterson, 2001), and uncertainty in illness (Mishel, 1988). After deliberations with my thesis committee as well as extensive study, I chose liminality as the most suitable theoretical lens for my study, as it enabled me to consider the waiting from a spatial and embodied perspective. Liminality is based 
on anthropological theory and is conceptualized as an in-between state of being (Turner, 1967, 1969, 1979). Specifically, I drew upon Turner $(1967,1969,1979)$ as well as Little, Jordens, Paul, Montgomery and Philipson's ideas (1998) concerning liminality to inform my theoretical lens. In order to articulate this theoretical lens, I first outline the historical context of liminality, followed by how it has been used in the healthcare context. Finally, I explicate how liminality theoretically guided my exploration of support persons' narratives of waiting for lung transplant.

\section{Historical Context of Liminality}

The concept of liminality was first derived from Arnold van Gennep's anthropological work (1960) on rites of passage, with a focus on the nature of liminal or transitional rites. Van Gennep contended that life progresses through stages, and the movement from one stage to another is characterized by rites of passage that contain the elements of separation, margin or limen, and re-aggregation or incorporation (Turner, 1967; van Gennep, 1960). As an individual experiences a change in their social identity or status, this change is marked by separation (van Gennep, 1960); this can be a physical separation, such as a prepubescent teen leaving his/her family, or a symbolic separation, where an individual is no longer able to wear his/her old clothes. Following separation is the liminal period, where the individual is in a marginal or transitional state, devoid of social standing or belonging (van Gennep, 1960). Finally, reaggregation signals the individual's reintegration into society, bearing a new identity or standing (van Gennep, 1960). Birth, adolescence, initiation into adulthood, marriage, pregnancy and death are all examples of rites of passage (van Gennep, 1960). Much of van Gennep's work explored the attributes and progression of various rites of passage and how they weave through an individual's life, with varying degrees of formality and social significance.

Of particular interest was van Gennep's research on initiation rites, which were based on 
his observations of "semi-civilized" societies (1960, p. 18), or pre-industrial civilizations in the early $20^{\text {th }}$ century. Initiation rites differed from other rites of passage in that they were primarily concerned with a prepubescent youth's transition to adulthood and contained extended liminal phases. Van Gennep delved into the initiation rites of many different societies, and found that they varied in length, ranging from months to years. While some rites were based more on physiological changes such as the start of menstruation, other rites such as circumcision bore more symbolic or even religious significance (van Gennep, 1960). Van Gennep noted that within some initiation rites, individuals were cast out of their own community, in which he/she "wavers between two worlds" (1960, p. 18). As such, the liminal phase was conceptualized as a marginal or transitional space containing both a temporal and spatial quality, as the liminal person is physically and socially separated from their places of belonging for a prolonged duration (van Gennep, 1960). The notion of liminality can be observed in the patient and the support person waiting for a viable lung. Waiting for transplant figuratively shifts them out of the regular patterns of daily living, into a high-stakes world of medical appointments, endless physiotherapy sessions, and a constant watchfulness to protect the body in hopes that it does not expire before new lungs arrive (Dellon et al., 2009; Macdonald, 2006; Yelle, Stevens, \& Lanuza, 2013).

Not only does the liminal space mark a physical and social separateness for the individual, it also shapes his/her identity and state of being. Victor Turner $(1967,1969)$ extended van Gennep's concept of the liminal period in his anthropological work examining initiation rites among the Ndembu tribe in Zambia. In this tribe, prepubescent males undergoing circumcision had to leave their homes and enter into a period of seclusion in the wilderness (Turner, 1967, 1969). He referred to them as "liminal personae" (1967, p. 95) or "neophytes" (1967, p. 96), because they were considered to be ambiguous beings. Liminal persons in the Ndembu tribe lose 
their identity and social standing as they go through the circumcision rite; they do not belong to the world or life stage they previously came from, and they are not yet allowed access to their new world, which is full manhood (Turner, 1967). In this not-boy-not-man state, liminal persons are rendered socially invisible, because in this transitional period, they bear no social standing or rights (Turner, 1967). As liminal persons partake in initiation rites, the symbolic separation from their past identity coupled with the physical separation from their community leaves them in an inferior position "possessing nothing" (Turner, 1967, p. 95) in terms of material and social belonging. Furthermore, Turner remarked that individuals dwelling in the liminal space must become passive, submitting to the authority of instructors. From these observations, it appears that the liminal period strips individuals of their personhood, which may be a vulnerable position to inhabit. In applying the lens of liminality to support persons' experiences of waiting, I was inspired to consider how this liminal period of waiting influences them: What is occurring in this liminal space for support persons? How do support persons describe this liminal space and make sense of it? How does the support person label impact their sense of self and purpose? Moreover, Turner proposed that to be liminal is to exist in a paradoxical state, that is: "that which is neither this nor that, and yet is both" (1967, p. 99). Turner observed that as neophytes in the Ndembu tribe lost their sense of self, they were encouraged to engage in self-reflection to re-imagine their identity, their way of being and their communities. Carrying an ambiguous identity created opportunities to re-imagine and re-define their sense of self as well as the spaces they were occupying. Likewise, the support person can be re-imagining multiple ways of being that may include life where his/her loved one receives new lungs, or a life without his/her loved one (Kurz, 2002).

The transitional space of liminality can be viewed as both a vulnerable and opportune 
space and time (Turner, 1967, 1969). Turner returned to the concept of liminality in his later works, and formally defined liminality as:

... literally "being-on-a-threshold," means a state or process which is betwixt-andbetween the normal, day-to-day cultural and social states and processes of getting and spending, preserving law and order, and registering structural status ... it is a time of enchantment when anything might, even should, happen ... Liminality is full of potency and potentiality (1979, p. 94).

Hence, in this study, I described liminality as a transitional space in which a person suspends their life from what they consider to be normal routines and structures (Turner, 1979). There is a sense of vulnerability in this state when one loses their previous identity and social status as they enter the liminal phase (Turner, 1979). However, like a piece of unworked clay or a blank canvas, there is tremendous transformative potential in the liminal space, whereby waiting could abruptly end with a transplant call or prolong indefinitely until the patient passes. Hence, the liminal waiting space possesses a paradoxical quality, where hope for life is interwoven with anticipatory grief, where uncertainty is mingled with transformation, where neither this nor that is also both.

\section{Liminality in the Healthcare Context}

Nursing researchers have applied the concept of liminality to the context of illness primarily in the field of oncology nursing (Blows, Bird, Seymour, \& Cox, 2012; Little et al., 1998) but it also has been seen in other clinical areas such as mental health (e.g. Simich, Maiter,

\& Ochocka, 2009; Warner \& Gabe, 2004), fertility and childbirth (e.g. Granek \& Fergus, 2012; Mahon-Daly \& Andrews, 2002) and migrant worker experiences (e.g. McGuire \& Georges, 2003). Little et al. were major players in introducing the concept of liminality into healthcare 
research in their exploration of the embodied experiences of cancer patients' diagnosis, treatment and remission. They proposed that upon a cancer diagnosis, patients entered into a liminal space, where their lives and bodies became disrupted and segregated from those who did not have cancer. Their identity of being a cancer patient or survivor was in itself a liminal state, in that they were caught between the social states of health and illness (Blows et al., 2012; Little et al., 1998). Thompson (2007) found that a cancer diagnosis created a social separateness, where patients might have trouble relating their illness experience with friends and family. However, identifying as a cancer patient also evoked a sense of camaraderie and community among fellow patients/survivors (Thompson, 2007). It appeared that a cancer diagnosis opened to a liminal space, where fellow cancer patients/survivors found resonance with each other, but this space was not necessarily accessible to patients' closes family and friends (Thompson, 2007).

In the healthcare context, it was not fully understood how the support person fits into waiting spaces of illness. Sabo (2014) was one of the few researchers who conceptualized the experiences of waiting for haemotopoeitic stem cell transplant as a liminal period, in which family caregivers were also situated in between the possibility of death or cure. Sabo noted: "For caregivers, liminal space affords an opportunity to create meaning out of the illness experience of the partner" $(2014$, p. 4). The meaning ascribed to the illness experience in the liminal space might provide a transformative potential for family caregivers to reconsider their role and identity (Sabo, 2014). Within the betwixt and between, support persons' lives are at the brink of transformation, with the potential to leave their caregiver roles if the patient is transplanted, or face grief and loss if the patient passes or experiences other complications. 


\section{Liminality as a Theoretical Lens}

In this study, Turner's $(1967,1969,1979)$ and Little et al.'s (1998) ideas concerning liminality served as the theoretical lens. For the purposes of this study, liminality was defined as: "a state or process which is betwixt-and-between the normal, day-to-day cultural and social states and processes" (Turner, 1979, p. 96). As I reflected back to the support group I attended for lung transplant support persons, their stories of waiting expressed a sense of alienation and separateness, where their world was reduced to just them and the patient. As such, I felt it was appropriate to draw upon the related attributes of separateness and marginality to frame my understanding of support persons' waiting experiences (Little et al., 1998; Turner, 1979) and consider how they shape support persons' narratives of waiting for lung transplant. Additionally, a key feature of liminality is a sense of openness: that within the betwixt-and-between, there is no scripted narrative or process of how this experience will progress. To extend this, the liminal space is conceptualized as a potent space for re-imagination (Turner, 1979). In my study, it was then important for me to explore how support persons made meaning of their liminal experiences and roles in this transformative space.

Liminality, as my study's theoretical lens, guided how I critiqued and synthesized the literature, as well as my data collection and analytic methods. By framing the waiting period as a liminal space and time, I aimed to understand how support persons experienced their separation through physical relocation and role changes, as well as their experiences within the transitional space of waiting. Additionally, the use of liminality in my study was congruent with the constructivist paradigm that underlies a narrative approach, whereby knowledge is coconstructed between the listener and narrator (Guba \& Lincoln, 1994; Lieblich et al., 1998). I expand on my paradigmatic approach in the next chapter. Eliciting support persons' narratives 
was appropriate in exploring the fluid and ambiguous nature of the liminal space and the liminal person. My study findings extended the conceptual understanding of the illness encounter as a liminal space in the context of the support person role, which resulted in implications that apply to the broader family caregiver population. Hence, situating the waiting period for lung transplant as a liminal passage facilitated an in-depth and nuanced exploration of support persons' experiences in this transitional space. In the next chapter, I provide a critique and synthesis of the literature. 


\section{CHAPTER 4}

\section{CRITIQUE AND SYNTHESIS OF THE LITERATURE}


I said to my soul, be still and wait without hope, for hope would be hope for the wrong thing; wait without love, for love would be love of the wrong thing; there is yet faith, but the faith and the love and the hope are all in the waiting. Wait without thought, for you are not ready for thought: So the darkness shall be the light, and the stillness the dancing.

(T.S. Eliot, East Coker, Four Quartets, 1940)

The complexities of waiting are summed up poignantly in Eliot's poem, which was written in the midst of World War 2. Though he was born and raised in America, Eliot imagined this war torn space of his ancestral roots, contemplating on the emotions of death and mortality. In this passage, Eliot wrestled with the darkness of humanity, suggesting that one should not rely on their self-sufficiency, hope and faith within this dark world. In reading his work, I was drawn to the fact that war is a liminal space, where hope, devastation, love and hate dwell together, where one becomes powerless to shape his/her fate. Similarly, for support persons who are waiting for lung transplant, their hope is precarious. They are powerless to control when the patient would receive his/her lungs, powerless to ensure that he/she would survive transplant surgery and the recovery that follows. Waiting is laced with myriad emotions such as anticipation, dread, joy, sadness, hope, and despair.

In this chapter, I critique and synthesize relevant research and theoretical literature concerning the waiting period for lung transplant as well as experiences of caregiving. I found limited literature exploring support persons' experiences of waiting for lung transplant. Through my literature search in the CINAHL and Ovid databases, using the keywords "support person OR family caregiver OR informal caregiver OR caregiver," "waiting," and "lung transplant," I found only eight studies referring specifically to the support persons' experience of waiting for lung transplant. None of these studies employed a narrative methodology, which can provide a 
contextual and temporal understanding of waiting. Thus, I broadened my search to just "waiting" and "lung transplant," yielding 14 articles focused on patients' experiences of waiting. As such, I expanded my search of the literature to consider a conceptual view of waiting as well as family caregiver perspectives related to the illness experience in general; both of these areas facilitated a better understanding of the support person's experience. Using the theoretical lens of liminality to examine the literature, I have organized this chapter into the following sections: (1) Waiting: a conceptual view; (2) The shared views of waiting for lung transplant; (3) Experiences of being a family caregiver; and (4) Summary of literature synthesis.

\section{Waiting: A Conceptual View}

A conceptual view of waiting in the healthcare context was important to examine because this literature better positioned my understanding, synthesis and critique of the empirical literature related to the study topic. Two concept analyses using Walker and Avant's methodology (1995) explored the concept of waiting in the healthcare context. Fogarty and Cronin (2008) provided a concrete definition of waiting for healthcare: "An unspecified yet measurable period of time between identification of a healthcare problem and its diagnosis and treatment, when clients experience uncertainty and powerlessness whilst anticipating a disease outcome" (p. 467). In their analysis, Fogarty and Cronin focused on the temporal quality of waiting, specifically how extended wait times resulted in a greater amount of anxiety and uncertainty for the patient. Similarly, Irvin (2001) defined waiting as: "A stationary, dynamic, yet unspecified time-frame phenomenon in which manifestations of uncertainty regarding personal outcomes remain in suspension for a limited time" (p. 132). The word usage of "between" and "suspension" reflects an in-between state and resonates with the theoretical lens of liminality, where waiting may cast one into a transitional space, in which anticipation of the 
outcome becomes the foreground. In both concept analyses, the authors suggested that the ambiguity in the length of waiting contributed to a sense of anxiety, uncertainty and powerlessness (Fogarty \& Cronin, 2008; Irvin, 2001). Waiting led to a loss in personal control (Irvin, 2001), as well as increased stress, which might exacerbate existing symptoms (Fogarty \& Cronin, 2008). However, Fogarty and Cronin noted that waiting might provide the time and space for patients to adapt positively to their situation and make preparations for the future. While patients' stresses and anxiety were emphasized in these concept analyses, support persons' experiences were not considered in this liminal space of waiting. My study sought to address this gap in the literature by exploring support persons' experiences of dwelling in this transitional space of waiting.

From theoretical literature concerning waiting, the concepts of anxiety, anticipation, hope and frustration resonated with support persons' stories shared in the support group meeting I attended. While Fogarty and Cronin (2008) as well as Irvin (2001) utilized Walker and Avant's method (1995), one limitation of this approach was that concept attributes remained consistent across all contexts (Weaver \& Mitcham, 2008). Although the studies included in these two concept analyses (Fogarty \& Cronin, 2008; Irvin, 2001) explored a wide range of clinical diagnoses and care settings, they limited their conceptual discussion to waiting for a diagnostic test or general surgery (e.g. Oudhoff, Timmermans, Bijnen, \& van der Wal, 2004; Poole, 1997). For patients and support persons waiting for lung transplant, they are waiting for the last possible life-saving treatment (Belkin et al., 2006). A viable organ can lead to a new life, but there is no guarantee that a lung will arrive in time for transplant. The authors of these concept analyses recommended the provision of informational and emotional support to mitigate patients' feelings of powerlessness and uncertainty during waiting (Fogarty \& Cronin, 2008; Irvin, 2001). 
However, this conceptual literature and the associated recommendations were focused on the patient's care; researchers have not examined the support person's experiences and needs during this liminal time period. This was an important gap in the literature considering that the support person has an integral role in the waiting process. My study contributed to the conceptual knowledge of waiting in relation to support persons and how waiting impacted their wellbeing.

\section{Shared Experiences of Waiting for Lung Transplant}

It was important to synthesize and critique the literature related to the support person, but also the patient. The reason for this is because the support person's experience of waiting for lung transplant is not an individual journey but can be viewed as inextricably linked to the patient he/she is waiting with. In reviewing the literature, it appeared that patients' experiences were often mirrored by their support persons (Kurz, 2002; Stubblefield \& Murray, 2002). Hence, in examining the literature concerning the shared experience of waiting for lung transplant, I first highlight patients' experiences then follow with the support person's experience. I have organized this section of the synthesis according to the following themes: 1) Life on hold; 2) Psychosocial issues; 3) Positive aspects of waiting; and 4) Need for support.

\section{Life on Hold}

Researchers found that patients' lives were on hold and in limbo during the waiting period prior to lung transplant (Macdonald, 2006; Yelle et al., 2013). Patients recalled feeling uncertain and restricted in their options about the future, such as whether they would survive the surgery, and if they would be able to return back to their normal lives prior to their illness (Ivarsson, 2012; Naef \& Bournes, 2009). In Macdonald's exploratory study ( $\mathrm{n}=8)$ of cystic fibrosis patients that received a lung transplant, participants described a sense of chaos as their normal routines gave way to a life revolving around waiting. Similarly, in a secondary analysis 
exploring patients' illness narratives of waiting for lung transplant ( $n=7)$, it was found that other rites of passage such as marriage and work were put on hold due to the uncertainty and demands associated with waiting (Yelle et al., 2013). The chaos that MacDonald described reflected a loss of control within patients' lives, in which the wait for transplant overtook their activities, social roles and relationships. Ivarsson et al.'s (2014) retrospective descriptive study (n=16) found that patients referred to their bodies being physically on hold when they required mechanical circulatory pumps while waiting for heart or lung transplant and thus, were restricted to their home or hospital space. Patients experienced spatial confinement as their bodies deteriorated during the waiting process. Naef and Bourne conducted a phenomenological study ( $\mathrm{n}=11)$ examining the lived experience of waiting for lung transplant, and found that patients' gradual physical deterioration while waiting for transplant led to mounting frustrations and emotional turmoil. Patients expressed the need to "buy time" (Macdonald, 2006, p. 507), and focused on maximizing their odds of receiving a transplant by maintaining optimal weight and not overexerting themselves (Ivarsson, 2012; Yelle et al., 2013). Within this liminal period of waiting, patients experienced separation from their past lives as well spatial and emotional confinement as they became physically limited by their illness.

Lung transplant patients however were not the only ones who had their lives on hold. Although they did not have end-stage lung disease, support persons were also held in waiting (Kurz, 2002; Stubblefield \& Murray, 2002). Stubblefield and Murray conducted a secondary analysis of parent caregivers' experiences $(n=6)$ of relocating for their child's lung transplant. Parents also described putting their lives "on hold" (Stubblefield \& Murray, 2002, p. 501) during the waiting period, as activities around their children's health took precedence over all other everyday tasks. Similarly, Kurz's secondary analysis exploring stressors among spousal 
caregivers $(n=12)$ pre- and post- lung transplant found that they reported fatigue and exhaustion in trying to manage their loved ones' lung disease and associated treatments in addition to their daily routines. Spousal caregivers noted relinquishing their past interests and social circles, which sometimes led to frustration and resentment towards others who were not in their position (Kurz, 2002). In their mixed methods study examining caregiver strain and stress among the lung and liver transplant population $(\mathrm{n}=52)$, Meltzer \& Rodrigue (2001) found that fear and uncertainty associated with waiting as well as concern for their loved ones' worsening health were the most significant stressors for family caregivers. Existing literature on support persons' experiences suggested that on a psychosocial level, they shared similar waves of emotions and distress with the patient. Additionally, support persons contended with the stressors associated with their new responsibilities. All of the studies noted above were conducted in the United States more than 10 years ago, where there are 61 lung transplant programs (Thabut et al., 2013) compared to five programs in Canada (CIHI, 2014; The Lung Association Alberta \& NWT, 2009), where patients and support persons would more likely need to relocate for surgery. It was therefore, unclear how relocation impacts their experience of waiting. As such, understanding the support person's experience in a Canadian context in today's current healthcare system was important to elucidate their unique needs.

\section{Psychosocial Issues}

The waiting period for lung transplant led to psychosocial issues as patients and support persons suspended their lives and focused solely on waiting (Barbour, Blumenthal, \& Palmer, 2006; Ivarsson, 2012; Kurz, 2002; Myaskovsky et al., 2005; Rickman \& Roberts, 2001; Rodrigue \& Baz, 2007; Stubblefield \& Murray, 2002; Yelle et al., 2013; Yorke \& CameronTraub, 2008). Researchers found that waiting for lung transplant was related to higher incidences 
of depression and anxiety (Yelle et al., 2013; Yorke \& Cameron-Traub, 2008) and subsequently, lower QOL for patients compared with the general population (Barbour et al., 2006; Myaskovsky et al., 2005). Although lung transplant patients underwent thorough psychosocial assessments to ensure that they were mentally capable of handling the waiting process (Barbour et al., 2006; Evon, Burker, Galanko, Dedert, \& Egan, 2010), over time the stresses of waiting produced a toll on their emotional wellbeing (Rickman \& Roberts, 2001; Yelle et al., 2013). In several studies, lung transplant patients recognized that their family caregivers also experienced negative emotions while waiting, and wished that psychological support was extended to them (Ivarsson, 2012; Yorke \& Cameron-Traub, 2008). An existing gap in the literature was whether support persons are assessed or followed by the healthcare team, and what supports are available to them, which I addressed in my study. An additional element of the waiting experience that my study offered was explicating support persons' emotions and wellbeing during the waiting period.

My search yielded mixed research findings in regards to the literature specifically examining the impact of waiting on support persons' wellbeing. In a few correlational studies measuring QOL, emotional wellbeing and/or stress, researchers found that family caregivers reported QOL levels and rates of depression and anxiety comparable with normative samples (Claar et al., 2005; Goetzinger et al., 2012; Meltzer \& Rodrigue, 2001; Catherine J. Whytehead, 2006). However, Rodrigue \& Baz’s (2007) survey study (n=73) found significantly lower QOL and mood scores among spousal caregivers relative to a normative sample $(\mathrm{p}<0.001)$. In Lefaiver et al.'s (2009) correlation study exploring both patients' and primary caregivers' wellbeing ( $\mathrm{n}=29$ dyads), they found that while caregivers reported positive QOL scores that were greater than patients' scores, there was a large variability in their mental health scores using the Profile of Mood Statements Short Form tool. Lefaiver et al. found that despite reporting positive QOL, 
primary caregivers might still be at risk for experiencing mood disturbances, and conceded that these measures might not sufficiently describe caregivers' mental health. These mixed findings could be attributed to a number of factors. First, in three of the studies, participants were recruited while they were being evaluated for the wait-list and the authors did not indicate when participants completed the questionnaire (Claar et al., 2005; Goetzinger et al., 2012; Meltzer \& Rodrigue, 2001). As such, participants in these samples might not have engaged in waiting for a long period of time. Additionally, given that their reported wellbeing could impact the wait-list assessment, they might have been motivated to report more positive QOL scores with hopes of enhancing their family members' chances of listing. Second, a few studies contained pilot or small sample sizes (e.g. Lefaiver et al., 2009; Whytehead, 2006), which limited the generalizability of the results. Linked with this, studies with larger samples did not specify whether a power analysis was employed to determine the sample size needed to detect an effect (Claar et al., 2005; Goetzinger et al., 2012; Meltzer \& Rodrigue, 2001). Although correlational designs provided insight into experiences of waiting, the use of a qualitative approach in my study enabled a contextualized and in-depth understanding of such experiences.

Studies also measured caregiver strain and burden through the use of the Caregiver Strain Index (Rodrigue \& Baz, 2007) and Scale for Caregiver Burden (Goetzinger et al., 2012). It was found that higher burden or strain scores were associated with increased incidences of depression and emotional distress (Goetzinger et al., 2012; Rodrigue \& Baz, 2007). Additionally, family caregivers who reported decreased social functioning were more at risk of experiencing psychological distress (Meltzer \& Rodrigue, 2001). Based on the literature, family caregivers' psychosocial wellbeing might be negatively impacted during the waiting period for lung transplant. However, it was not clear whether these poor psychosocial outcomes could be 
directly attributed to waiting. Also, such measurements provided numerical data about narrowly defined outcome variables. As used in my study, a narrative approach illuminated the moment to moment complexities and emotions of waiting for support persons.

\section{Positive Aspects of Waiting}

Researchers have highlighted positive aspects to waiting for lung transplant (Ivarsson, 2012; Macdonald, 2006; Naef \& Bournes, 2009). Patients reported experiencing a pendulum of emotions as their uncertainties of waiting for lung transplant were coupled with excitement over the prospect of possible surgery and recovery (Macdonald, 2006). In their struggle to remain healthy enough for transplant, patients expressed feelings of anticipation towards receiving a life-saving organ (Naef \& Bournes, 2009) and thankfulness that a viable treatment option was available to them (Ivarsson, 2012; Macdonald, 2006). However, a number of these studies used a retrospective approach and explored patients' waiting experiences post-transplant (Ivarsson, 2012; Macdonald, 2006). It is possible that since patients were no longer waiting and had completed surgery, their reflections on the experience might have changed. This might have incited a response bias, such that patients would be more likely to focus on or highlight the positive aspects of waiting as they had already received transplant surgery.

In a similar manner, family caregivers also revealed benefits to providing care during the waiting period (Meltzer \& Rodrigue, 2001; Rodrigue \& Baz, 2007; Stubblefield \& Murray, 2002). In the paediatric context, parent caregivers reflected that despite the stresses of waiting for lung transplant, there was also a sense of adventure and newness in their experiences (Stubblefield \& Murray, 2002). They even noted some joy in being with their ill child and caring for them (Stubblefield \& Murray, 2002). Similarly, Meltzer and Rodrigue found that family caregivers indicated that being able to help their loved ones was a benefit to caregiving. In a 
study examining spousal caregivers' QOL, mood, strain and social intimacy, spouses expressed personal growth and interpersonal benefits in this role (Rodrigue \& Baz, 2007). It appears that the liminal space of waiting was multi-layered and nuanced, where support persons might simultaneously experience positive as well as negative emotions. Although Rodrigue and Baz studied family caregivers' experiences using a variety of measurement tools, it was unclear how positive aspects of caregiving were experienced in relation to the caregiver burden they reported. The use of a narrative approach allowed me to elaborate on the previous research by uncovering the experiential dynamics of waiting for transplant and explore how this myriad of emotions can co-exist in this liminal period for support persons.

\section{Need for Support}

I found in existing literature that patients' waiting experiences were impacted by the amount of formal and informal emotional and social support received (Phillips, Burker, \& White, 2011; Yorke \& Cameron-Traub, 2008). Phillips et al. conducted an observational study examining the relationship between social support and psychological distress in individuals who were being evaluated for lung transplant $(n=191)$. They found that increasing patients' perceived availability of social support alleviated their depression and anxiety, and strengthened their coping abilities. Similarly, other researchers found that regular emotional support from family and friends improved patients' psychological health during wait-listing (Ivarsson, 2012; Naef \& Bournes, 2009). Yorke and Cameron-Traub postulated that provision of timely emotional support from nurses could help decrease the anxiety of waiting and strengthen the nurse-patient relationship.

Less was known about the support person's needs as patients reported that healthcare professionals' support was only available to them and not accessible to their family caregiver 
(Ivarsson, 2012; Yorke \& Cameron-Traub, 2008). Rodrigue, Widows and Baz (2006) conducted a randomized controlled trial measuring primary caregivers' QOL after a three month telephonebased QOL supportive intervention for the patient $(\mathrm{n}=13)$ compared to a control patient group who received regular supportive therapy $(n=15)$. Primary caregivers in the intervention group reported significantly higher QOL scores $(\mathrm{p}=0.03)$ as well as lower mood disturbance scores $(\mathrm{p}=0.001)$ compared to the control group (Rodrigue et al., 2006). Although Rodrigue et al. explored caregiver QOL, their interventions still centered on improving patients' wellbeing. There was no current research found implementing or evaluating supportive interventions for support persons despite the fact that a number of authors discussed the need for healthcare professionals to attend to family caregivers' experiences (Kurz, 2002; Rodrigue \& Baz, 2007) and provide added informational and psychological support to them (Meltzer \& Rodrigue, 2001; Stubblefield \& Murray, 2002). There was only one recent qualitative descriptive study exploring relatives' perceptions of information and support received during the waiting period (Ivarsson et al., 2014). Ivarsson et al. found that family members reported dissatisfaction with the amount and timing of information received from the healthcare team, and indicated a need for more assistance with the patient's daily activities. However, as Ivarsson et al.'s study originated in Sweden, it was difficult to draw conclusions about this work because policies surrounding support care may vary according to region and healthcare infrastructures. By exploring support persons' narrative accounts of waiting for lung transplant, I delved into how support persons coped with the emotional experience and their perception of support within the liminal waiting space. 


\section{Experiences of Being a Family Caregiver}

It was important to review the literature about family caregivers in general particularly because the support person was usually a family member and there was not a significant quantity of research specific to the lung transplant context. In this section, I examine family caregivers' shifting priorities and the sense of community that emerges from their caregiving activities. Additionally, I explore how family caregivers found purpose and meaning in their roles, and how support facilitated this process.

Researchers have found that transitioning to the caregiver role for family members involved shifting life priorities and activities such that the patient became their primary focus (Duggleby, Williams, Holtslander, Cunningham, \& Wright, 2011; Pereira, Anto, \& Botelho, 2011; Plank, Mazzoni, \& Cavada, 2012; Silva-Smith, 2007). Silva-Smith conducted a grounded theory study to explore the process of becoming a caregiver after a family member suffers a stroke. During the early phases of caregiving, family members reported overwhelming stress, as they learned the skills needed to care for their loved ones and rearranged their schedules to make time for caregiving (Silva-Smith, 2007). Silva-Smith found that restructuring life was a core theme, which involved integrating new daily routines associated with caregiving, changed relationship dynamics, uncertainty towards the future, and a changed sense of self. Similarly, in a

phenomenological study exploring the lived experience of informal caregivers during unexpected illness encounters, participants reported feeling a loss of their own lives as they dedicated time to caregiving, which contributed to reduced social circles and feelings of loneliness (Pereira et al., 2011). Although the experience of loneliness was linked to shrinking social networks, informal caregivers reported that it was also associated with providing care to loved ones who exhibited differing behaviours and characteristics following illness, and feeling abandoned by friends and 
family who did not recognize the work they put forth into caregiving (Pereira et al., 2011). In another phenomenological study, Plank et al. found that informal caregivers felt as though they were absorbing all the care responsibilities when patients transitioned from hospital to home. Although informal caregivers' accounts of shifting priorities and social withdrawal were echoed in findings concerning family caregivers' experiences of waiting for lung transplant (Kurz, 2002; Stubblefield \& Murray, 2002), the former focused on spousal caregivers' stressors and coping during the pre- and post- transplant period, while the latter focused on parental caregivers' experiences of relocation in the paediatric population. Moreover, both studies were conducted over ten years ago, so it was not known if additional supports have been implemented into transplant programs since then, and whether support persons' experiences, stressors and emotions within the liminal space of waiting have changed. Facilitating storytelling through my study shed light on this gap in the literature regarding support persons' experiences in assuming the supportive role specifically within the adult lung transplant population.

In reviewing the literature, I found that a sense of community emerged in the caregiving role (Kurz \& Cavanaugh, 2001; Stubblefield \& Murray, 2002; Yelle et al., 2013). Family caregivers often found comfort in meeting those who were in the same position of shifting their existing social roles and responsibilities to the background in order to fulfill necessary caregiving activities (Kruse, 2006; Silva-Smith, 2007). In Kruse's study, using the Parse method to analyze family caregivers' stories of surviving a hurricane, participants revealed that caregiving involved moving away from people who did not share their experiences, and moving towards others whom they shared a likeness. Kruse found that participants experienced a sense of belonging with others who were also in caregiver roles. This finding was echoed in the lung transplant literature, where patients and their family caregivers found community with others who were 
waiting for transplant (Kurz \& Cavanaugh, 2001; Stubblefield \& Murray, 2002; Yelle et al., 2013). Exploring support persons' narrative accounts of waiting for transplant in my study provided further insight into the nature of these relationships within the community of lung transplant patients and support persons.

In my synthesis of the family caregiving literature, finding purpose and meaning in caregiving positively impacted family caregivers' experiences (Duggleby et al., 2011; Hoppes, 2005; Kruse, 2006). Hoppes provided a powerful autoethnography of his experience in caring for his father who had congestive heart failure. He found that reflecting on his experiences facilitated him to re-consider his relationship with his father, which provided affirmation in his decision to be a family caregiver. Similarly, Duggleby et al. utilized a narrative approach to analyze family caregivers' journal entries of caring for loved ones with terminal cancer. They found that hope was prevalent within the chaos and burdens of caregiving narratives (Duggleby et al., 2011). Family caregivers spoke about finding hope when they appreciated the small joys of everyday life, or perceived that they were making a difference in their loved ones' lives (Duggleby et al., 2011). Kruse also asserted that perseverance within the caregiver role involved adopting a positive attitude, finding the upside of situations, and envisioning a better future. Although these studies noted some of the positive aspects related to caregiving specific to terminal illnesses, researchers have not explored what meaning support persons derived from their experiences of waiting for a life saving treatment such as lung transplant surgery. My study informed this body of literature through descriptions of support persons' liminal experiences of waiting and how they made sense of it.

Information and emotional support was been identified as an important element in caregiving literature (Claar et al., 2005; Clukey, 2007; Goetzinger et al., 2012; Kurz \& 
Cavanaugh, 2001; Lefaiver et al., 2009; Plank et al., 2012; Silva-Smith, 2007). Family caregivers expressed that informational support and healthcare professional presence decreased the stresses associated with caregiving and promoted hope (Clukey, 2007; Plank et al., 2012; Silva-Smith, 2007). Conversely, decreasing support was associated with increased frustration and burden for the caregiver (Kurz, 2002; Plank et al., 2012). Researchers recommended that healthcare professionals should adopt a family-centered approach in caring for the lung transplant population in order to address family caregivers' individualized needs (Claar et al., 2005;

Goetzinger et al., 2012; Kurz, 2002; Lefaiver et al., 2009). In the context of lung transplant, it was unclear whether healthcare professionals attended to the needs and perspectives of family caregivers. My study aimed to better understand support persons' experiences with the healthcare system during this liminal waiting period.

\section{Summary of Literature Synthesis}

Within the broader caregiving literature I found that shifting into a caregiving role was a significant transition for individuals resulting in increased responsibilities, new roles and routines, loss of social networks and a myriad of emotions (Duggleby et al., 2011; Pereira et al., 2011; Plank et al., 2012; Silva-Smith, 2007). While conceptual literature on waiting focused solely on patients' views, empirical literature specific to lung transplant population demonstrated that both the patient and family caregiver's psychosocial health were impacted during the waiting period (Claar et al., 2005; Kurz, 2002; Macdonald, 2006; Naef \& Bournes, 2009; Rodrigue \& Baz, 2007; Stubblefield \& Murray, 2002). Much like patients, family caregivers described waiting akin to putting their lives on hold (Stubblefield \& Murray, 2002) as they adjusted to new routines for the patient as well as their new caregiving responsibilities, which resulted in increased stress, fatigue, and depression (Kurz, 2002; Lefaiver et al., 2009; Rodrigue \& Baz, 2007; Stubblefield \& Murray, 
2002). While there were a few studies specific to the lung transplant population that highlighted the support person's experiences (Claar et al., 2005; Goetzinger et al., 2012; Kurz, 2002; Lefaiver et al., 2009; Meltzer \& Rodrigue, 2001; Rodrigue \& Baz, 2007; Stubblefield \& Murray, 2002; Catherine J. Whytehead, 2006), this research was neither current or specific to the Canadian context, nor specific to the adult patient population. This was a significant gap in the literature because resources for support persons are context dependent and shaped by national and regional funding and policies. Also, the use of retrospective and correlational approaches did not permit a contextual and temporal understanding of the support person's experience. In employing a narrative methodology, it was my plan to build on the existing research and provide a deep and rich understanding of the support person's experience of waiting for lung transplant with the aim of ultimately supporting the development of evidence-informed interventions for this vulnerable population. In the next chapter, I provide an overview of the study methodology and methods. 


\section{CHAPTER 5}

RESEARCH METHODOLOGY AND METHODS 


\section{History isn't about dates and places and wars. It's about the people}

who fill the spaces between them. (Jodi Picoult, The Storyteller, 2013)

Since childhood, I have enjoyed historical fiction, and Picoult's (2013) novel about a young woman exploring her grandmother's past as a Holocaust victim was no exception.

Although historical fiction features fabricated characters set in factual settings, exploring these characters' lives in narrative form somehow makes the historical accounts more real and more alive to me. As Picoult traversed between the protagonist's present and her grandmother's past, the interweaving stories shed light on who they were and how they have come to be who they are now. Stories have been told since early human existence and many cultures possess a strong tradition in oral history as a means to preserve both cultural and historical knowing (Lai, 2010). Similarly, as I sat in the lung transplant support person support group, participants naturally gravitated towards storytelling. I was amazed to hear emotional stories that support person shared with one another: stories of frustration, stories of excitement and hope, stories of grief and fear. As such, I chose narrative inquiry as the methodological framework to guide this study because of the rich and contextualized nature of stories. Specifically, I drew upon Lieblich et al.'s (1998) narrative approach. By eliciting narratives in this study, it provided a safe space for support persons to voice their inner perspectives, thoughts and feelings and a method to facilitate a better understanding of their experiences of waiting. In this chapter, I provide an overview of narrative inquiry as the research methodology and the methods related to recruitment, data collection, data analysis, rigour and reflexivity, and ethical considerations.

\section{Methodology: Narrative Inquiry}

Narrative inquiry falls under the realm of qualitative research and involves a focus on stories and storytelling (Lieblich et al., 1998). Researchers study narrative both as a phenomenon 
and as the means through which a study is carried out (Creswell, 2013; Lieblich et al., 1998). I situated this study in the constructivist paradigm using Lieblich et al.'s (1998) methodology for narrative inquiry. As Lieblich et al (1998) indicated, storytelling is a co-constructed act that is influenced by the relationship between the storyteller (ie. the participant), the listener/audience (ie. the researcher) and the context and focus of the story. An ontological assumption of narrative inquiry is that it is pluralistic (Lieblich et al., 1998), where the story is not a static body of text in one objective reality but is a dynamic organism existing in multiple realities (Lai, 2010). Epistemologically, one comes into knowing and experiencing through the interaction with an other, whether it is another individual, family, and cultural and social environment (Clandinin \& Connelly, 2000; Freeman, 2007). Narrative is an important medium to organize one's thoughts, actions, and events into a coherent portrait as a means to make sense of his/her experiences (Holloway \& Freshwater, 2007; Polkinghorne, 1988). Lieblich et al. posited that stories can be situated both temporally and contextually. Contextually, this approach enables the researcher to grasp the intersection between the storyteller's social world and the meaning he/she ascribes to it (Lieblich et al., 1998). Temporally, as a person shares a story, he/she decidedly links certain events together in a particular sequence, while providing the listener with his/her view (Holloway \& Freshwater, 2007; Lieblich et al., 1998). The telling and re-telling of stories, as well as attending to how these stories are being told, have the potential to reveal to the listener the storyteller's life experiences and meanings.

As a nurse, narratives play a central role in my daily practice. As I arrive to work, I read the Kardex of the patient assigned to me. The Kardex highlights the patient's medical history, reason for admission, level of independence in activities, diet, oxygen requirements, and ability to eliminate waste. In essence, the Kardex provides a beginning narrative of the patient's care 
requirements, indicating the amount of functional support that I must provide. I then receive a shift report, an oral narrative of my patient's last twelve hours, and what pertinent details I need to attend to during my shift. As I complete an initial assessment for the patient, I ask focused questions that elicit personal narratives to understand his/her concerns and needs. As I develop therapeutic rapport throughout the day, I often gain deeper insight of the patient's illness experience as well as the support person's experience. As the shift draws to an end, I prepare my own oral narrative to pass on to the next nurse. Thus, narratives allow me as a nurse to gain valuable insight into patients' worldviews of their life and their illness, and to understand them as persons, not just patients. Similarly, the use of narratives in nursing research enables the researcher to consider the person as participant in a broad and holistic manner (Holloway \& Freshwater, 2007) and accounts for multiple realities to co-exist and inform one another (Lieblich et al., 1998).

Lieblich et al's narrative approach involves a focus on both the content (e.g., what is said) and the form of story (e.g., how it is said). Lieblich et al. indicated that stories help people connect their experiences and are the primary vehicle of communication with others. Narratives also allow listeners and storytellers to gain an understanding of the storyteller's internalized world and their perception of reality (Lieblich et al., 1998). As storytellers tell and retell their stories through editing, adding or omitting details, they are in fact re-creating their identities and their perceptions of their selves (Freeman, 2007; Lieblich et al., 1998). That is not to say that narratives are an exact rendition of the truth; rather, Lieblich et al. proposed that stories are a construct shaped by the meaning ascribed by the storyteller. One's rendition of their own story is contingent on the time, the space, the purpose as well as the audience to whom the story is told 
(Lieblich et al., 1998). As such, one's narrative is actually a co-construct between the storyteller and the listener (Lieblich et al., 1998).

\section{Sample, Setting and Recruitment}

The study population was support persons of lung transplant patients who have been wait-listed. Four study participants were recruited, which was consistent with other research located in the narrative domain (e.g. Carter, 2013; Retta, 2011). A rich amount of data emerged from narrative accounts to provide an in-depth view into the phenomenon under study (Lieblich et al., 1998). Additionally, the use of multiple data collection points and methods (detailed below) also contributed to a large quantity of rich data. As such, my sample plan was aligned with both the methodology and the feasibility of my thesis research. While my plan was to recruit three participants, one participant was not able to complete the second interview because the patient was removed from the wait-list as a result of an unrelated illness. I recruited a fourth participant so that I had a complete data set for three participants.

The inclusion criteria were: 1) self-identified as the support person for a lung transplant patient who has been wait-listed; 2) wait-listing time between one to nine months at the time of participation; and 3) proficient in written and spoken English. As discussed with the pre-lung transplant coordinator, this minimum timeframe (one month) allowed sufficient time for support persons to settle into the role of waiting, while the upper timeframe (nine months) decreased the chance for attrition in the case that patients are called for transplant. The exclusion criterion was support persons of patients who were being re-listed for lung transplant, as their previous waiting experiences might influence their current experience.

The study setting was a pre-transplant centre located in a large urban hospital in Canada. I established rapport with the pre-transplant coordinator, social worker, psychiatric nurse and 
physiotherapists in the lung transplant program to gain preliminary knowledge of the pretransplant program and support persons' involvement during the waiting process. As per hospital's ethical guidelines, I did not initiate any direct contact with the target sample prior to and during recruitment. Instead, the physiotherapist acted as the recruiter. Support persons in the physiotherapy room were approached by the physiotherapist and invited to hear about a study. I recruited one support person at a time, so as to maintain immersion within each participant's narratives. Hence, recruitment at the physiotherapy centre occurred roughly every two to three weeks. Also, recruitment posters (Appendix A) were displayed near the elevators where lung transplant patients and support persons frequent for their physiotherapy sessions and appointments. One support person contacted me directly through the information provided in the recruitment poster. Six individuals were approached by the physiotherapist and screened to be eligible for the study, but only three consented to participate. Reasons for not participating in the study were related to stress and fatigue, as such individuals replied they already had a lot to manage.

\section{Informed Consent}

A salient step was voluntary and informed consent (see Appendix B for the informed consent form). Following recruitment and screening, I provided individuals with the consent form. I reviewed with them the study purpose, study expectations and potential risks and benefits (further highlighted below in Ethical Considerations), and responded to any questions that arose. After all aspects of the study were explained, potential participants were given the opportunity to voluntarily sign the consent form or take the consent form away to further consider and/or discuss with their family members/friends. All four participants signed their consent forms at our initial meeting. 


\section{Data Collection}

For each participant, I conducted two semi-structured, narrative-based interviews three weeks apart. Additionally, participant journaling occurred for two weeks in between the two interviews. The purpose of multiple data collection methods and points was to provide the opportunity to develop rapport with participants, allow for reflection between the two interviews and engage in meaning making at the second interview. Additionally, participants completed a demographic form (Appendix C), which provided information to describe the study sample. With the participant's permission, all interviews were audio-recorded and transcribed. One-on-one interviews were conducted in private conference rooms at the hospital while the patient was completing his/her physiotherapy session. The interviews lasted 50-110 minutes. Meetings were set up for journal collection two weeks after Interview 1 at the hospital site. Each of the data collection methods are described below and an overview of the data collection procedures are provided in Appendix D.

\section{Interview 1}

Following consent, participants had the option to set up a future meeting time or complete Interview 1 in the same sitting. Interview 1 consisted of a semi-structured narrativebased interview to establish rapport with participants and collect preliminary data. Semistructured interviews are often used in qualitative research to provide a flexible framework for participants to enter into storytelling (Streubert \& Carpenter, 2011). A semi-structured interview guide contains a prepared set of open-ended questions to ask all participants (Whiting, 2008) but there is not necessarily a defined order during the interview process (Dearnley, 2005).The use of broad, open-ended questions can elicit in-depth accounts from participants on their experiences, and create space for questions and new concepts to emerge based on their answers (Dearnley, 
2005). In this study, participants' responses influenced the order of questions asked in the guide, or led me to probe further into an aspect of their experiences. The interview guide questions were informed by a narrative approach drawing upon Lieblich et al.'s (1998) methodology. For example, questions were constructed in ways that elicited information about narrative components (e.g., what happened? who was involved? how did you feel?) (Lieblich et al., 1998). During Interview 1, a sample of questions that were asked included: Tell me about your experience of waiting for lung transplant? Describe what a day of waiting is like? See Appendix E for the complete interview guide.

\section{Support Person Journals}

I used journaling both as a data collection method (Holloway \& Freshwater, 2007) and an elicitation device (Jacelon \& Imperio, 2005) that informed interview two. Participant journaling is a common qualitative data collection method (Clandinin \& Connelly, 2000; Jacelon \& Imperio, 2005) to broaden the diversity of data being collected (Creswell, 2013), and is considered to be a counterpart to oral stories (Holloway \& Freshwater, 2007). Journaling provides participants the opportunity to document their feelings in a more temporal fashion as they are experiencing the phenomenon being studied (Holloway \& Freshwater, 2007). Journaling as an elicitation device allows researchers to develop questions for follow-up interviews based on what participants write (Jacelon \& Imperio, 2005).

At the end of Interview 1, I provided notebooks to participants and invited them to journal their experiences of waiting for lung transplant for two weeks. Included in the notebook was a journal guide sheet with instructions and a few prompting questions (see Appendix F). My contact information was provided in the journal guide sheet for participants to contact me if they had questions about what or how to journal. Participants also had the option to use any format to 
record their journals, such as typing entries into a Word document or voice recording entries using personal mobile phones. Three participants used the notebooks provided, while one participant opted to type entries into a Word document.

Once journaling instructions were given, a date was arranged to meet the participant approximately two weeks later for me to collect journals and answer any additional questions that arose. For the one participant who typed entries onto a Word document, I downloaded these onto an encrypted USB. During this brief meeting, a meeting date was scheduled with participants approximately one week later for Interview 2.

\section{Interview 2}

Preliminary analysis of Interview 1 and journal data informed questions to be asked in Interview 2, and served to probe participants' experiences highlighted in earlier narratives. This emergent design is essential to narrative inquiry, as it permits the introduction of new concepts or ideas, and facilitates a deeper introspection into their experiences (Dearnley, 2005). For example, there were probing-like and narrative-based questions designed to expand on and clarify earlier responses, such as:

- In your journal, you mentioned , tell me more about this.

○ What was it like? How did you feel? Who was involved? How would you like it to be different?

- After reflecting further on your interview one, I noticed , tell me more about this?

In concluding this interview, two salient questions were asked to engage the participant's perspective: Is there anything else you would like to tell me about your experience of waiting for lung transplant? Last, tell me anything else about your role as a support person during the 
experience of waiting for lung transplant? The inclusion of these questions served to inform any additional perspectives support persons may not have articulated regarding their role and experience of waiting.

\section{Researcher Fieldnotes}

Reflexivity is an important component to achieve rigour (Leung \& Lapum, 2005) because of the interpretive nature of narrative inquiry (Josselson, Lieblich, \& McAdams, 2003). In narrative inquiry, the researcher is essentially an "instrument of research" (Josselson et al., 2003, p. 4) shaping the interpretive process of meaning making. As such, it was highly important for me to situate and illuminate my assumptions.

At the outset of the study, I engaged in storytelling to uncover my internalized feelings and values of waiting. I continued in this reflexive process throughout the study and contributed to data collection through writing researcher fieldnotes. For example, I documented fieldnotes after each interaction with participants about my experiences and observations. This allowed for deeper immersion into participants' narrative accounts as my fieldnotes helped me recall the interactions and setting. Also, reflexive writing was also pertinent to my recruitment, data collection and analysis process to explicate my positionality, explore how my personal lens shaped the manner to which I reacted to participants' stories and our interactions, and question my own interpretations and decisions in the research process (Leung \& Lapum, 2005). As such, my reflexive fieldnotes enabled me to provide an audit trail for my research decisions and enhance the rigour of the study (Lapum, 2008). Engaging in varying methods of data collection as well as reflexive writing enabled me to elicit support persons' narrative accounts in a multifaceted manner and capture the nuanced layers of their experiences in this liminal space of waiting. 


\section{Data Analysis}

Data analysis in narrative inquiry involves immersion into participants' stories and an iterative process between reading narrative accounts and forming narrative ideas (Lieblich et al., 1998). The researcher must be able to attend to the storyteller's voice and study's theoretical framework, while simultaneously remaining reflexive to his/her own lens in exploring the phenomenon (Lieblich et al., 1998). The analytic approach involved both a categorical content and form analysis (Lieblich et al., 1998). Lieblich et al. introduced four approaches of analysis that fall under a combination of: holistic versus categorical analysis, and content versus form. Analyzing a narrative from a holistic as compared with a categorical approach refers to considering one's entire life story versus specific narrative ideas pertaining to a phenomenon (Lieblich et al., 1998). Attending to content versus form refers to focusing on elements of the narrative such as plotline, characters and setting, compared to focusing on linguistic devices such as metaphors, repetitions, word usages, etc. (Lieblich et al., 1998). Lieblich et al. contended that researchers may use varying combinations of holistic and categorical as well as content and form analysis based on their research question and data.

For my study, the employment of categorical content and form analysis was most appropriate to answer my research question of how support persons experienced waiting. I was interested in the specific phenomenon of waiting as opposed to their life story. Through the use of a semi-structured interview guide informed by the lens of liminality, I elicited narrative content specific to participants' experiences of waiting and their roles as support persons. Subsequently, within my analysis, I attended to narrative ideas illustrating the liminal space of waiting. In particular, categorical content analysis involved exploring support persons' descriptions, perceptions and emotions of waiting and their roles; whereas in categorical form 
analysis, I focused on how they narrated their experiences, through highlighting linguistic devices, metaphors, and stylistic features in their storytelling. The theoretical lens of liminality oriented me to attend to how participants described and articulated the liminal waiting space, and how participants made sense of this transitional time period. The specific data analysis steps I took included:

1. Transcribed interview audio files and written or audio journal entries.

2. Conducted data analysis of Interview 1 and participant journals. This involved:

- Reading interview transcript while simultaneously listening to interview audio files

- Attending to narrative content (e.g. plot, setting, characters, situations, tensions/climaxes and resolutions) and form (e.g. metaphors, repetitions, vocal intonations, non-verbal body language) pertaining to the experiences of waiting for lung transplant

3. Drawing on narrative ideas from analysis of Interview 1 and journals, formulated interview guide for Interview 2.

4. Transcribed audio files of Interview 2

5. Conducted data analysis of Interview 2 focusing on content and form.

6. Last, I reflected on the data and analysis of all participants' data collection methods. No one method took precedence. Rather, I considered them as a whole in order to identify the main narrative ideas. I then, created a textual character sketch that introduced each participant.

Extensive analysis fieldnotes were documented for each interview and participant journal to capture the categorical content and form analysis observations. Writing fieldnotes allowed me 
to highlight significant passages and describe my analysis decisions leading to my interpretation that exemplified a layered understanding of waiting and being a support person. The listed steps for data analysis did not simply progress in a linear fashion. Rather, I operated in an iterative fashion, going back and forth among participants, transcripts, journal entries, analytic fieldnotes and reflexive fieldnotes to examine and identify narrative ideas. This involved re-reading transcripts, comparing interviews and journal entries, and critically reviewing tentative narrative ideas. My reflexive fieldnotes helped me to integrate all forms of participant texts and document my research decisions.

\section{Ethical Considerations}

I took active measures to protect participants' welfare and confidentiality, and ensure that my research process complied with the ethical guidelines established by Ryerson University, the transplant recruitment site, and the Tri-Council Policy Statement: Ethical Conduct for Research Involving Humans (Canadian Institutes of Health Research, Natural Sciences and Engineering Research Council of Canada, and Social Sciences and Humanities Research Council of Canada, 2010). In this section, I discuss risks and benefits; protection of participants' rights; and privacy and confidentiality.

\section{Risks and Benefits}

Although there were no physical harms associated with this study, the act of storytelling can be a time-consuming and vulnerable act, and lead participants to confront or relive negative emotions, which could pose a psychological risk. However, I had measures in place if such instances arose, such as reminding participants that they could take a break or re-schedule the interview, and that they were free to withdraw from participating at any time point. If research participants required someone to talk to, I would encourage them to speak with their primary 
care provider. None of participants in my study informed me of discomfort or distress during their participation.

There were no direct benefits to participating in this study. However, participants noted that they found it enjoyable and for some, therapeutic to engage in storytelling. By telling their stories during interviews, participants benefited from making their voices heard and being listened to by another person. Additionally, participants may have also found it beneficial to contribute to a broader body of research in this clinical area and population.

\section{Protection of Participants' Rights}

As detailed in the informed consent process, participants were made aware that they had the right to voluntarily end their involvement in the study at any time and/or withdraw their data from the study. Their participation or withdrawal from the study would not be communicated to members of the transplant team and had no bearing on the patient's wait-list status. In my contact with participants regarding subsequent meetings to collect journals or conduct Interview 2, if I did not receive a response after two contact attempts 10 days apart, I would have made the decision to cease their participation in the study. This ensured that repeated attempts at contact would not pose a pressure on participants to continue their involvement in the study. However, all participants responded to my contact within my indicated timeframes.

It is important to note that participants' involvement in the study would have been terminated should the patient that they were caring for undergo transplant surgery prior to the completion of all components of data collection. Participants' frame of mind would likely completely shift from that of waiting, and further involvement in the study might pose an added stress post-transplant. While this did not occur in the study, a participant did voluntarily withdraw from the study as she was no longer eligible to participate. During our closing 
exchange, she provided consent for me to include her Interview 1 and journal entries in my study, as these data still provided valuable insights into her experiences of waiting as a support person.

Participants were not paid for their involvement in this study. However, an honorarium was provided to cover some possible costs related to commuting and parking: $\$ 10.00$ at Interview 1; \$5.00 at meeting to collect journals; $\$ 10.00$ at Interview 2.

\section{Privacy and Confidentiality}

Concerted efforts were made to safeguard participants' privacy and right to confidentiality. Journal entries and interview transcripts were assigned a code and then pseudonyms were given to each participant during the thesis writing. All collected data were stored in a secure storage space, where an encrypted USB key was used for digital files, and a locked cabinet for paper files in my thesis supervisor's office. The code sheet containing contact information was stored in a separate location from participants' data.

I attended to the balance of honouring the rich narrative accounts and maintaining confidentiality in my thesis writing. Kaiser (2009) referred to the phenomenon of deductive disclosure, whereby the rich and unique participant accounts could make an individual identifiable. While common responses to this problem often involve altering or omitting participants' details in dissemination, researchers might inadvertently lose the original meaning in participants' accounts (Kaiser, 2009). As the ultimate goal of my narrative study was to elicit rich nuanced accounts, such details when considered collectively could reveal a participant's identity. In approaching my thesis dissemination, my process of deliberating upon which details to present was based on several considerations. I began by omitting information such as names, places, specific ages, locations mentioned in transcripts, as well as identifiers related to the study site. Subsequent decisions were based on adherence to my narrative methodology in which 
nuances of the individual narrative and contextual details were important to participants' accounts. In line with a narrative methodology, I excluded details that were identifying characteristics but did not affect the original meaning of participants' accounts. All decisions to include/exclude information were brought forth and critically discussed with my supervisor and committee.

\section{Rigour}

The process of meaning making in narrative analysis is an immersive, dialogical process between the researcher and participant (Lieblich et al., 1998). The process is informed by the constructivist paradigm in which story construction is influenced by the storyteller and listener (Lieblich et al., 1998). In advancing rigour throughout my study, I adhered to Lieblich et al.'s four criteria for rigour in narrative analysis: width, coherence, insightfulness and parsimony. These criteria are congruent with the constructivist paradigm in narrative research, where the focus is not in the determination for a truthful or accurate narrative account per se, but rather elucidating the meanings support persons ascribe to their waiting experience in this particular liminal, spatial and temporal context. Attending to width, coherence, insightfulness and parsimony helped to construct a comprehensive and in-depth understanding of the waiting as a liminal space and facilitated meaningful interpretation of data.

Width pertains to achieving and evaluating the quality of all related data, observations and analytic interpretations (Lieblich et al., 1998). I strove to achieve width through my concurrent data analysis, as well as documenting and developing rich and thick descriptions in my analytic fieldnotes. Additionally, width was developed by considering alternative explanations for data (Lieblich et al., 1998) and constant engagement and questioning by others of the interpretations that I inferred from the data. My reflexive fieldnotes were also instrumental 
to elucidating my positionality in relation to my narrative analysis and achieving width. For example, interview 2 provided the opportunity for me to take my key interpretations back to participants and ask them questions such as: did I interpret what you said correctly? Would you like to add to this? My thesis supervisor and committee were instrumental in this process as they provided feedback and critically questioned my analytic interpretations.

The second criterion of coherence refers to the congruency of the data findings, as well as the fit with existing literature and my theoretical lens of liminality (Lieblich et al., 1998). I addressed coherence by reflecting in my fieldnotes on how my narrative analysis related back to my research questions and with the lens of liminality. In particular, my analysis sought to explore how the study findings expanded my understanding of a liminal space. Also, I sought structural corroboration by comparing and contrasting participants' narratives in order to elicit a comprehensive understanding of the phenomenon of waiting. As well, I considered my data analysis in the context of the literature as another way to corroborate my findings. While narrative inquiry seeks to explore the richness and diversity of individual stories and does not subscribe to the concept of generalizability, my analysis strove to explore the diversity and richness of common narrative ideas and relate them to existing literature concerning the substantive topic and the theoretical literature of liminality.

Third, insightfulness refers to whether analysis has led to greater understanding about the experience of waiting and whether findings have been articulated with adequate conciseness and breadth (Lieblich et al., 1998). I aimed to develop insightfulness by keeping all concurrent findings tentative, as narrative analysis is an iterative process for which later readings may further refine interpretations. I engaged in multiple readings of entries and interview transcripts. Additionally, I engaged in discussion with my thesis committee to solicit their views on the 
breadth and brevity of narrative ideas. I also presented preliminary findings at a number of qualitative research conferences to seek a broader interdisciplinary view of my results.

Last, parsimony reflects whether the research text and findings are presented in a succinct and aesthetically pleasing manner that readers would find to be compelling (Lieblich et al., 1998). I aimed to hone an aesthetic appeal in my writing through engaging in reflexive journaling as well as personal storytelling. I worked closely with my thesis supervisor and committee members to gauge the readability and engagement of my writing.

In my findings chapter, I endeavoured to weave each participant's voice throughout the study findings to create a compelling composite of stories that exemplified the experience of waiting for lung transplant as a support person. 
CHAPTER 6: FINDINGS 
All stories have a curious and even dangerous power. They are manifestations of truth - yours and mine. And truth is all at once the most wonderful yet terrifying thing in the world, which makes it nearly impossible to handle. It is such a great responsibility that it's best not to tell a story at all unless you know you can do it right. You must be very careful, or without knowing it you can change the world.

(Vera Nazarian, Dreams of the Compass Rose, 2002)

Nazarian's fantasy novel (2002) is a collection of short stories depicting an exotic land filled with warriors, spirits, and princesses. These characters were written in different dream vignettes in which each presented a different perspective within the same space and time. As each story was interconnected, Nazarian demonstrated that truth can be shed from different angles and lenses. Similarly, in this chapter, I present a composite of the study findings from the varying perspectives of support persons concerning their experience of waiting for lung transplant. I begin by providing a brief character sketch of each support person followed by a detailed analysis of the study findings in terms of the main narrative ideas, and conclude with a summary. I used pseudonyms to protect participants' anonymity. Given that the lung transplant population is relatively small, with 40 to 60 wait-listed patients at the study centre at any given point, I did not include some narrative details or I described some details more ambiguously so as to maintain the confidentiality of participants' identities. However, as outlined in my previous chapter, some potentially identifying descriptors that were crucial to support persons' stories of waiting were included.

\section{Character Sketches}

\section{Caitlin: Mom's "Protect[or]"}

Caitlin was in her thirties when she became the support person for her mother. They 
relocated from Eastern Canada to reside in a one bedroom condominium in an urban city in Southern Ontario. Her mother had been on the waiting list for six months at the time of the interview. Caitlin took a leave of absence from her company, and left her family, her boyfriend and her dog to become her mother's support person. During this waiting period, she reported struggling with chronic back pain and mental health issues, and was being treated at a health clinic nearby the transplant site. She found joy in the caregiver role and considered herself to be her mother's "protect[or]", by facilitating follow-up with medical staff and investigating errors in scheduling tests. She remarked: "I had to keep reminding myself, they are human, and things happen. But at the same time, 'You are taking care of my mother, don't screw [it] up!' [laughs]." Her primary goal as a support person was to ensure her mother's physical and emotional wellbeing, noting: "She [my mother] doesn't need ... extra stress."

Caitlin often smiled through her tears in the interview despite reporting a cheerful demeanor when interacting with healthcare professionals and other patients. She recounted the difficulties of watching her mother struggle with chronic obstructive pulmonary disease, and the disappointments of encountering delays in their medical care. Caitlin was the only support person in the study who encountered false alarms, in which her mother received a transplant call twice, but in both instances the surgery did not occur. Caitlin's mother was actually a match for the donor lungs when called the second time. However, several routine tests showed that she had another underlying diagnosis. As a result, her wait-list status was suspended followed by removal from the wait-list until the medical issue was treated. Caitlin was unable to continue in this study and complete the second interview due to the change in her mother's wait-list status. She indicated that she was devastated during our closing exchange. She was extremely sad and disappointed, yet hopeful that the medical team would develop a suitable treatment plan for her 
mother. As agreed upon by Caitlin, all collected data, including interview one and her journal entries, were included in the study.

\section{Matthew: Being Prepared for the "Waiting Game"}

Matthew was in his forties and the support person for his wife, who was suffering from idiopathic pulmonary fibrosis. They were living in a one bedroom condominium unit for nine months at the time of the interviews. They had relocated from Central Canada, but Matthew was able to retain his employment by working remotely. While Matthew's oldest son was away for post-secondary education, his youngest son was left under the care of his paternal grandmother. In waiting for lung transplant, Matthew balanced multiple roles of caring for his wife, maintaining his full-time work and acting as a father despite the geographic separation.

Matthew shared that he had been planning for the transplant process a few years prior to wait-listing. However, he was still taken aback by the length of time in the actual waiting period. Akin to hunting, he described the experience as a "waiting game" and advised others to "be ready for the wait." While it appeared that Matthew was cognitively aware of the time commitment, the experience of waiting for lung transplant was emotionally enduring. He often referenced his cultural ways of knowing to make sense of his wife's illness and his experiences of waiting. Matthew noted that although he and his wife missed their family and friends, he found it pleasurable to meet new friends at the transplant site. He also indicated that, "we're [my wife and I] still able to be together and enjoy the time."

\section{Dianne: The "Interminable" Wait}

Dianne was in her sixties and relocated to serve as her friend's support person. Dianne volunteered to be the support person for a one year time period, knowing that her friend would be financially stressed if her husband had to leave work to relocate. Dianne's relocation involved 
physically separating from her own husband. She had been waiting for over five months at the time of the study, and described the waiting experience as "interminable." As the waiting period continued to lengthen, Dianne stated:

In the beginning, it was like, the phone would ring, we'd make sure we had the cell phone with us when we went out ... check to make sure it was fully charged. Um [pause] listen to messages as soon as we got home, and, um, sirens would go by, and we'd say, "Oh, maybe that's our lungs!" that sort of thing. And now, it's like, nobody says anything anymore.

They started out their wait in great anticipation for a phone call, but as the months passed, their anticipation began to wane, giving way to sadness and disappointment.

Of all the participants, Dianne's friend was most advanced in her lung disease and required the most support and assistance in the home. Despite this fact, Dianne was very comfortable with her responsibilities as a support person due to her professional background as a retired healthcare professional. While Dianne and her friend had been close friends for over fifteen years, tensions arose as they negotiated their living dynamics as roommates. Dianne's knowledge was also an asset in working with members on the lung transplant team and advocating for her friend. However, as her friend's health continued to decline, Dianne felt unsupported in their goal to remain at home rather than being admitted to the hospital to wait for the transplant call.

\section{Roger: "Fish Out of Water" - Transitioning into the World of Waiting}

Roger was in his seventies and serving as the support person for his wife who had idiopathic pulmonary fibrosis. They relocated from Eastern Canada and his wife had been on the wait-list for five months at the time of the study. Roger reported feeling like a "fish out of 
water," and often compared how life "here" was vastly different from life "there." Although his wife had been ill for ten years, they still lived their lives freely, often travelling across the country and overseas. Having lived in a country home with many acres of land, he described how they were now physically confined in a small condominium unit in an urban city. He indicated that they were now restricted to a routine of travelling between the hospital and the condominium. Roger communicated that he and his wife missed their family, their dog and their lifestyle, but commented that they found ways to cope with the distance by having video chats with their children and grandchildren.

Roger found creative ways to engage his time despite the boredom of the routines associated with waiting. He described composing music to help keep his mind off of waiting. Having these hobbies allowed Roger to "switch off" and find solace from the daily stresses of travelling to the hospital and managing his wife's care, as well as his own medical concerns. Roger also found it frustrating to work with the lung transplant team while attempting to seek answers for his and his wife's concerns.

\section{Narrative Ideas}

The study findings are organized according to the main narrative ideas that structured the content and form of support persons' accounts of waiting and how they perceived their role. The main narrative ideas are as follows: 1) The physical and social space of waiting for lung transplant; 2) The patient as the focal point; 3) Hope(lessness) and fear; 4) Finding meaning; and 5) The (un)support of the support person. These five narrative ideas are not discrete categories, but influence each other. I discuss two to four sub-narrative ideas that fall under each main narrative idea. Refer to Table 1 for an overview of the narrative ideas. 
Table 1: Narrative Ideas

\begin{tabular}{|c|c|}
\hline Narrative Idea & Sub-Narrative Idea \\
\hline $\begin{array}{l}\text { 1. The physical and social space of } \\
\text { waiting }\end{array}$ & $\begin{array}{l}\text { - Relocation } \\
\text { - New spaces and relationship dynamics } \\
\text { - Confinement } \\
\text { - Emotional isolation }\end{array}$ \\
\hline 2. The patient as the focal point & $\begin{array}{l}\text { - Support person responsibilities } \\
\text { - Monitoring and anticipation of patients' needs } \\
\text { - Emotional support } \\
\text { - Support persons' needs shifting to the } \\
\text { background }\end{array}$ \\
\hline 3. Hope(lessness) and fear & $\begin{array}{ll}\text { - } & \text { Anticipation } \\
\text { - } & \text { Uncertainty of the unknown } \\
\text { - } & \text { Death and dying } \\
\end{array}$ \\
\hline 4. Finding meaning & $\begin{array}{l}\text { - } \quad \text { Purpose in waiting and caregiving } \\
\text { - } \quad \text { Reflection and thankfulness }\end{array}$ \\
\hline $\begin{array}{l}\text { 5. The (un)support of the support } \\
\text { person }\end{array}$ & $\begin{array}{l}\text { - Compassion fatigue and self-care } \\
\text { - Informal and formal supports } \\
\text { - Healthcare professionals } \\
\end{array}$ \\
\hline
\end{tabular}

\section{The Physical and Social Space of Waiting}

All participants found that waiting for transplant involved a major life change. In

relocating to a new city, support persons endured a spatial separation from their homes, work and social networks. While relocation to a new home reflected the physical space of waiting, support persons' narratives also revealed how their lives underwent a social upheaval in terms of their routines and roles. This idea relates to Turner's (1969) attributes of the liminal state. As such, I sought to uncover what was occurring physically and socially within this liminal space. I discuss four sub-narrative ideas to highlight the physical and social space of waiting for lung transplant: relocation; new spaces and relationship dynamics; confinement; and emotional isolation.

\section{Relocation.}

Support persons experienced varying stress associated with the separation that occurred while relocating. All of the participants had to move distances ranging 550 to 1,750 kilometres 
from their homes. Referring to relocation, Roger stated:

That's the biggest shock for your system ... the caregivers, the both of them, oh and the stress ... I think it's worse for the people who had to relocate, because you're, like, 'cause I tell people, I feel like a fish out of the water here.

The metaphorical reference "fish out of water" highlighted the displacement and unfamiliarity associated with the transition of relocation, given that fish typically suffocate and die when not in water. His linguistic usage of "shock" reflected the intense emotional and visceral impact of relocation. Matthew recounted his planning process concerning relocation: "Okay, where are we going to live? How far do we need to be? ... How we're going to support or find out everything?" Support persons' narratives reflected the stress associated with securing rental accommodations from a distance. Roger commented:

She [landlord] said, yeah, we can have the lease ... I didn't send any money; I just gave her a banker's reference. And, she said, "That's good," ... but the back of my mind, "Well maybe it's a con." [laughs] ... I've got a big truck just in case we need to rent somewhere else. But it worked out good. ... That's another worry we have ... how secure we are staying where we are, because it's month to month rent. As reflected in this quote, Roger experienced uncertainty considering the tentativeness of the relocation arrangements. Support persons did not want to sign leases because they were unsure of how long they would be staying. While relocating for lung transplant should be a temporary measure, this arrangement could last for several months and sometimes beyond a year. The uncertainty contributed to vulnerability within the liminal space of waiting as support persons negotiated their accommodations, which might exacerbate the stresses of relocation.

Support persons' narratives indicated the management of multiple stressors and burdens 
while arranging the logical and financial aspects of moving in the months preceding their relocation. Despite receiving a stipend for living costs through the healthcare system, Matthew noted that he still had to manage bills at home and other aspects of their lives:

There's a lot of emotional stuff. ... we got all the family issues that we were concerned about and, wondering how things are going to happen with the family while we're gone. And securing a place down here, and knowing that, although ... we are fortunate, we're able to get our rent paid. Then, but there's the thing about paying bills back home as well. So, making sure that we have money to pay bills for the existing house.

In addition to financial stressors associated with relocation, underlying his narrative were the emotions associated with being separated from his family. In the same month that Matthew was making relocation arrangements, his eldest son became suddenly ill and required surgery. Likewise, Roger's mother passed away the same month his wife was scheduled for her lung transplant assessment. He commented:

I was stressed for time, I had to fly back and arrange my mother's funeral ... as soon as I arrived in XXX, phoned [my wife] to tell her that I got there safely, she said, "You won't believe it, the lung transplant people just phoned me, said they want me to go there for an assessment." ... She had to explain the circumstances, and we delayed it for another month ... when I got back [home], I was really tired and everything. Then we flew here [transplant centre] in April ... flew back [home], and then they told her she's on the lung transplant list. Then, then we drove here in August.

This excerpt reflected how the complexities of daily life continued to influence support persons' experiences of relocation. Matthew and Roger's narrative accounts suggested that support persons might endure many stressors in their current lives as they transition to waiting for lung 
transplant.

\section{New spaces and relationship dynamics.}

Support persons' waiting experiences involved living with the patient in a new space that impacted existing relationship dynamics. Caitlin, who had lived alone all of her adult life, commented upon "adjusting to living" in close quarters:

It was adjusting to always being in someone else's space, and someone being in my space ... I was fairly independent, so now, it went from just doing things for myself, to, “OK," if your mom wants you to cook, your back hurts, she's, she's very considerate if I have a bad back day. She, she'll try not to ask me to, she'll just try to have toast. But that's not, I'm not here for me, I'm here for her.

Caitlin's comments reflected a disruption of personal space and the accompanying social processes as she and her mother relocated into their new home. It was apparent that a newly shared space emerged in which Caitlin shifted her identity from being an independent person to now living as a support person for her mother. Similarly, although Dianne shared a close bond with her friend, living together was a completely different experience. Dianne remarked:

When you're friends with someone, you think you have the same likes, and that's why you're friends. And then you live with them ... Living with a close friend is a lot different than having a close friend. ... Obviously, you get on each other's nerves.

Dianne's excerpt revealed that tensions could exist within this new liminal space of waiting, due to role changes and changed living dynamics. Even though Roger had been married to his wife for almost 40 years, the new living arrangements impacted the physical and social space. He stated:

There's a lot of tension, uh, between us, because we're not used to spending that much 
time together. We've been together since, we were married [a few decades ago]

[laughs] ... but, like, when we were younger, I'd be away, working. ... So it's just, we're enclosed ... we keep bumping up.

As reflected in Roger's excerpt, the physical proximity in waiting disrupted the social space, in which smaller living quarters changed the way that he and his wife interacted in their daily activities. His linguistic usage of "enclosed" suggested a sense of confinement to their relational and living dynamics. Living together in a new space altered relationship dynamics as they transitioned into their role as caregivers.

Relocating to another city for transplant led to a separation from support persons' home, family, and previous routines. Physical separation not only disrupted Matthews's normal routines, but his capacity to be a family with his sons. Matthew remarked:

We did a lot of outdoor activities with our boys, and that's what we really miss right now as being able to, really be a family. 'Cause right now, we should be a real close family ... Unfortunately, she has a disease that doesn't allow us to be.

There was an emotional tone underpinning Matthew's narrative. He shared that there was only a finite time left that his sons remained in his "nest" because they were transitioning to adulthood. The physical separation required for his wife's illness affected his role as a father to be present for his sons. Caitlin noted: "Now I get this wonderful boyfriend and I have a dog who I consider my son [laughs] um and so, why is God pulling me away from these now?" Her questioning and the linguistic phrase "pulling me away" reflected the emotional upset and personal cost associated with the lack of control in being displaced as she accepted the support person role. These narrative accounts suggested that relocating with the patient remarkably disrupted the support person's other personal relationships. 
As support persons were thrust into a new space to wait for lung transplant, they spoke of their longing for the spaces they used to occupy. In relocating to be her friend's support person, Dianne spoke about homesickness as she left her hometown, her husband and cat. She remarked: It's something I think about all the time, and I say, "Well, you are where you are. And you're doing what you're doing, and [pause] you know?” I just, I'm just not seeing the light at the end of the tunnel yet. [laughs]. I would like to see just a glimmer! [laughs]. I know it's there, it's just, I can't see it yet! It's, it's, it gets me a little antsy ... the light at the end of the tunnel for me, to go back to my life.

Dianne's comments revealed the impact of her displacement on her psychosocial wellbeing. The metaphor of a "tunnel of darkness" reflects the discomfort and possible anxiety of not knowing when she would be able to return home. Similarly, Roger lamented that waiting for lung transplant has caused he and his wife to miss out on important family milestones. He stated: “Above all, we miss, we just had another grandchild ... I mean, it's, like, not being able to go there." As reflected in his quote, the social separation that accompanied the physical separation from family was also disruptive to their lives. Matthew echoed: "We can't go back home, because once you're on the list, you're on the list." Matthew's statement suggested that choices were bound by the wait list and as such, he and his wife were geographically confined to the space of waiting. Within the liminal space of waiting, support persons experienced disrupted relationships, as they are bound to different living spaces, conditions and dynamics.

\section{Confinement.}

A sense of confinement emerged in support persons' narratives as they entered into this liminal space of waiting for transplant. In addition to being separated from their homes and relationships, support persons engaged in role changes and became first and foremost caregivers. 
In her journal, Caitlin wrote:

There are days I really hate being here! I feel miserable and sad and depressed and grumpy as hell. Mom gets on my last nerve by asking me to do the things I'm here for. "Did you plug in the oxygen?" "Yes." "Did you pack my sats meter?" "Yes." "Do we have any other appointments tomorrow?" for the $4^{\text {th }}$ time $\ldots$ I miss not having to take care of someone.

Caitlin's entry reflected an emotional upheaval in which she coveted her previous life, where caregiving was not her primary responsibility. Although Caitlin shared that she had been her mother's caregiver during past hospital admissions, her obligations were intensified in this waiting space. There was a sense of being confined by her caregiver tasks and a lack of choice to exit the support person role. The sense of role confinement was also remarked in Dianne's journal entry: "I can't leave [my friend] alone for that long. Feel stuck here." It appeared that in adhering to the support person role, there was perhaps an underlying fear of what would happen if Dianne were physically away from her friend for too long. Support persons might find their roles restrictive as they perceived an obligation to be bound to caregiving responsibilities.

Support persons' sense of confinement also manifested in a spatial manner. Dianne described:

I guess I could relate it to people in nursing homes. With a routine, it's the same day after day after day. And what are they waiting for? They're waiting to die! They know they're going to die. And it's just, the routine is the same. It's, I don't know what else to relate it to. Prison [laughs] yeah.

Her comparative reference to nursing homes and prisons reflected the confined nature of waiting for transplant and the associated strict and monotonous activity schedules. Furthermore, her 
parallel to nursing home residents "waiting to die" denoted a sense of hopelessness within the waiting space and routine. Roger also remarked upon the day-to-day routines, stating:

We're restricted, in so far as we come, the most we come out is to the hospital, which is stressful for her, just coming back and forth, you know? And for me too. Some days I feel it now, I just want to stay home.

Roger's statements indicated how the waiting space was bound between the home and the hospital. Underlying Roger's excerpt was not just being restricted by the routines associated with waiting, but the strenuous toll of these routines on his wife's physical and mental stamina. In his journal, Roger wrote about the shift in routine that occurs on weekends:

This is the time that we can both enjoy the break from the hospital trips. I do all the washing in the coin wash downstairs and then go to the gym for more work on the treadmill. I watch a lot of the football ... After that, she catches up on all her soaps on the TV and I read my book and have a few glasses of wine. I like Saturdays.

Roger's quote revealed the freedom that occurred when he and his wife were not confined by the routines associated with the waiting period.

Support persons' accounts reflected a sense of confinement as a result of patients' own physical limitations. Dianne remarked:

Up until a month ago, she would um, when she would finish her physio, we'd go to the store together. Um, but the weather changed and her physical condition changed, and she's not really getting out now at all. Um [pause], so it's, you know, it's tightening up. Dianne's linguistic usage of "tightening up" highlighted the restriction that her friend's condition imposed on her and the lack of capacity to move around freely. She added that her friend "is more and more insecure with being left alone," which meant that with this dependency, Dianne 
became even more bound to her friend's physical space. Roger shared that as a result of his wife's oxygen needs, they no longer went out and only traveled between the hospital and their condominium: "We're trapped here, you know? ... [My wife] calls it a prison sometimes. 'We're in a prison, let's go back to our prison now." While Dianne described the waiting routine to be akin to prison, Roger' metaphorical reference of his home as a prison and feeling trapped accentuated the confinement attributed by his wife's illness. It appeared the patient's deteriorating condition and physical limitations further limited the physical spaces of waiting.

\section{Emotional isolation.}

Emotional isolation was expressed in support persons' narratives when referring to the physical and social space of waiting. In her journal, Dianne wrote:

Strange, but it's an isolated [participant's emphasis] feeling being the "support" person. ... Awareness today for the first time that [my friend] is afraid to be alone. That puts an emotional burden on me, because now I feel even more trapped by these walls. Dianne's reflection suggested a sense of separation from her social world. For Dianne, the liminal space of waiting was an emotional experience closely interwoven with her friend's emotional state. The linguistic phrasing "even more trapped" suggested that the spatial confinement in the waiting space and routines exacerbated Dianne's own feelings of emotional isolation. Caitlin commented on her emotions, "I cry a lot in the shower [laughs]. Because I don't want her to, like I'm her daughter, so if I'm sad, she's going to worry. And she doesn't need that extra stress." Underlying this excerpt was a role reversal in which Caitlin deliberately concealed her emotional distress. It appeared that Caitlin perceived that the sharing of her own emotions could impose upon her mother's wellbeing.

The physical separation from friends, family and existing social supports increased 
support persons' emotional isolation. Matthew referred to a visit from his family, explaining how he immediately felt the difference with their presence:

We had a good time together for the ten days that everybody was there. So, it was good, but it was kind of sad, just seeing my mom and sister leave on New Year's Eve. And then seeing our boys leave, going back to school, so, it was um, sad for that to happen again, just because, it's just us two [my wife and me] again.

Although family visits eased the loneliness, Matthew's words "just us two again," suggested an aloneness within the support person-patient dyad. Even though support persons and patients lived together and had each other for companionship, the waiting experience might cast them into an isolating space. For Dianne who left her home, family and community to support her friend, the physical separation from her own life was beginning to weigh on her. In her journal, she wrote, "I want the best for [my friend], but I want my life back. I miss my husband, my cat, my former life." There was a sense of loss underlying Dianne's excerpt and clear distinction between her present and former life. The physical and social space of waiting for transplant was a life changing transition marked by separation, role changes and new routines. These separations resulted in physical and emotional confinement and isolation for support persons as they became the patient's sole companion and care provider.

\section{The Patient as the Focal Point}

Support persons' accounts reflected how the patient was the focal point. While most of the participants were involved in the caregiving role to varying degrees prior to being on the transplant wait-list, the waiting period was a unique space in that support persons now served as the primary caregiver for patients. The patient as the focal point is demonstrated through four 
sub-narrative ideas: support person responsibilities; monitoring and anticipation of patients' needs; emotional support; and support persons' needs shifting to the background.

\section{Support person responsibilities.}

Support persons considered their caregiving activities to be matter-of-course as they assisted patients with their daily routines and maintenance of health. Matthew described:

We've always been supportive of each other in the form of [pause] I'll do that extra thing for her, or she'll do that extra thing for me. ... being a supportive person, or what, what I am now, it's just a little bit more responsibility.

Matthew's linguistic use of "that extra thing" and "just" appeared to downplay the magnitude of his responsibilities and normalize his support person role by identifying it as an extension of the expectations associated with his marriage. While support was reciprocal in their relationship, he described taking on "a little bit more" in this transitional space of waiting. Although Dianne was not a family member, she felt that she did "a better job than anyone" in taking care of her friend. She compared her abilities to the patient's husband when he visited, stating: "He does everything that I would do, but she has to ask him. He doesn't, he doesn't anticipate. And as an old [healthcare professional] [laughs], we anticipate ... I anticipate." There was a sense of pride reflected in Dianne's statement in her capacity to foresee the patient's needs. Despite the stresses of their role, support persons might readily rationalize their caregiving responsibilities to be virtuous or as a natural extension of their familial or professional roles.

It was apparent that caregiving associated with a support person's responsibilities did not always come naturally. In Caitlin's narrative account, she described her role as "inevitable" because she was most knowledgeable about her mother's medical history and she was the only family member who could relocate. Her linguistic usage of "inevitable" suggested that 
transitioning into the support person role was both necessary and unavoidable, despite it involving the requirement to leave her own job and relationships. Caitlin wrote in her journal: "I feel like this is prepping me for my future, as a wife, as a mom, to take care of my dad or in-laws if needed." It appeared that Caitlin associated caregiving responsibilities with traditional gendered roles of wife and mother, and embraced the opportunity to develop these skills. Roger commented upon an unintentional oversight related to his caregiving activities:

I get annoyed at myself ... some nights, she goes in [the bathroom], and either one [of us] has forgotten to turn [the oxygen] up, and she comes out, she's not feeling well. She put the thing on the finger, and she's down to 78. And I get [pause], if I forget to do, I get so angry at myself.

His narrative demonstrated how support persons play an important part in maintaining the respiratory stability and safety of the patient. Underlying this excerpt was an element of emotional distress when Roger did not execute his tasks with precision.

\section{Monitoring and anticipation of patients' needs.}

Monitoring and being watchful was prevalent in support persons' narratives as they emphasized the importance of closely attending to the patient's physical wellbeing. Roger recounted:

That's why I always keep an eye on her on the walking machine, and uh, to make sure it doesn't drop too low, you know? ... it just seemed a lot easier back [home], 'cause, the oxygen wasn't that critical. It was coming here, she's dropped, you know?

The linguistic descriptor "always" emphasized the importance of continuous and consistent practice of monitoring in his support person role. Roger's need to closely observe and watch his wife stemmed from an awareness of her changing condition. Underlying his actions was an 
element of fear of the consequences if he did not engage in surveillance. Dianne wrote in her journal:

I vacillate between wanting her to stay here where she's "safe" and wanting her to be hospitalized. I'm afraid that she will die. ... I cautiously look at her every morning while she's sleeping, making sure that her chest is going up and down. If she dies on my watch, it will devastate me.

The intensity of Dianne's monitoring was interwoven with fear and distress. The linguistic phrasing in the last sentence was reflective of an internalized responsibility for her friend's wellbeing as well as the potential of an overwhelming grief. As Dianne "vacillates" in uncertainty over her decision for her friend to stay under her care rather than the hospital, she had cast herself into a protector role, where she perceived that her actions ultimately impacted the patient's welfare. These excerpts highlighted the pressure and accountability support persons imposed upon themselves as their attention unequivocally shifted to monitoring the patient's wellbeing.

Another aspect of the support person role was anticipating the patient's physical and emotional needs. Dianne described strategies used to promote her friend's comfort, such as putting on the fan so odours would not irritate her, or learning how to operate and troubleshoot her friend's scooter. She commented: "the support person, it's a more anticipatory thing. This is where you need the support, you know. You need to know that you're not going to run out of oxygen, I need to make sure that happens." Dianne's example demonstrated the importance of anticipation in maintaining her friend's physical safety. Moreover, her linguistic usage "I need to make sure" suggested that Dianne placed upon herself an immense accountability to ensure that the patient's needs are met. As Matthew's wife did not require as much assistance as other 
patients, this allowed him to continue his employment and schedule his work hours around his wife's appointments and activities. However, he commented about prioritizing his wife's needs:

But if it comes to a point where I have to spend more time with her, for whatever reason, if it's more caring or more moving her around, and whatever, then I'll discuss with my employer and start maybe go on medical leave or something.

Underlying Matthew's excerpt was his anticipation of how his wife's needs were in a dynamic state that might require him to modify his employment. There was no hesitation as to where Matthew's priorities lay. Within the liminal time and space of waiting, support persons faced an identity shift in which the supportive role and the patient commanded their undivided attention, leading to prioritizing other commitments and relationships to the background.

\section{Emotional support.}

Support persons' accounts reflected how they perceived emotional support, in terms of encouragement and motivation, to be an essential responsibility of their roles. Matthew noted: “she's mentioned it, just very very happy that I'm with her for this, for this stage that we're having. She's mentioned there's no way she'd be able to be where she is, without having me involved." Matthew's emphasis on the descriptor "very" demonstrated the necessity of the support person's presence in helping patients persevere during the waiting period. Of interest was his use of plural first person "we're having," which spoke to the identity shift in how support persons perceived themselves as coalesced with the patient; Matthew was both a support person and a partner sharing in his wife's emotional journey of waiting. Dianne also used the plural first person when referring to "our lungs." Despite the fact the patient was the organ recipient, it appeared that support persons perceived themselves to be active participants in the liminal space of waiting. Caitlin spoke of the importance of providing emotional support through active 
listening when her mother was put on hold on the transplant list due to a sudden diagnosis:

"How are you feeling about it?" And, as opposed to, like uh, kind of a dialogue where she'll talk and I'll talk, I kind of listen to what she has to say, and keep my responses as, um, almost as clinical I can, with keeping the emotion from it ... just 'cause, if I cry, she's going to cry. And she doesn't need that extra stress.

Underlying Caitlin's narrative was the perception that composed and objective responses were best when providing emotional support. It appeared that support persons were attuned to patients' emotional wellbeing and needs, and mindful not to add to their psychological distress.

An important layer of emotional support was motivating patients to remain committed to waiting for lung transplant. Dianne spoke of her role in motivating her friend to adhere to the exercise schedule: "She's not trying as hard to lose weight, um, although she's lost two pounds this week. But, she's not trying as hard, and she's not as animated. I have to pull it out of her more." Underlying Dianne's statement was the effort and emotional labour she needed to assert when encountering her friend's resistance. Also, this quote revealed Dianne's sensitization to her friend's emotional state, and recognizing the need to emotionally uplift her. Roger also encountered similar circumstances when his wife wanted to return home:

That's what I tell her when she's a bit cracking up ... 'cause she's like "Okay, I'll get a deadline, I'll go back [home if I don't receive lungs by then]." And I said, you know, "The problem there is, you're going to be limited by what you do, because you're still going to be on oxygen, and you can't, you can't travel on the airplane, because there's not enough oxygen."

Roger's use of logic and rationalization demonstrated how motivation was embedded in his emotional support. It appeared that while the patient might grow discouraged in this liminal 
space, the support person was charged with the task of remaining encouraged and committed to the waiting process.

\section{Support persons' needs shifting to the background.}

Support persons' narratives reflected how their own needs shifted to the background.

Matthew remarked:

I have no hard feelings in regards to having to do this, and having to structure my work, and needing to relocate. ... in regards to how I feel about structuring my routine around her is, I have no objections doing it because I'm fully aware it was going to be happening and I knew that we would have to adjust. And, we have adjusted to it fairly well.

Although the linguistics of "having to" suggested an obligation to restructure his life, Matthew was prepared to make these changes within the liminal waiting space. It appeared that Matthew's mental preparation for this transition facilitated his shift into the support person role. Dianne on the other hand, who agreed to be the primary support person to her friend, felt torn between her commitment to her friend and to her own obligations back home, commenting:

Her needs supersede my needs. And being the selfish person that I am [laughs], I feel that my needs aren't being supported, you know? I feel her husband should step up to the plate and ... say "Listen, I will come for two or three weeks ... you can get down to [home]".... I don't feel like I can make a stand.

Dianne's joking remark about being “selfish" highlighted the way in which her own needs began to feel secondary. Furthermore, while she volunteered to be the support person to alleviate her friend's financial pressures, a sense of powerlessness emerged in her excerpt. Yet, when her friend's husband applied for work leave, allowing Dianne to return back home for two weeks, she stated: 
Her husband asks me, “Are you happy you're going home?” And I started, I filled right up [cries]. Because I'm very ambivalent right now. [My friend] is at her worst and I want to go home ... it would be silly for the two of us to sit there. And I have that opportunity to go. But, it's a difficult situation because it's [pause] you know, she is at her worst. Dianne experienced an internal conflict even as her friend's husband provided respite, recognizing that she might be leaving at a time when her friend was facing her "worst," or impending death. Possibly underlying this excerpt was Dianne's fear that her friend might die while she was away. Support persons deferred their own commitments in order to attend to the patient's physical and emotional needs, especially in the threat of possible death for the patient. It appeared that this supportive role could overtake or eclipse support persons' personal obligations or needs.

By placing patients' needs above their own, support persons' wellbeing was impacted. At the time he relocated with his wife, Roger was undergoing evaluations for his blood pressure and multiple other health conditions. Roger commented:

I tried to make an appointment with my [new] family doctor but she is not back til later this month ... since we came here ... she has arranged for me to get an appointment to get a steroid injection in my hip but I am still waiting. Also, she requested a consultation with a dermatologist about my skin but I am still waiting. I am really losing out on my medical treatment here and [my wife] is always worried about me. It causes me stress also, as if I got really ill, there is no one else here to be her caregiver.

As reflected in this excerpt, Roger's stress in the support person role was further compounded by delays in obtaining adequate medical treatment for himself. Roger's linguistic usage "I am really losing out" suggested his wellbeing was being jeopardized due to relocation and interfacing with 
a new healthcare team. Additionally, there was an overwhelming concern that there was no other person to be his wife's support person if his own health declined. Conversely, Caitlin, who was struggling with narcotic dependency related to chronic back pain, shared that caregiving allowed her to focus on her own health, explaining: "it's allowing me to take care of myself, while taking care of my mom. And it's a nice deflection, because I don't, it's not, 'Okay, I have to work on coming off narcotics.' That's just a background thing to taking care of my mom." Although Caitlin considered caregiving to be a positive distraction, it appeared that her health issues became trivial or secondary despite her statement that her struggle with narcotic dependency was "not any less important." These excerpts suggested that the shift into the supportive role was all encompassing, whereby support persons began to view their own lives as an extension of the patients.

\section{Hope(lessness) and Fear}

Support persons' narrative accounts of waiting for lung transplant contained feelings of both hope and hopelessness interwoven with fear. In this section, I discuss hope(lessness) and fear according to three sub-narrative ideas: anticipation; uncertainty of the unknown; and death and dying.

\section{Anticipation.}

Embedded within the narrative idea of hope was the eager anticipation of a transplant call. Caitlin remarked:

Anytime the phone rang, you drop everything, everyone in the room stops talking. If you're in the middle of a shower, you jump out of the shower [laughs]. ... So let's say, “'Okay we've done physio for the day, so we'll be able to get home and get something to eat, and she'll be able to get a nap." And then, if the call hasn't come in, she wakes up 
from her nap ... if the call comes in now, she's got some rest. ... so if the call comes in now, her breathing won't be as bad to get to the taxi and from the taxi to the hospital. And then at dinner, "Okay, so she's had something in her stomach, so if we get the call now, she won't be hungry."

As reflected in this excerpt, Caitlin was constantly anticipating and planning out how she would manage and respond to the transplant call. It appeared that her day-to-day activities were structured so that her mother was perpetually readied if the call were to come. Roger noted his plans: "She's got her bag packed, with you know, pajamas and slippers ... if she gets a call, she's all ready to go. And me, I'll just take my cell phone and charger.” Much like expectant parents packing their hospital bags in anticipation of a new birth, support persons were excited at the prospect of receiving a transplant call. Roger's linguistic usage of "she's all ready to go" reflected a sense of great potentiality for change that can occur within the liminal period of waiting. The anticipation of a call, manifested by support persons' perpetual readiness, fueled their hope for this life changing transplant surgery.

Support persons expressed hope through envisioning how lung transplant would change their lives. In reflecting on the progress of other patients and support persons following surgery, Matthew commented:

We hear of people doing well. We hear people, some people having little bumps along the way, but they're doing good. So we see that, and that's what really keeps us going ... knowing that good days could be coming pretty soon, that um, it's what we're really looking forward to.

Seeing others "doing good" after surgery promoted anticipation of the possible life transformation through transplant and departing the liminal space of waiting. Matthew's 
linguistic usage of "keeps us going" suggested that envisioning a better future was a source of strength to persist in waiting. Similarly, Roger commented on the future following transplant: "If she gets the lung transplant, and she makes it, and she's no longer on oxygen, we're going to travel ... do things we like to do. So, that's what we get to look forward to." Roger differentiated the confining space of waiting with the post-surgery space, whereby transplant would return to them the freedom to "do things we like to do." At the same time, his use of "if" highlighted his awareness that his hopes were not guaranteed. Lurking under his hopeful anticipation was the possibility of death. It appeared that support persons might draw upon hopeful futures in order to manage or avoid hopelessness.

\section{Uncertainty of the unknown.}

Support persons' anticipation was coupled with uncertainty and disappointment with each passing day that a transplant call did not materialize. In her journal, Dianne shared her initial reactions when she heard that two other patients received lung transplant:

Frustrated, never even a false alarm call for [my friend].

Anger: Can't explain it - I'm just angry

Disappointed: like a sinking feeling in my stomach

Sad: will [my friend] ever get a chance?

Hopeless: losing faith every day

Depressed, homesick, sad, sad, sad day. I know I should feel happy for the people who got their lungs, but I have to be honest about my feelings and I don't feel happy for them at all. I don't like that I feel this way, but I can't help it.

A myriad of distressing emotions were reflected in Dianne's account. Her "sinking feeling" and loss of "faith" suggested that hope dissolved into hopelessness as she began to question whether 
her friend would receive the same opportunity. Underlying Dianne's narrative was a comparative tone with those who received lungs and those who continued to wait. It appeared that being in the latter group created a sense of segregation and guilt because Dianne could not feel the happiness that she believed she should feel for the former group. In seeing his wife gradually deteriorate, Matthew expressed a fearful anticipation, noting:

Hopefully this is not the point where she starts turning, kind of thing, eh?". ... It's scary, well, just because it's the unknown. You don't know where it's gonna go. You don't know, it [wife's deterioration] could be fast, could be slow, could be, you don't, it's just the unknown, right?

His hope was interwoven with fear and thoughts of mortality. His linguistic phrasing "starts turning" suggested that within the unknowns of waiting, there was the potentiality of a shift in the liminal space from one of waiting for transplant to one of waiting for death. The liminal space of waiting was fraught with tension as the support person was caught between the fear of the uncertain timeframe of receiving a transplant call and the unknown course in the patient's physical decline. Uncertainty pervaded the liminal space of waiting, in which change is imminent, but the outcome can be positive or negative.

Support persons experienced powerlessness as they contemplated the uncertain nature of the waiting period. Matthew remarked:

I can provide the support and the stuff that she needs to make her not exert so much energy. I can do that part, and I know that's what I can do. But, in regards to really helping her out in her body, and the transplant role, then that's out of my hands, and that's just, I mean when the day comes, and it's just something I can't control. 
His linguistic phrase "helping her out in her body" was a powerful reflection of the limits to his role. Despite the best of his abilities as a support person, Matthew's excerpt revealed how he was powerless over many aspects related to the waiting process, such as his wife's physical decline. Dianne commented:

It [deep breath] it feels [pause] like you're in a cocoon, and there's no [pause] it's just, the cocoon, instead of you evolving in the cocoon, you're dying, you're done ... or you're in a tunnel, you're in, you know, it's just, like, being in a dark room, and you don't, you don't where the door is, you don't know where the light is. It's [pause] just very um encompassing, that feeling that, is there ever, ever going to end?

Dianne's metaphors demonstrated how powerlessness was manifested in a sense of suffocation that may heighten the support person's distress while waiting. The encompassing feeling of being trapped in a cocoon or a dark room without light suggested she had no control or resources to seek a solution or escape. Her question whether it was "ever going to end" suggested that uncertainty enhanced her hopelessness in this liminal period of waiting. Uncertainty was a pervasive force that propelled support persons' powerlessness and hopelessness. Although support persons were not the direct recipients of care, they were acutely impacted by the liminal space and engulfed by the uncertainty, hope and hopelessness.

Support persons had to temper their anticipation by rationalizing their situation and adjusting their expectations. Dianne noted:

I have been looking forward to [receiving a transplant call] from day 1, you know? You just don't anticipate length of time, you anticipate um, step by step. When you walk into this, you come, you move here, you go through a process, you get your lungs, you move on. And, it's not [laughs] not that smooth. 
Dianne's excerpt suggested that in her anticipation of transplant, she was perhaps blindsided by her expectation that the waiting period would move in a linear trajectory. She described her experience of waiting to be "interminable," which reflected a sense of stagnancy in the liminal period of waiting. Matthew highlighted the importance of being psychologically prepared: "Be ready for the wait ... in your mind, you hope that it's going to be tomorrow. But in reality, it could be weeks, months, hopefully it's not years so [laughs] ... And you gotta be patient to wait." Matthew's quote suggested that the uncertainty in waiting created a space brimming with potentiality, where there was a chance that patients might receive a transplant at any time.

However, Dianne and Matthew's use of second person pronouns (highlighted in these excerpts) reflected a distancing from the disappointment that their hope has not been actualized yet. Matthew's advice for patience suggested that the mismatched expectations for waiting might lead to disappointment and distress. Support persons' narratives indicated that hope needed to be contained such that it does not overshadow the reality that waiting for transplant might involve a longer timeframe.

\section{Death and dying.}

Support persons' narratives reflected contemplations concerning the real possibility that the patient might die while waiting for lung transplant. Dianne stated: "And there's the fear factor. We know of three people who've died while being admitted." Dianne's excerpt revealed the main reason for her hesitancy for admitting her friend to the hospital despite her ailing health. As noted above, although seeing other patients undergo surgery was a source of hope, witnessing other patients die while waiting promoted fear and hopelessness. Matthew described how he coped with the fear of his wife's death:

It's [transplant surgery] gonna happen. Like, you know, she's been pretty good for, she's 
been first diagnosed seven years ago. She's been pretty good about kind of being stable. And, then over the past year and a half ... she's been going down, just very slow, like deteriorating minimally. Like, it hasn't been drastic. So, you know that it's going to be going down, lower and lower, as the months go on. So, I understand that it's going to be, she will be getting deteriorating, or getting worse as the months go on. And then, just back of my mind, just hope that it's not fast [laughs], it's not a fast deterioration. Matthew's linguistic usage of "it's gonna happen" conveyed a determined attitude, which highlighted the importance of hope in managing his thoughts of mortality. Meanwhile, his reference to the "back of my mind" suggested that the constant and interwoven nature of hope was coupled with a fear of mortality and anticipatory grief. His excerpt demonstrated that the space of waiting is potent and transformative, filled with possible death but also enormous potential for new life. In this potent liminal space, there appeared to be paradoxical expectations for the progression of time: wishing for the transplant call to quicken while simultaneously wishing for the patient's decline to slow down.

Support persons' narrative accounts illustrated that hope was mingled with hopelessness concerning death and life. Roger commented:

There's a lot of extremes. There's one that she might not make it, and I'm going to live without her, for the rest of my life [pause]. That's really, and the other thing is the good thing, is if she makes it, and the nice things we'll be able to do.

His phrasing "for the rest of my life" followed by a linguistic pause highlighted his contemplation of the finality of death and how this potential loss weighed heavily on him. As Roger shifted from eager anticipation to fear of mortality and anticipatory grief, the "extremes" that he experienced demonstrated how waiting allowed hope, hopelessness and fear to 
simultaneously co-exist. Caitlin recalled waiting with her mother for test results that might have impacted her status on the waiting list. Referring to their conversation, Caitlin stated: "I said, 'I really honestly don't think it's cancer, I think it's just polyps.' And she said, 'You're lying to make me feel better.' I said, 'Mom, I'm really not.' I'm terrified it's cancer. I am [pause] so [pause] terrified." Caitlin's excerpt revealed the degree she strove to in order to conceal her fear, to the point of withholding her true feelings to promote hope. It was apparent that support persons perceived that within the space of waiting, they should not openly share their inner fears of mortality with the patient. As support persons struggled with thoughts of mortality and anticipatory grief, it was unclear who was supporting support persons' emotional distress.

\section{Finding Meaning}

Support persons' accounts of waiting reflected ways that they were able to find meaning through their role and experiences. This narrative idea resonated with Turner's $(1967,1969)$ findings that self-reflection within liminal space prompted the liminal person to re-imagine and re-define oneself. I discuss the following sub-narrative ideas: purpose in waiting and caregiving; and reflection and thankfulness.

\section{Purpose in waiting and caregiving.}

Narrative accounts reflected support person's use of spirituality to discern meaning and purpose in waiting for lung transplant. Matthew referenced the Aboriginal concept of the Red Road to make sense of his experience:

In our culture, we're taught that, you're pointed down the road that you don't know. But along the way, things happen, that gets you thinking, "Oh, this is why I am here." ... So for our culture, I think we're down this road [pause] to learn. And then share. 
Matthew noted that he and his wife were deliberately placed on this road for the broader purpose of "First Nations people to be more aware of what organ donation is." His linguistic usage of "pointed" suggested a fatalistic view of life in that he was meant to experience this process. Caitlin also relied on her belief in a higher power, stating that "God has a reason for something. ... So, instead of being down and sad about it, we say, 'Okay, why did this happen? Why did something not go as planned?' So we try to go and look for the bright side of things." Caitlin attributed a supernatural force for how events unfolded in her life as a means to make sense of and rationalize her situation. It also appeared that her need to "look for the bright side of things" acted as a coping strategy to counter or manage medical problems and setbacks. Engaging in spirituality to find meaning in their experiences of waiting might allow support persons to find acceptance in their struggles during this liminal time.

Support persons' narrative accounts illustrated moments of finding meaning through embracing their role as caregivers. Dianne commented:

She, um, has to get her hair washed twice a week ... it's, getting her oxygen at the right level, get her over to the sink, and, I wash and blow-dry her hair, so. And, I think we both take great pleasure in that [laughs].

Underlying Dianne's account was the amount of effort and skill required to complete this activity: evaluating the patient's activity level and adjusting their oxygen needs accordingly. It appeared that Dianne derived a sense of achievement when she was able to competently provide for the patient. Caitlin also shared: "I feel like I have to be selfless, which I kind of love.” Caitlin's description of being "selfless" denoted a sense of self-sacrifice, as she reveled in the opportunity to care for her mother. However, her linguistic usage "kind of love" suggested that this selfsacrificial role might not be unequivocally embraced. As reflected in these narratives, finding joy 
in their caregiving activities might affirm support persons' purpose in dwelling in this liminal space of waiting.

\section{Reflection and thankfulness.}

Support persons' narrative accounts revealed a sense of enjoyment in being in a new city and being with the patient during this time period. Matthew "explored the city" with his wife and spoke of the impact of the waiting period on their relationship: "We've been pretty, pretty lucky together that uh, we've had an overall, in general, we've had a very good marriage. ... We're still able to be together and enjoy the time." Though waiting for lung transplant had not affected Matthew's relationship with his wife in a negative way, his linguistic usage of "still able" denoted an uncertainty in their present situation. Roger and his wife celebrated their wedding anniversary at the time of the study, and he noted:

The weather was so cold, we just spent the last three days in a condominium. It's nice and warm, and it's bright, sitting by the window looking out with the sun coming in. And it was nice. ... I mean, you can't say it's a bad life, we're, we've got a nice comfortable life. The condominium's beautiful. We're living comfortably.

Underlying Roger's excerpt was a sense of gratefulness for the small moments in life. While he had previously referred to this new home as a "prison," Roger was able to seek the comforts of being in this enclosed space, such as enjoying the sunlight. Engaging in reflective thinking to find the positive aspects in this transition time period might deflect support persons from the daily stresses and confinement of waiting for lung transplant.

\section{The (Un)Support of the Support Person}

Embedded in support persons' narratives of waiting for lung transplant were discussions about the ways they were and were not supported. Participants spoke about this support from an 
individual level, a systems level as well as an interpersonal level. I describe support persons' support and unsupport in the following sub-narrative ideas: compassion fatigue and self-care; informal and formal supports; and healthcare professionals.

\section{Compassion fatigue and self-care.}

Support persons' narratives revealed elements of compassion fatigue as they dwelt in the liminal space of waiting. Dianne stated:

I feel like I've [pause] done [pause] pretty much all I can do. I don't [pause] know how far, how far, much further I can go support wise, you know? ... But, in my mind, when I committed to this, I committed to a year. And now I'm thinking, how can I do this for another seven months?

Underlying Dianne's excerpt was mental exhaustion in her support person role. The rhetorical question, concluding the excerpt, suggested the potential of succumbing to this exhaustion. Roger shared about his conversations with other support persons: "Some of these caregivers that I talk to, they, they look really drained ... 'Oh, I'm fed up with this. Same thing every day ... getting the weights, wiping down the things, the treadmill when they're finishing up."' His quote suggested that the repetitive nature and monotony of the waiting routine was emotionally tiring for support persons. Additionally, use of the word "drained" implied that support persons became deprived of strength or exhausted their resources. Matthew stated: “'Are you burning out? You think you're adjusting? Do you need more support?' Those kind of questions should be asked to caregivers ... especially the more senior individuals, it can be very [pause] it can burn out that caregiver." It was interesting to note that both Roger and Matthew referred to fatigue indirectly by referencing other support persons. This suggested that support persons may resist 
talking about their own fatigue possibly as a way of distancing themselves, or it might also conjure up feelings of guilt.

Support persons' narratives highlighted the importance of self-care during the waiting period. Dianne commented:

I do have the me-time that I have selected. I have that six-thirty to eight-thirty time.... then I have the me-time at night, before I go to bed. Call my husband, sometimes I'll call my grandson, that sort of thing ... Check my email in the morning, check my email at night, that sort of thing. So, I have time when it's my time.

Dianne's emphasis of "me-time" and "my time" suggested a spatial separation in which there was protected time where she was absolved from her support person duties. Also, her excerpt reflected how personal time created a shift in focus from the patient's activities and needs to the support person's relationships and needs. Matthew had family members visit, so "they'll take the role of being caregiver." In speaking about this respite, he noted:

I went home to go hunt ... I spent three days in the bush, by myself. [pause] Nothing around me, no cell phone, no cars, no concrete jungle, just me in the trees and, and I felt like I recharged my batteries. I felt real nice when I - my mind was with my wife. But my body was recharging, and it was, it was relaxed.

Implicit in Matthew's narrative was the sense that his body could not relax in the routinized space of waiting with the associated routines. His excerpt suggested that he was able to find true physical rest and renewal when he left the liminal space and connected with nature. However, he commented, "my mind was with my wife." It appeared that this liminal space of waiting did not just inhabit his body, but also his mind. Caitlin wrote about her feelings following a visit back home: 
I was really cranky because within two hours of being back I had to check appointments for the week and make sure mom got a refill on some medication. I'm really sad again but it will pass once I acclimate to being here again.

Caitlin's excerpt suggested that as she entered back into her role as support person, negative emotions emerged associated with her caregiver tasks and the routines of waiting. Even though she was away for two weeks while her father cared for her mother, her emotional state changed upon returning, whereby her use of the term "acclimate" suggested a social shift requiring one to familiarize and accommodate to the liminal space of waiting and her support person role. Roger was the only participant who was unable return home, but he spoke about "switching off." $\mathrm{He}$ explained: “[I] get engrossed in what I'm doing ... When I get into my music, I'm switched off. I mean, once I'm focused on the music, there's nothing else that exists in the world, you know?" Roger's comments implied that music acted as a self-care strategy that allowed him rest from his constant support person role. It appeared that having one's own time and space outside of the waiting routine as well as activities that shifted them away from the supportive role could be uplifting and protective for support persons' wellbeing.

\section{Informal and formal supports.}

Support persons described the importance of connecting with family members back home. Dianne commented: “I have to bring this up. I would never be able to do this, if I didn't have a very supportive husband." It appeared that Dianne's own familial support was vital to ensure her capacity to act as a support person. Caitlin commented: "My boyfriend back home is incredibly supportive ... if I need to call, he hates talking on the phone, but if I need to call him, he'll stay on as long as I need. ... if I didn't have him, I would be prone to depression." Caitlin's excerpt revealed a parallel in support; just as she was unconditionally "here for my mother," likewise her 
boyfriend provided unconditional emotional support for her. Her linguistic usage "prone to" reflected the importance of emotional support in mitigating psychological distress from the support person role.

Support persons also expressed positive aspects in forming relationships with other lung transplant patients and support persons. Matthew spoke about the "lung transplant community" and affectionately referred to the patients as "hosers," due to their reliance on oxygen tubes that resembled hoses, while support persons were dubbed "posers." He stated:

We see them on a regular basis ... and being with the group has really been very rewarding, because we've learned from everybody, 'cause we know how everybody is dealing with different situations, whether good or bad. And seeing everybody get through surgery and move on.

Matthew's comment suggested that finding a sense of belonging among other lung transplant patients and support persons was therapeutic. Underlying his excerpt was the vital importance of mentorship and socialization that can occur in this informal community. Matthew's linguistic usage of "move on," suggested that observing others' success with surgery facilitated his own optimism. However, not every transplant patient and support person were part of an informal group. Matthew's community was a group of twenty support persons and patients, which was roughly one quarter of the actual lung transplant cohort. Dianne commented on a monthly support group meeting where they share a meal afterwards. She stated: "We've been together for lunch and we hear, 'Oh, a bunch of us got together and went to the lake on Saturday. A bunch of support people.' I'm just sitting there, thinking to myself, 'What am I, chopped liver?"” Dianne's metaphor of "chopped liver" indicated she felt isolated and devalued by being excluded from additional support person activities. While Roger enjoyed meeting new people, he sometimes 
found it challenging to be around other support persons and patients: "Seventy-five percent of the time I find it depressing, being in there [physiotherapy centre] ... everybody in the same position as we are." Dwelling in the same space with others who were in the "same position" as Roger exacerbated his distress and hopelessness.

Support persons' narratives reflected the need to modify and enhance the formalized support program for lung transplant patients and support persons. Dianne noted:

There's not a lung transplant network. There's not a support person network. Unless you develop it yourself. So one of the things that we, [my friend] and I both talked about, is when you come into the program, being assigned a big sister or big brother, someone who's either waiting, or [pause] someone. Their phone number, their contact information, so you can learn the ropes. We were here a few months before we found out that they get together Wednesday to have lunch.

The linguistic phrasing "learn the ropes" suggested that there were nuances associated with waiting that one needed to become acculturated with. Dianne's excerpt reflected the importance of a network to facilitate information sharing through a mentorship strategy using a one-on-one approach. Matthew's account also echoed the importance of a one-on-one approach to facilitate "more direct conversation" and "get to that level of discussion." Both Dianne and Matthew remarked that the current monthly support group format was not productive because "I just felt

like it was a venting ... they [other support persons] just take up the whole time ... I got nothing out of it." (Matthew). Matthew's comments reflected that support persons might have deeper psychosocial needs that could be sufficiently addressed in a one hour group format.

\section{Healthcare professionals.}

Support persons had mixed feedback towards the functioning of the entire lung transplant 
healthcare team. As a support person, Caitlin received referrals for her back and narcotic issues, noting: "We're [my mother and I] floored at how well they take care of the caregiver. Which again, goes back to making it easier on the caregiver, so, in my opinion, I can focus all that energy now on mom." Caitlin's remark reflected how the healthcare team was a facilitator to the support person's role. Matthew observed that the healthcare team tried to "steer us in the direction where we have to go," which suggested an orientation or guidance role. He commented on a situation when his wife reported flu-like symptoms during a physiotherapy appointment, stating: "The physiotherapist called the transplant coordinator ... the coordinator made arrangements for us to drop the sample off ... stuff like that made us, made us at ease.” His excerpt revealed how the timely communication and coordination among various healthcare professionals alleviated support persons' moment-to-moment concerns.

Support persons expressed frustration when they perceived that their concerns were not being considered seriously. Roger recalled:

I've asked, "I'm really concerned, like, when she drops her oxygen, like it can really plummet at times, and it gets me worried." And she's [nurse practitioner], "Don't. Nothing to worry about that. It's natural for people who've got interstitial lung disease." ... So they're not [laughs], it's just, well like, they could say, "Well, don't worry." And explain it to me, like just say "That happens sometimes with people sometimes, but don't worry about it, just make sure she's OK." So, they're just ... “don't worry about that, that's natural."

Reflected in Roger's account was how support persons' perception of nonchalant and condescending tones or dismissive words could lead them to feel like their informational needs were being invalidated. Underlying his narrative was how a major concern for him was being 
reduced to something minor by healthcare professionals. Dianne also recalled receiving "platitudes" from healthcare professionals, and even altered her voice when mimicking their voices: “[raises pitch] 'Oh, you're going to get your lungs!' And I really wish you wouldn't do that. ... It's very condescending, she has no way of knowing how soon the lungs are coming." While the healthcare professional might have been trying to be encouraging, Dianne found these assurances to be patronizing and inauthentic. Dianne's excerpt also highlighted some healthcare professionals' lack of sensitivity concerning the indeterminable nature of waiting for transplant. These accounts indicated how support persons were sensitive to healthcare professionals' verbal and non-verbal language, in which assurances intended to be encouraging were recognized instead as demeaning.

Narrative accounts revealed support persons' desire for their voices to be heard. Dianne stated:

Healthcare providers become [pause] too immersed in what they're doing. And forget to see the whole person. They forget to, they forget to listen. They forget, they need to step back, look at the individual and say, "What is it that you want? What can I help you with?" ... it's the listening, they need to be more ... attuned to what the patient is saying. Dianne's excerpt reflected the importance of holistic and person centered approaches in which communication and support were tailored to support persons' and patients' needs. Furthermore, her linguistic usage "attuned" suggested that not only were healthcare professionals not hearing what the support person and patient were saying, but that they might not be fully aware of the individual struggles in the waiting period. Matthew referred to the benefits of participating in this study, stating: "I talked to a few people who were around and said that I felt this [the study] was very good ... I got something out of it. ... I felt very positive coming out of our first meeting." 
His comment suggested that the opportunity to vocalize his personal story was therapeutic. Roger also noted "It's been really nice talking to you [interviewer]. It's been helpful you know? Talking it out, it's actually nice talking to somebody about it, you know, that seems to understand what you're saying." Roger and Matthew's excerpts emphasized the supportive element of communication in terms of working through an issue and the importance of having someone acknowledge and empathize with the support person's experiences in the liminal space of waiting.

Support persons suggested that members of the healthcare team should provide dedicated support to them. Roger noted: "Nurse practitioners, they ask [my wife] how she feels, none have ever expressed any_asked me how I'm coping with her ... apart from 'Tell me about—make sure she does this, and make sure she does that." His statement reflected an identity shift that was almost imposed upon him in which the support person was addressed as merely an important appendage or resource for the patient. His own wellbeing became unimportant in the wait for transplant. Dianne advised:

They've heard a lot of this. They can help people with some of these, um [pause] psychological turmoil and issues that goes on! You know? How do I keep my spirits up when her spirits are down? How do I keep my spirits going? How do I keep myself going? Dianne's linguistic usage of "turmoil" highlighted the depth of psychological distress that support persons experienced. Furthermore, this excerpt demonstrated the relational aspects of wellbeing between support person and patient; hence, it would be in the healthcare team's interest to protect and maintain the support person's psychosocial wellbeing. Matthew also advocated for "an initial meeting set up with the psychiatrist or doctor to discuss ... 'How are you doing?'. ... Let's say, I'm sure there'll be some, some worry inside me that I'd probably 
want to share, or help me alleviate the frustration as to what may be going on." His excerpt reflected the desire for the support person to also be considered as the healthcare team's client. Matthew's tentative articulation suggested that he might conceal his psychological distress from those around him, which might require professional help to uncover.

\section{Summary of Findings}

Support persons' accounts of waiting for lung transplant reflected a liminal experience, whereby they were separated from their existing social spaces and relationships, and entered into a new space marked by confining routines and changed relationship dynamics. This liminal space was an enclosing space where support persons experienced an identity shift as they placed the patient as their focal point, assuming a protector role and deferring their own needs to the background for the sake of caregiving activities. While support persons were the main source of emotional support, this was not necessarily a reciprocal relationship as they often concealed their own fears, worries and thoughts of mortality from the patient. Within the enclosing liminal space, support persons wavered between feelings of hope and hopelessness as they contended with the uncertainty of receiving a transplant call in the context of the patient's physical decline and contemplations of mortality. Support persons articulated the importance of finding meaning in their experiences of waiting, self-care and support systems outside of the waiting space. While monthly support groups and informal networks were helpful, support persons articulated the need for these networks to be facilitated and tailored. Support persons noted the effective functioning of the transplant healthcare team, but found some of their responses to be placating rather than genuinely supportive. There was a desire for formalized healthcare support for the support persons, so that they would have opportunity to have their voices heard in this liminal space of waiting. 
In the following discussion chapter, I consider the five main narrative ideas in the context of the existing literature as well as concepts associated with the theory of liminality. 


\section{CHAPTER 7}

DISCUSSION 
Sketching in the big woods is wonderful. You go, find a space wide enough to sit in and clear enough so that the undergrowth is not drowning you ... Everything is waiting and still. Slowly things begin to move, to slip into their places. Groups and masses and lines tie themselves together. Colours that you had not noticed come out, timidly or boldly ... Air moves between each leaf. Sunlight plays and dances. Nothing is still now. Life is sweeping through the spaces. Everything is alive. The air is alive. The silence is full of sound. The green is full of colour. Light and dark chase each other. Here is a picture, a complete thought and there another and there...

(Emily Carr, Hundreds and Thousands: The Journals of Emily Carr, 2006)

Carr's (2006) account of sketching in the woods was an analogy to the construction of my discussion chapter. She poignantly described the process of seeing and re-seeing the forest, and finding clarity to the details she wanted to capture on her canvas. What was a seemingly static view became a vibrant forest, teeming with life. Similarly, as I analyzed and sifted through support persons' rich narrative accounts of waiting for lung transplant, I was also weaving together narrative ideas, critically connecting these ideas to current literature, while trying to highlight each support person's unique voice. Throughout my study, the theoretical lens of liminality was the underpinning framework that posits how rituals play a major role in shaping and transforming society (Turner, 1969). In this chapter, I conceptualized support persons' experiences as a liminal rite of passage, by illustrating the attributes of the liminal space of waiting, and those who dwell within this space. I present discussion ideas in three main sections: interpretive discussion; study implications; and strengths and limitations.

\section{Interpretive Discussion}

In this section, I provide an interpretive discussion of the research findings in the context of both my research questions and the existing literature. My research questions were: What are 
support persons' experiences of waiting for lung transplant and how do they narrate these accounts? How does the role of being a support person appear in these accounts? I present two interpretive ideas in this discussion: a potent physical and social space; and the liminal person. These are theoretically-informed interpretive ideas that synthesize the narrative ideas from the findings chapter to answer the research questions. These interpretive ideas are closely interwoven, but I organize them in two different sections so I can clearly explicate elements related to the space and the person.

\section{A Potent Physical and Social Space}

Support persons' narrative accounts reflected a potent physical and social space. Although there were a multitude of possible outcomes surrounding the patient, the support person's narrative focused upon life or death within the liminal waiting space. Imagining these polarizing and conflicting possibilities made this a potent space where feelings of hope, uncertainty, and fear co-exist.

My research extends Turner's (1967) conceptualization of liminality as a transitory threshold in which one is "betwixt and between" (Turner, 1967, p. 97). There is an emerging body of literature depicting family caregiving as a liminal experience (Bruce et al., 2014;

Gibbons, Ross, \& Bevans, 2014; Jordan, Price, \& Prior, 2015; Sabo, 2014). Using the lens of liminality, Gibbons, Ross and Bevans conducted an integrative review and found that family caregivers were thrust into the liminal space, marked by role ambiguity, social changes, suffering, and uncertainty (Gibbons et al., 2014). My research corroborated findings from this integrative review in terms of how support persons experienced feelings of being displaced from their old world to the new liminal space of caregiving. Additionally, support persons' separation was intensified as relocation for lung transplant formed a barrier between them and their social world 
that existed beyond the physical liminal space. The physical and social separation disrupted relationships and reduced emotional support. Although Jordan et al. (2015) focused on parents of a dying child, my study echoed their findings in which family caregivers experienced a social separation through abandoning previous routines to engage in fulltime caregiving. Like Kelly (2008), who studied family caregivers' experiences in the context of HIV/AIDS, I found that support persons became focused on anticipatory grief. However, interwoven within support persons' narratives of grief was the hope for new life. Unlike family caregivers caring for a patient facing imminent death (e.g. Jordan et al., 2015; Kelly, 2008; Watson, 2011), support persons' wait for a transplant call promoted hope and anticipation alongside the patient's gradual deterioration. Although waiting was a central facet to support persons' narrative accounts in my study, through critically examining the related literature, I argue that waiting is a ubiquitous feature to the liminal experiences of family caregivers and carers. All family caregivers in the illness encounter are waiting for something, be it the patient's recovery, stabilization, death, or even the absolution of caregiving roles. While support persons dwell in a liminal space where waiting is prevalent, perhaps all family caregivers within the illness trajectory are also occupying a liminal waiting space. What my research adds to this body of literature is how waiting is a salient aspect of being a family caregiver or support person, which greatly impacts their mental and emotional health.

In the liminal space of waiting, support persons found themselves confined to the physical space of their new home, the routine between home and hospital, and their interactions with healthcare professionals. Akin to a liminal rite of passage (Gibbons et al., 2014; Turner, 1967; van Gennep, 1960), their social structures were displaced as their lives revolved around the patient's pre-transplant routines, such as physiotherapy sessions, medical appointments, and 
activities of daily living. The focus upon the patient and confinement within the liminal waiting space contributed to feelings of isolation, frustration and fatigue as they succumbed to the monotonous and constant routines of waiting. My study supports other research describing how family caregivers experienced stress, anxiety, depression and loneliness due to reducing social networks (Gibbons et al., 2014), as well as disengagement with other family members as they struggled with fatigue and uncertainty (Jordan et al., 2015). To add to this body of literature concerning the restrictive nature of the liminal space, support persons in my study were sometimes able to mitigate their confinement by maintaining social contact with family members and friends through technological advances such as social media, electronic communication and the telephone. Moreover, support persons experienced emotional benefits, albeit temporarily, when returning back to their social worlds for brief periods. Therefore, my findings suggest that connecting with their loved ones outside of the liminal space worked to assuage their emotional isolation and distress.

Support persons' accounts of waiting for transplant reflected the importance of establishing supportive networks with others who also occupied this liminal space. Turner (1969) posited that the liminal space creates a dissolution of social structure, status and hierarchies. It is suggested that social differentiations such as class, age, race and gender become irrelevant in the liminal space and give way to the "even communion of equal individuals who submit together to the general authority of the ritual elders" (Turner, 1969, p. 97). He termed this phenomenon as communitas, which refers to a common state of being (Turner, 1969). While support persons shared rich and diverse narratives, they acknowledged being part of a special community of waiting, and generally valued their collective experiences of waiting. Jordan et al. (2015) also found that the hospital space generated communitas, as family caregivers gravitated towards 
each other to offset feelings of being displaced and shared in common pains and struggles of caring for their ill child. However, support persons' accounts revealed that not everybody was integrated into these networks, which inadvertently exacerbated feelings of separation and isolation. As such, support persons emphasized the importance of formalizing relationships within the lung transplant community to ensure a sense of belonging for all who dwelt in this liminal waiting space.

\section{The Liminal Person}

The idea of the support person being conceptualized as a liminal person began to emerge as I considered their paradoxical existence within the liminal waiting space: the circumstances that necessitate their presence and involvement in the patient's care juxtaposed with their invisibility. The supportive role gained primacy as support persons shifted the patient's needs to the foreground while relegating their own needs to the background. I found resonance between my findings and Turner's description $(1967,1969)$ of Ndembu boys entering into the liminal initiation rite. He termed the boys as liminal persons or neophytes who "have no status, property, insignia, secular clothing indicating rank or role" (Turner, 1969, p. 95) as they resided in this transitional space. Likewise, the support person became an appendage of the patient and their own identity and needs were invisible to healthcare professionals. They essentially became a liminal person in that their role as a support person was vital, but their own needs became concealed. As noted in the findings, support persons' accounts reflected healthcare professionals' attention to the patient's physical symptoms and emotional state. At the same time, support persons expressed frustration and a sense of powerlessness when their own perspectives and concerns were not acknowledged, or they were placated by healthcare professionals. Parental caregivers in Jordan et al.'s study (2015) echoed a sense of helplessness as they had to rely 
heavily on healthcare professionals' expertise in patient care. Given that healthcare professionals can play a vital role in providing information and emotional support to manage feelings of uncertainty and fear, this relationship can have a significant impact on support persons' wellbeing.

As liminal persons, support persons were at risk for compassion fatigue that stemmed from their vigilant watchfulness within the waiting space. Compassion fatigue refers to the negative effects of remaining empathic and attuned to a patient's suffering for a prolonged period of time, to the point where the carer has trouble distancing themselves from the situation (Perry, Dalton, \& Edwards, 2010). The consequences of compassion fatigue are poor self-care, depleted energy and the support person's constant sacrificial stance (Lynch \& Lobo, 2012; Perry et al., 2010). Although the concept of compassion fatigue originally applied to healthcare professionals (e.g. Gleichgerrcht \& Decety, 2014; Ledoux, 2015; Zeidner, Hadar, Matthews, \& Roberts, 2013), researchers have found that family caregivers could also be prone to this phenomenon (Lynch \& Lobo, 2012; Perry et al., 2010; Ward-Griffin, St-Amant, \& Belle Brown, 2011). Similar to others (Jordan et al., 2015; Watson, 2011), I found that vigilant monitoring was an all encompassing experience that consumed support persons' attention and energy to the point that their own selfcare was secondary and sometimes, placed at risk. Support persons' engagement in the protector role impacted their relational dynamic with the patient, such that they provided unconditional emotional support to him/her, but withheld from sharing their own fears and emotions. Similar to the above caregiving literature, support persons in my study noted the emotional struggle and hopelessness of waiting for several months without a guarantee of a transplant call. Other authors also noted that the constant presence of the patient's illness contributed to hopelessness (Sabo, 2014) or "living loss" (Kelly, 2008, p. 337) for family caregivers as they watched their loved 
ones' gradual decline and eventual passing. My study supports related caregiving literature in illustrating the detrimental effects that compassion fatigue can impose upon support persons' wellbeing and mental health.

The uncertainty that pervaded in this liminal waiting space led to experiences of anticipation and hope, coupled with fear and hopelessness for support persons. These paradoxical experiences were found in another study exploring persons living with life-threatening illness, where patients described being alive yet not living, being fearful and also letting go of the fear, and being both invisible and visible due to their diagnosis (Bruce et al., 2014). In Turner's (1967) work, he suggested that liminality ends with personal transformation and re-aggregation, whereby the prepubescent boy who goes off to complete his initiation rite will be reintegrated into society as a man. In the context of caring for a patient with terminal illness or an acute debilitating condition, re-aggregation for family caregivers typically occurred with the patient's death, whereby they were released from their responsibilities (Gibbons et al., 2014; Jordan et al., 2015). However, as support persons waited for lung transplant, they were positioned with both hope and fear, whereby the unknown extended beyond the liminal space and into their future states of being. My findings suggested that meaning making was protective for support persons because it grounded them in the present to derive value and meaning in their role as a liminal person. My work complemented Sabo's (2014) study found that within the betwixt and between, the liminal space facilitated a transitional experience for spousal caregivers, in which meaning making could help support persons reframe their experiences and role, as well as acknowledge the paradoxical emotions they are facing. My research also corroborated other authors (Gibbons et al., 2014; Jordan et al., 2015), who suggested that engaging in spirituality and self-reflection to find meaning were adaptive coping mechanisms for family caregivers. 


\section{Study Implications}

\section{Implications for Theory}

My study findings indicated that support persons were liminal beings within the waiting space for lung transplant. While patients' illness narratives of waiting for lung transplant have been conceptualized as a liminal experience (Macdonald, 2006; Naef \& Bournes, 2009; Yelle et al., 2013), lung transplant support persons' experiences have not been acknowledged as such until now. A few studies have utilized the theory of liminality to frame family caregivers' experiences of managing loss and their role (Gibbons et al., 2014; Jordan et al., 2015; Kelly, 2008; Sabo, 2014; Watson, 2011), leading them to also advocate for support persons' inclusion within the liminal space. Liminality as a theoretical lens promoted a deeper understanding of support persons' vulnerable experiences of illness and can inform how healthcare professionals assess their health and facilitate their involvement in the patient's care.

Findings from my study highlighted the importance of liminality as a theoretical framework in nursing knowledge and research. While the concept of liminality is rooted in anthropology, it has theoretical applications for nursing theory and practice, and has gained momentum in health research over the past decade (e.g. Bruce et al., 2014; Thompson, 2007). However, many of these studies referred broadly about the liminal nature of patients' and caregivers' experiences, but most did not delve into the concepts of a liminal space and person. Future research should focus on expanding these concepts to better understand the spatial and relational impact of illness on support persons' or family caregivers' health. While Turner's (1967) work on initiation rites was published more than fifty years ago, further research is needed to advance the concept of the liminal space in the present healthcare context. As technological advances in communication and travel have rendered the boundaries of the liminal 
space more transient, it is important to understand how technology is harnessed within the confining liminal space and in support persons' communication with those back home. Exploring the concepts of liminal spaces and persons in the healthcare context might enable educators and researchers alike to gain a nuanced understanding of illness experiences for patients, as well as support persons or family caregivers.

\section{Implications for Practice}

Support persons' narrative accounts indicated that healthcare professionals need to address the impact of waiting on support persons, and facilitate their inclusion as care recipients. Even the use of the term "support person" appears to be reductionist as it does not clearly highlight the indispensible nature of the role, and almost renders the individual as an appendage to the patient. The transplant program at the recruitment site had produced a support person manual a few years ago, which provided a bevy of written information about the process of waiting, as well as education on caregiver stress, burnout and self-care. The manual also made reference to the availability of transplant psychiatry or social work services for support persons. However, it was still support persons' responsibility to assess their own needs and then, contact and access these services. Alongside of this, none of the study participants mentioned these manuals during interviews. Healthcare professionals should critically reflect if the "support person" label fully encompasses the work involved in this role and seek to actively include support persons' voices in decision-making and dialogue.

In recognizing the social and personal cost of dwelling in the liminal space of waiting for lung transplant, as well as compassion fatigue in engaging in this supportive role, healthcare professionals should provide dedicated psychosocial support to support persons. As noted in the interpretive discussion, finding meaning is significantly important for liminal persons such as 
support persons. Healthcare professionals have to capacity and skillset to help support persons uncover this meaning. For example, having one-on-one dialogues or counselling sessions can enable healthcare professionals to help support persons explore the meaning of waiting and caring for the patient, assess for compassion fatigue and information needs, and explore the mental and physical health impact of separation and confinement on support persons. In the context of patients undergoing dialysis, Beanlands et al. (2005) also advanced that healthcare professionals need to attend to the complexities of caregiving and continually assess family caregivers' informational needs as well as their perception of the caregiver role. The need for continued assessments is important with support persons because the wait for lung transplant can often be lengthy, and as narrative accounts in this study suggested, they experienced or were at risk for compassion fatigue. Moreover, healthcare professionals should assess support persons' social networks and help establish strategies to engage in social networks outside of the waiting space. Based on their individual concerns, healthcare professionals can develop responsive and tailored interventions that may mitigate support persons' fear, and feelings of uncertainty and isolation.

Narrative accounts in my study highlighted the need for more tailored strategies to foster inclusivity of support persons while waiting. Healthcare professionals are well positioned to develop supportive networks to facilitate relationships among incoming lung transplant patients and support persons. Based on my research, support persons indicated the need for more facilitation and interface beyond what was offered in a large support group format, which was viewed as impersonal and only elicited a minority of voices among attendees. For example, healthcare professionals could develop a buddy program, whereby interested support persons who have been waiting for a period of time are assigned to an incoming support person. This 
strategy can lead to a tri-support approach whereby the incoming support person would at a later point begin to provide support to a newer support person. These types of initiatives might mitigate the stresses of relocation for the new support person and promote information sharing and emotional support. There is a recent increase in web or electronic-based interventions targeting family caregivers and patients across a variety of settings such as oncology, renal failure, dementia care and palliative care (Badr, Carmack, \& Diefenbach, 2015; Boots, de Vugt, van Knippenberg, Kempen, \& Verhey, 2014; Eneanya et al., 2015; Zulman et al., 2012). Given support persons' confining schedules, social media or web-based applications may serve as effective tools to promote support person networks during the waiting period and communication with healthcare professionals. Moreover, support persons in the post-operative phase can continue to participate in these networks and provide informational and emotional support to those waiting even after they relocate back home. Additionally, initiatives for periods of respite could be implemented so that support persons have the opportunity for their own self-care and reconnect with family and friends back home.

\section{Implications for Education}

My study findings contributed to a broader understanding of support persons’ experiences, and extended the lens of family-centered care in the context of transplantation. It is imperative that curricula for healthcare professions directly address the pervasiveness of unpaid supportive work, the health and emotional consequences of supportive care, and the experiences of dwelling in the liminal space of illness. Integrating the theory of liminality in the curriculum may enable students to understand family caregivers' and support persons' role in monitoring and providing, and the impact of this role on their own wellbeing, social world and relationships. For example, courses concerning theory and illness should introduce concepts of confinement 
and social isolation in relation to providing supportive care, and develop students' competencies in conducting support person or family caregiver interviews to assess for compassion fatigue and distress. Also, an experiential approach to teaching-learning through the sharing of stories may permit students to better understand compassion fatigue and stress in the classroom setting. Clinical instructors and preceptors in practicum settings could provide opportunities for students to conduct family caregiver or support person assessments, or encourage students to attend interdisciplinary family meetings to enhance their understanding of supportive care. Leaders in education should promote the lens of relational inquiry that expands students' gaze beyond that of the patient, and includes family caregivers or support persons as members of the care team (Hartrick Doane \& Varcoe, 2015).

\section{Implications for Policy}

Policies related to employment protection and financial support for support persons should be enhanced. In Canada, it has been reported that three in ten individuals provide caregiving support to family members (Turcotte, 2013) and family caregivers contribute to \$25 billion of unpaid care annually (Hollander, Liu, \& Chappell, 2009). Due to the nature of relocation, support persons were usually the only individuals caring for the patient, and often had to adapt to living in a different city for a significant and indeterminate amount of time. As the patient gradually deteriorated, support persons' responsibilities continued to grow until their supportive work became a full-time endeavor. In my study, one participant applied for a leave of absence from work, while another modified his/her employment contract, which placed them in a vulnerable position financially. As such, employers should strengthen workplace policies that provide options for extended leaves of absence to ensure the job security of individuals who are family caregivers or support persons. In Canada, there are currently no policies providing 
financial support to unpaid caregivers, with the exception of a compassionate grant that is only available if the patient is projected to die within six weeks (Keefe \& Rajnovich, 2007; White \& Keefe, 2005). Policy researchers have advocated for non-taxable caregiver allowances as a means to acknowledge and initiate critical dialogue on unpaid caregiving work in Canada (Keefe \& Rajnovich, 2007; White \& Keefe, 2005). These policies can raise awareness and visibility of support persons' and family caregivers' contributions to patient care. Additionally, my findings highlighted the importance of support persons maintaining relationships outside the liminal waiting space. Legislators should also create policies to provide respite for support persons so they can reconnect with their loved ones.

\section{Implications for Research}

Study findings suggested that future research focusing on supportive interventions for support persons during the waiting period is needed. Specifically, research evaluating the effect of supportive interventions on psychosocial and physical health measures such as QOL, mood, stress, and perceived coping should be implemented. There have been studies examining the use of communication and supportive interventions for caregivers of oncology patients (Bowman, Rose, Radziewicz, O’Toole, \& Berila, 2009; Klodnicka Kouri, Ducharme, \& Giroux, 2011; Pailler et al., 2015), patients with Alzheimer's Disease (Klodnicka Kouri et al., 2011; Mittelman, Roth, Coon, \& Haley, 2004), and heart failure patients (Etemadifar, Bahrami, Shahriari, \& Khosravi Farsani, 2014). These interventions included telephone support programs (Bowman et al., 2009), individual sessions (Klodnicka Kouri et al., 2011) and therapy support group sessions (Etemadifar et al., 2014; Mittelman et al., 2004; Pailler et al., 2015). The results of these studies demonstrated moderate to significant gains specifically related to caregivers' QOL and mood. It would be worthwhile to examine whether these findings translate to support persons in the 
context of lung transplant given that the populations targeted in the above mentioned studies might not experience intensive physical separation and confinement while waiting. A few studies documented joint supportive interventions for both patients and family caregivers to facilitate shared decision-making in end-stage renal disease (Eneanya et al., 2015) and increase communication in the oncology setting (Badr, Carmack, \& Diefenbach, 2015). Such measures could benefit support persons, as the patient suffering from end-stage lung disease relies heavily on them to facilitate communication with the healthcare team and advocate on his/her behalf. The prolific increase in interventions targeting these caregiver populations stems from the fact that the illness trajectory for diagnoses such as Alzheimer's disease and cancer may last several years. While the waiting time for lung transplant is multifactorial, the average wait time is often several months, and it can be over two years in some outlier cases. As such, these supportive and communicative interventions need to be examined in the lung transplant population. In considering that support persons often felt unsupported by the healthcare team while they were confined within the waiting routines, it would be worthwhile to explore healthcare professionals' perceptions about how support persons are supported and not supported. This research can assist to identify any discrepancies between healthcare professionals' and support persons' perceptions of support, which ultimately could be addressed through clinical training and allocation of necessary resources for this indispensible population.

Future research about support persons' relationships in the context of waiting is warranted. Support persons' narratives of waiting reflected that their wellbeing was closely tied with that of the patient, forming a coalescence within the liminal space of waiting. One area of research that has not been undertaken is a dyadic approach, whereby both the support person and patient's viewpoints are elicited. It would be helpful to explore and compare how a patient and 
his/her primary support person articulate their experiences of waiting for lung transplant. This may yield more insight into the impact of relational dynamics on both the patient's and support person's wellbeing during this waiting period. Understanding the interplay of patient and support person wellbeing within the liminal waiting space may provide additional insight into strategies that would benefit support persons and in turn, patients. Also, further study should be devoted to understanding support persons' health while dwelling in the liminal space and after they leave this potent space. Moreover, this study identified the social disruptions that occurred as support persons and patients entered into the liminal space of waiting. For example, the impact of this disruption extended beyond the support person and patient, resulting in other family members being left behind during the relocation. In this study, children and spouses became separated from the support person and patient. Exploratory research should elicit the views of those left behind and dwelling outside the immediate liminal space of waiting to understand the impact of the spatial and relational separation from their perspective.

\section{Strengths and Limitations}

Based on Lieblich et al.'s (1998) criteria of rigour, coherence, width, insightfulness and parsimony were achieved in a number of ways in this study. First, multiple points of data collection served to solidify width and coherence. Facilitating two interviews with participant journaling in between allowed me to construct rich and thick descriptions of support persons' experiences of waiting. The second interview in particular enabled me to revisit narrative ideas that participants raised in their first interview and journal entries, which elicited deeper dialogue into their experiences. The width and coherence was demonstrated by rich and numerous participant quotes that reflected my findings. Second, my interview field notes coupled with my analytic and reflexive fieldnotes clarified my positionality as a researcher and expounded my 
interpretive decisions to enhance the width of this study. Third, the lens of liminality was an underpinning framework that directed my analysis in exploring what was occurring within the liminal space of waiting, which served to further the coherence of narrative ideas. Fourth, my preliminary findings and narrative ideas were discussed with my thesis supervisor and committee members; this process was an important step to crystallize and refine some narrative ideas. Within the thesis meetings, dialogue on each narrative idea led to group consensus or raised issues which required me to clarify my thought process in formulating the idea or rethink the organization. I also presented my preliminary findings at a number of qualitative research conferences. Attendees' acknowledgement of the waiting period for lung transplant as a liminal space helped me affirm my analytic decisions and their questions regarding the support person role helped refine my discussion points. Dialogical engagement with thesis committee members as well as the broader academic community helped to promote the insightfulness and coherence of my findings. Last, throughout my writing process, I strove to retain each support person's narrative voice. While my findings were a composite of narrative ideas, I continued to weave each participant's individual voice within these ideas, which contributed to study parsimony.

It is important to note that the goal of narrative research is to elicit an in-depth understanding of a phenomenon of interest as opposed to focusing on breadth of data. Support persons' narratives provided highly contextualized accounts into their experiences, such that findings may be transferrable to other support person contexts. Furthermore, as part of this narrative research, I collected ample data using multiple methods and data collection points. As such, the sample size was limited in order to conduct an in-depth and contextualized exploration of the study phenomenon. While multiple data collection methods enhanced the richness of findings, it might have been burdensome to support persons who are already inundated with their 
roles and responsibilities. Although four support persons participated in the study, there were also three eligible individuals who declined to take part in the study due to the amount of stress they were facing. The commitment required for study participation may have been a detractor to those who were already encountering a large amount of distress. 


\section{EPILOGUE}


It was a long day. I ended my nursing shift late, staying almost an extra hour to finish up my documentation. I was weary and tired, my back a little sore. My husband was kind to pick me up for burgers so instead of taking my usual route home I headed deeper into the heart of the city, neon business lights flashing everywhere. It was to my surprise that on this impromptu detour, I bumped into someone I did not expect to see. We recognized each other the minute we locked eyes.

\section{Oh hey!}

Hi! I can't believe I'm bumping into you here!

\section{Me too! Do you remember me?}

How could I not? Standing in front of me was the daughter of a patient whom I cared for over the course of several months. This patient, whom I will refer to as Marie, was a double lung transplant patient who suffered significant post-operative complications. She spent the better part of a year recovering in hospital, having lost her voice, her ability to swallow as well her muscle strength. She also contracted an infection that required her to remain in an isolated room. As nurses, we had to remember that she was bed bound and voiceless when she used the call bell. As such, we had to go to her room directly because she was not able to communicate her requests and she was easily anxious about her oxygen levels. But what was most memorable about Marie was the amount of family support she received. Her husband and three daughters provided around the clock assistance and company. Marie was quite self-conscious, so her family members often assisted the nursing staff with care activities, such as turning, bathing, and changing her undergarments. As she became stronger, they would take over these activities and provide the care themselves. This daughter was the most involved of all her sisters, but second only to her father. 
Marie's husband, who I will call James, was truly her primary support person. He was by her bedside day in, day out, rain or shine. He coached her through her anxiety when she was short of breath. He encouraged her to sit longer in the chair or take another walk in the day when Marie did not feel like it. He kept her company. He made her smile. Slowly, Marie became stronger. She began to get out of bed with minimal assistance. Her infection subsided and she was able to share a room with another patient. She was able to rest without oxygen. James only had to walk along side her when they left the room. She was able to laugh out loud. Going home was on the horizon. Marie's swallowing would remain an issue, but James was dedicated to administering her tube feedings through her stomach. In the last week of her stay, James bought one of those three foot tall cards and made every healthcare staff sign it, because they wanted to remember each of us. I wrote Keep your eyes on the prize and fight the good fight! I was so happy for them and for their new lease on life.

Roughly a year later, Marie was admitted with pneumonia, and would remain in the hospital for several months again. Pneumonia turned into organ rejection, and she was losing weight fast. She traversed between the intensive care unit and the surgical wards, and her strength was slowly depleting. The dietician increased her tube feedings, which made her blood sugars difficult to manage. James ended up renting a dormitory room from a local University so he could walk to the hospital each day. It turned out he owned a business, so he delegated the daily operations to a nephew. He had become an expert in troubleshooting Marie's stomach tube if it was blocked so he preferred to administer her g-tube medications himself. He helped her transfer to the commode. He would read the newspaper or do puzzles while watching over her sleep. He continued to encourage her to sit up longer or take an extra walk, but this time, he was met with refusals. Treatments were not working and Marie's lung function continued to decrease. 
Her anxiety was also increasing, to the point that on certain days, she would kick everyone out of her room. You are taking all of my air. Helpless, James would stand outside and watch her hyperventilate. As her healthcare team, we tried numerous strategies and psychotherapies to help decrease her anxiety, all to no avail. Marie felt like she was drowning and continued to hyperventilate. On one such occasion, I patted James on his shoulder and asked him directly how he was doing. He shrugged and I told him This must be very hard on you. He gave me a sad smile. She's worth every little bit of it.

Marie never left the hospital. As her lung function worsened, she developed respiratory acidosis due to hyperventilation. After many long months of struggle, she passed away in the intensive care unit.

A few months later, standing on the busy city street with Marie's daughter brought back all these memories. How are you doing? We're doing better. It's hard, but it's getting better. We both agreed that her mother's passing was a relief to her physical suffering. How is your father doing? He sold his business and moved down to [his vacation home]. He's [pause] not doing well [pause] but time will pass. We hugged each other and she left. As people passed by me on the bustling street, under the neon lights, I wept.

My story of Marie and James is not representative of the recovery trajectory for lung transplant; it is just one story of many. Of course, given that I work on a transplant surgical ward, I know that I always see people at their worst. There are many more outside the hospital who are living and thriving with their new lungs. Yet, my recollection of Marie and James and their daughters led me to question about the liminal space of waiting. For James whose wife experienced so many complications, I felt as though he had never left the liminal space or his support person role. And when he did leave the liminal waiting space, his life was forever 
changed. While James and his daughters may now have a new lease on life, this new state of being is accompanied by the tremendous loss of a wonderful wife and mother.

Becoming a family caregiver is life-transforming. Although time continues, caregiving may leave you rooted in the past. Since I started my thesis, my mother in law has been in remission for two years but we still get a little nervous when she has to complete her bi-annual blood tests and oncology appointments. My grandfather passed away while I was writing my final thesis chapters. And in my grief, I remain stunned in guilt over what I could have done to advocate for him in the last throes of his suffering. The experience of re-aggregation is different for everyone. For my grandmother and uncle, within their grief was relief from the physical burdens of caregiving. For myself, while I am no longer physically bound to the family caregiver role, I am emotionally having a difficult time leaving this liminal space where my grandfather once occupied. Caregiving left me winded, exhausted, depleted. Even now, as I write these words, I am overcome with a heavy sadness. The world outside of illness can seem very far away and inconsequential. Or, perhaps in my grief, I do not want to leave this liminal space. I do not know for sure.

Support persons' rich and powerful stories of waiting for lung transplant have redefined for me the nature of patient care. In fact, the term "patient" is a misnomer as I am a firm believer that as a nurse, I am ethically bound to care for all who share in and are impacted by the patient's illness: the spouse who sleeps only four hours a night and spends the next 18 hours in the patient's room; the sibling who does not see his parents because they are always at the hospital; the best friend who accompanies the patient to chemotherapy sessions. I understand that some may thrive in their caregiving work, while some may flounder. My hope is that others may 
acknowledge and honour these experiences so that family caregivers find purpose and joy in this liminal space. 


\section{Study Title:}

Exploring support persons' narrative accounts of waiting for lung transplant

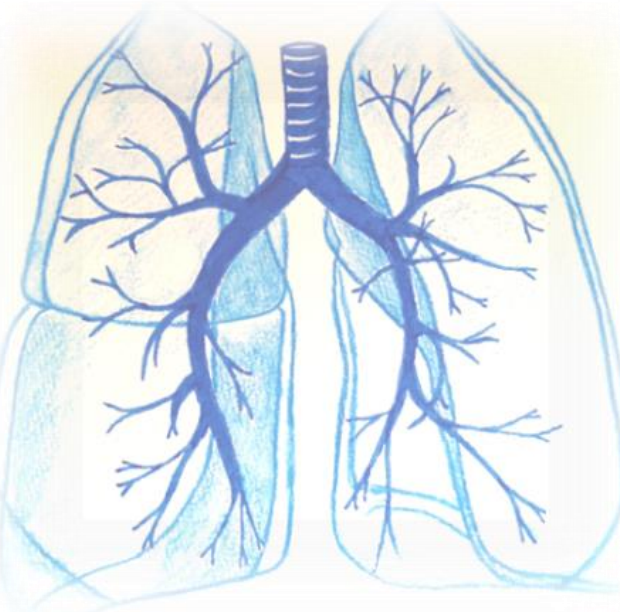

Illustration credit: S. Hume, 2014

\section{Are you a support person for a lung transplant candidate who is on the waiting list?}

\section{Would you like to share your experiences of waiting in two research interviews?}

Study Purpose: We are interested in understanding support persons' experiences of waiting for lung transplant.

To participate in the study or for more information, please contact:

Email: Linda.y.liu@ryerson.ca

Phone:

Principal Investigator: Linda Liu, RN, MN student, Ryerson University

Thesis Supervisor: Dr. Jennifer Lapum, RN, PhD, Associate Professor, Ryerson University

Email is not a secure form of communication.

Please do not include any sensitive information in email messages 


\section{RYERSON UNIVERSITY}

CONSENT FORM TO PARTICIPATE IN A RESEARCH STUDY

Study Title:

Investigator:
"Exploring support persons' narrative accounts of waiting for lung transplant"

Study Supervisor: $\quad$ Dr. Jennifer Lapum, PhD, RN

Contact Information: Tel:

Email: linda.y.liu@ryerson.ca

\section{Introduction}

You are being asked to take part in a research study. Please read the information about the study presented in this form. The form includes details on study's risks and benefits that you should know before you decide if you would like to take part. You should take as much time as you need to make your decision. You should ask the study staff to explain anything that you do not understand and make sure that all of your questions have been answered before signing this consent form. Before you make your decision, feel free to talk about this study with anyone you wish including your friends, family, and family doctor. Participation in this study is voluntary.

\section{Background/Purpose:}

You are being asked to consider participating in this study because you are the support person caring for a patient on the lung transplant waiting list. Existing research has indicated that lung transplant support persons find the waiting period to be challenging. We want to better understand your experience of the waiting experience through the use of interviews and journals. The purpose of this study is to understand the experiences of waiting for lung transplant from the perspective of support persons.

\section{Study Visits and Procedures:}

The expected duration for your involvement in this study is approximately three weeks. Should you wish to be involved in this study, your activities will involve participating in two interviews, one at the start and one at the end of the study; and journaling about your experiences of waiting that will take place between the two interviews. The interviews will be conducted in a private location of your preference such as Ryerson 
University or at Each interview will last approximately 45-90 minutes. You may request to stop the interview at any time.

You will be provided a notebook and a guide sheet to journal about your experience of waiting for lung transplant for approximately two weeks. Journal entries can be completed at your own time and leisure. Although you are given notebooks, you can also use any format to journal (e.g. typing journal entries into a word document, voice recording journal entries in your phone, etc.). At the end of this period, the investigator will meet with you to collect any journal entries you have. If you have any electronic journal entries, the investigator will transfer them to an encrypted USB flash drive.

In addition, the investigator will also be documenting fieldnotes throughout interviews to journal their experiences and observations of the meeting. These fieldnotes will serve to enhance the investigator's recall and analysis of your narrative accounts. We will also be collecting some background information from you such as your age, gender, education level, employment status, and the relationship to the patient you are caring for.

\section{Outline of study procedure}

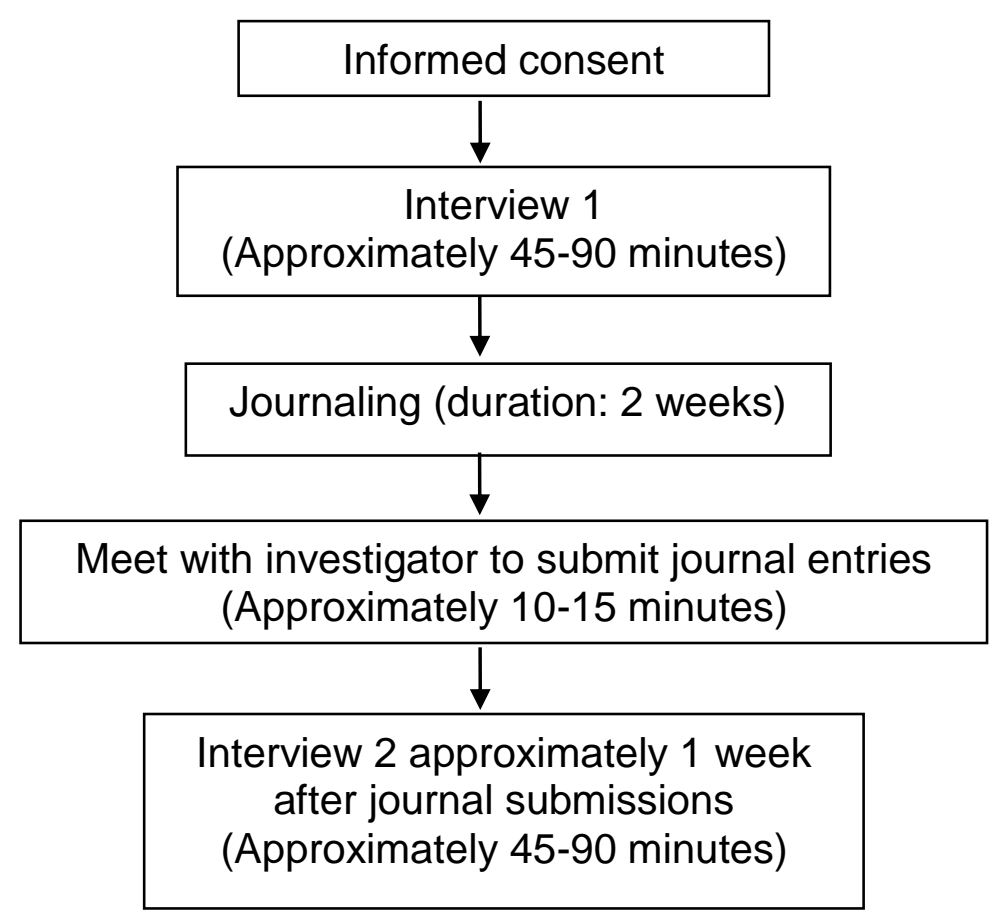

\section{Risks:}

Taking part in this study may have some risks for you. Some of these risks we know about. There is also a possibility of risks that we do not know about and have not been seen in humans to date. Please call the study staff if you have any side effects even if you do not think it has anything to do with this study. 
The potential risks may be as follows but are not exhaustive:

- $\quad$ Physical and/or emotional discomfort

- $\quad$ Feeling upset or anxious over recalling unpleasant memories

- Fatigue

You may refuse to answer questions or stop journaling at any time if you experience any discomfort. You may withdraw from the study at any time point, and your participation is completely voluntary.

You will be told about any new information that might reasonably affect your willingness to continue to participate in this study as soon as the information becomes available to the study staff. This may include new information about the risks and benefits of being a participant in this study.

\section{Benefits:}

You may or may not benefit directly from participating in this study. However, possible benefits may include an enjoyment of sharing and talking about your experience with the study staff. Additionally, sharing and reflecting on your experience waiting during the interview or in your journaling may or may not positively influence your views on waiting for lung transplant. Your participation may help other people in the future in terms understanding support persons' experiences of waiting and contribute to a wider body of health research for lung transplantation.

We cannot guarantee, however, that you will receive any benefits from participating in this study.

\section{Alternatives to Being in the Study:}

You may wish to exit the study at any time point of your involvement. Also, should you require to take a break from journaling, you may do so at your discretion.

\section{Confidentiality:}

You have the right to have any information about you that is collected, used or disclosed for this study to be handled in a confidential manner. If you decide to participate in this study, the investigator will look at your personal information and collect only the information they need for this study. Personal information will only be collected from you. This information could identify you because it includes data such as your:

- name, address, telephone number,

You have the right to access, review and request changes to your personal information. The following people may come to the hospital to look at your personal information to check that the information collected for the study is correct and to make sure the study followed the required laws and guidelines:

- Representatives of the they oversee the ethical conduct of research studies at

Ethics Board, because

- Representatives of the Ryerson University Ethics Board 
Access to your personal information will take place under the supervision of the Principal Investigator. Please note that none of the investigators are affiliated with the Pre-Transplant Program. Any transplant coordinators involved in your care will not be informed of your participation or withdrawal from this study.

"Study data" is information about you that is collected for the study, but that does not directly identify you. Any study data about you, such as interview notes and journal entries will be re-coded so that it will not contain your name or address, or any information that directly identifies you. Study data that is sent outside of the hospital will be used for the research purposes explained in this consent form. The data will be used to disseminate the research findings and may be included in various mediums such as articles, reports and conference presentations. Aspects of your data and/or particular quotes from your interviews may be used, but at no point will your name be used or any identifying information.

Additionally, you may disclose information that may identify people or facilities. To minimize such risk, the interviewer will encourage you to refrain from using proper names. All names and identifiers will be deleted during the transcription process. Transcription is taking the words and dialogue on the audio tape and writing or typing it word for word.

The investigators above will keep the information they see or receive about you confidential, to the extent permitted by applicable laws. Even though the risk of identifying you from the study data is very small, it can never be completely eliminated. All electronic study data will be stored on a password protected USB flash drive. The Principal Investigator will keep any personal information about you as well as any study data in a locked cabinet site for 10 years and then destroy it according to $\square$ and Ryerson University policy. You have the right to be informed of the results of this study once the entire study is complete. If you would like to be informed of the results of this study, please provide your name, email address and telephone number to Linda Liu.

\section{Voluntary Participation:}

Your participation in this study is voluntary. You may decide not to be in this study, or to be in the study now and then change your mind later. You may leave the study at any time. You may also choose not to answer any question(s) and still remain in the study.

We will give you new information that is learned during the study that might affect your decision to stay in the study.

\section{Withdrawal from the Study:}

If you choose to withdraw from this study you may also choose to withdraw your data from the study. Your choice whether or not to participate will not influence your future relations with Ryerson University or 
If the patient you are caring for undergoes transplant surgery before the conclusion of your participation in this study, your involvement will be automatically terminated.

However, all data collected prior to this time point will still be included in the research study. If you wish to withdraw your data after the patient undergoes his/her transplant surgery, please contact the study investigator.

\section{Costs and Reimbursement:}

You will not be paid to participate in this study. If you decide to participate in this study, you will be offered small reimbursements ( $\$ 10$ at Interview $1, \$ 5$ at meeting for journal collections, $\$ 10$ at Interview 2 ) to offset any travel/parking costs.

\section{Rights as a Participant:}

By signing this form you do not give up any of your legal rights against the investigators, sponsor or involved institutions for compensation, nor does this form relieve the investigators, sponsor or involved institutions of their legal and professional responsibilities.

\section{Conflict of Interest:}

There is no conflict of interest between the study staff and affiliated organizations (i.e. , Ryerson University).

\section{Questions about the Study:}

If you have any questions about the research now, please ask. If you have any questions, concerns or would like to speak to the study team for any reason, please contact:

Linda Liu

Email: Linda.y.liu@ryerson.ca

Phone:

Dr. Jennifer Lapum (study supervisor)

Email: Jlapum@ryerson.ca

Phone:

This study has been reviewed by the Ryerson University and Research Ethics Boards. If you have any questions about your rights as a research participant or have concerns about this study, call the Chair of the

Research Ethics Board ( REB) or the Research Ethics office number at . You may also contact Toni Fletcher, Research Ethics Coordinator, Ryerson University at 416-979-5042 or email her at toni.fletcher@ryerson.ca The REB is a group of people who oversee the ethical conduct of research studies. The and Ryerson REB is not part of the study team. Everything that you discuss will be kept confidential.

You will be given a signed copy of this consent form. 


\section{Consent:}

This study has been explained to me and any questions I had have been answered. I know that I may leave the study at any time. I agree to the use of my information as described in this form. I agree to take part in this study.

Print Study Participant's Name

Signature

Date

My signature means that I have explained the study to the participant named above. I have answered all questions.

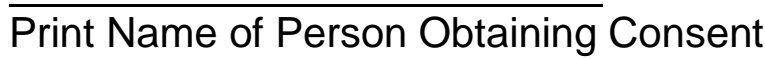

Signature

Date

Was the participant assisted during the consent process? $\square$ YES $\square$ NO If YES, please check the relevant box and complete the signature space below:

$\square$ The person signing below acted as an interpreter for the participant during the consent process and attests that the study as set out in this form was accurately interpreted has had any questions answered.

Print Name of Interpreter

$\overline{\text { Signature }} \overline{\text { Date }}$

Relationship to Participant

Language

$\square$ The consent form was read to the participant. The person signing below attests that the study as set out in this form was accurately explained to, and has had any questions answered.

Print Name of Witness

Signature

Date

Relationship to Participant 
Participant Number:

AGE:

SEX: Female
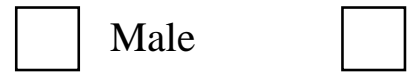

Other

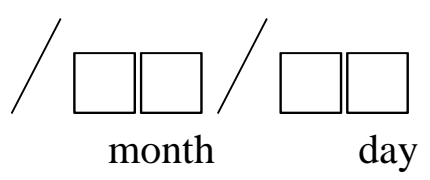

month
Date:

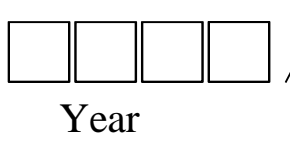

Year

Please indicate your marital status:

Single

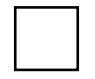

Divorced

Married/Co-habiting

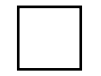

Widowed

Other (please indicate):

Please indicate your highest education level completed:

Less than Gr. 12

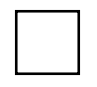

University/College Degree

High School Diploma

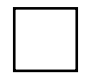

Graduate Degree

Other (Please indicate):

Please indicate your employment status prior to wait-listing:

Full-time

Part-time

Student

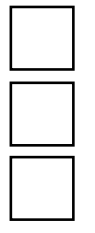

Unemployed

Retired

Other (please elaborate):
Stay-at-home caregiver:

Contract/Casual

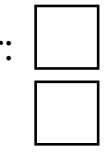

Please indicate your current employment status:

Full-time

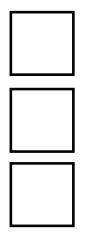

Unemployed

Stay-at-home caregiver:

Part-time

Retired

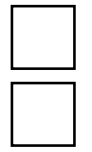

Contract/Casual

Student

Other (please elaborate):

How are you related to the person listed for lung transplant? 
APPENDIX D: RECRUITMENT AND DATA COLLECTION PROCEDURE

\section{Obtain Research Ethics Board Approval from:}

- REB

- Ryerson University REB

\section{RECRUITMENT:}

- Via recruitment posters around physiotherapy centre and transplant floor elevators

- Physiotherapists to introduce study to support persons

- Interested support persons contact study author or pass their contact to Physiotherapist

- Participants are screened via inclusion/exclusion criteria

- Explain study and consent form

- Obtain informed consent; or individuals leave and think about their decision to participate

\section{Interview 1}

(May take place at same time after informed consent obtained)

- Collect Demographic data

- Conduct Interview 1

- Give notebooks and clarify instructions for journalling

- Arrange for subsequent meeting time and place

\section{Collect Journal Entries}

- Approximately 2 weeks after Interview 1

- Arrange for subsequent meeting time and place

- Concurrent data analysis

\section{Interview 2}

- Apprxomiately 3 weeks after Interview 1

- Conduct Interview 2 


\section{APPENDIX E: INTERVIEW GUIDE I}

\section{Introduction}

Today I am interested in hearing about your experience of waiting for lung transplant. Do you have any questions before we begin?

\section{Opening question}

Tell me about your experience of waiting for lung transplant?

(Probes: What is the experience like? How does it make you feel? Who is involved? How would you describe it to others? Did it involve relocation? Tell me about that.)

\section{Additional questions}

Can you describe how a day of waiting is? (Probe: What are your daily activities? How do you feel about waiting?)

Tell me about your role as a support person? (Probe: What is it like? How do you feel as a support person?)

In what ways have you been supported or not supported during this time? (Probes: By who? How did it help/not help? Can you give an example?)

If you had the opportunity to tell healthcare providers what you needed as a support person during this time, what would you say? (e.g., How could you be better supported?)

Note:

- The interviewer will use communication techniques in order to elicit elaboration of the participant's experience

- paraphrasing (e.g., when you said this, what did you mean?)

- facilitation (tell me more...)

- The interviewer will probe further if the participant mentions a specific physical, emotional or cognitive response

- You mentioned ... can you tell me more about this? (Probe: At what point during did you start feeling this? What made you feel this way?)

\section{Closing}

Before we close, is there anything else you would like to tell me about your experience of waiting for lung transplant?

Do you have any questions before we finish?

Thank-you for your participation 


\section{APPENDIX F: JOURNALING GUIDE}

[This guide will be inserted in a notebook given to all participants following Interview 1 . The interviewer will provide a brief introduction to the guide and notebook.]

Although you are given a notebook, you may choose to journal in any format you prefer. Some suggestions include:

- Writing your journal entries in this notebook

- Typing your journal entries in a word document

- Voice record your journal entries on your Smartphone

\section{Instructions for journaling}

- Include the date and time of your journal entry

- Try to journal every day, even if it is just one word about how you are feeling. There is no limit on the frequency of your journal entries. However, you may stop journaling at your discretion.

- You may write in point form. You may reflect or tell a story. You may sketch or doodle

- Consider the following guiding questions in your journal entries:

- How is your day of waiting for lung transplant?

- Any interesting events?

- What are you feelings towards waiting for lung transplant?

- How do you feel about your role as a support person?

\section{Questions or Concerns}

If you have any questions or concerns about what to journal or how to journal, please feel free to contact me

Linda Liu

Email linda.y.liu@ryerson.ca

Phone 


\section{References}

Badr, H., Carmack, C. L., \& Diefenbach, M. A. (2015). Psychosocial interventions for patients and caregivers in the age of new communication technologies: Opportunities and challenges in cancer care. Journal of Health Communication, 20(3), 1-15. http://doi.org/10.1080/10810730.2014.965369

Barbour, K. A., Blumenthal, J. A., \& Palmer, S. M. (2006). Psychosocial issues in the assessment and management of patients undergoing lung transplantation. Chest, 129(May), 1367-1374. http://doi.org/10.1378/chest.129.5.1367

Beanlands, H., Horsburgh, M. E., Fox, S., Howe, A., Locking-Cusolito, H., Pare, K., \& Thrasher, C. (2005). Caregiving by family and friends of adults receiving dialysis. Nephrology Nursing Journal, 32(6), 621-631. Retrieved from https://www.annanurse.org/resources/products/nephrology-nursing-journal

Belkin, R. A., Henig, N. R., Singer, L. G., Chaparro, C., Rubenstein, R. C., Xie, S. X., ... Bunin, G. R. (2006). Risk factors for death of patients with cystic fibrosis awaiting lung transplantation. American Journal of Respiratory and Critical Care Medicine, 173(9), 659-666. http://doi.org/10.1164/rccm.200410-13690C

Blows, E., Bird, L., Seymour, J., \& Cox, K. (2012). Liminality as a framework for understanding the experience of cancer survivorship: A literature review. Journal of Advanced Nursing, 68(10), 2155-2164. http://doi.org/10.1111/j.1365-2648.2012.05995.x

Boots, L. M., de Vugt, M. E., van Knippenberg, R. J., Kempen, G. I., \& Verhey, F. R. (2014). A systematic review of internet-based supportive interventions for caregivers of patients with dementia. International Journal of Geriatric Psychiatry, 29(4), 331-344. http://doi.org/10.1002/gps.4016 
Bowman, K. F., Rose, J. H., Radziewicz, R. M., O’Toole, E. E., \& Berila, R. A. (2009). Family caregiver engagement in a coping and communication support intervention tailored to advanced cancer patients and families. Cancer Nursing, 32(1), 73-81. http://doi.org/10.1097/01.NCC.0000343367.98623.83

Bruce, A., Sheilds, L., Molzahn, A., Beuthin, R., Schick-Makaroff, K., \& Shermak, S. (2014). Stories of liminality. Journal of Holistic Nursing, 32(1), 35-43. http://doi.org/10.1177/0898010113498823

Canadian Institute for Health Information. (2014). Canadian organ replacement register annual report: Treatment of end-stage organ failure in Canada, 2004 to 2013. Retrieved from https://secure.cihi.ca/free_products/2015_CORR_AnnualReport_ENweb.pdf

Canadian Institutes of Health Research, Natural Sciences and Engineering Research Council of Canada, and Social Sciences and Humanities Research Council of Canada. (2010). TriCouncil policy statement: Ethical conduct for research involving humans. Retrieved from http://www.pre.ethics.gc.ca/pdf/eng/tcps2/TCPS_2_FINAL_Web.pdf

Carr, E. (2006). Hundreds and thousands: The journals of Emily Carr. Vancouver: Douglas \& McIntyre Ltd.

Carter, C. (2013). Urban First Nations men: Narratives of identity striving to live a balanced life. (Master's thesis). Retrieved from Ryerson Library Digital Repository (Paper 2027)

Claar, R. L., Parekh, P. I., Palmer, S. M., LaCaille, R. A., Davis, R. D., Rowe, S. K., ... Blumenthal, J. a. (2005). Emotional distress and quality of life in caregivers of patients awaiting lung transplant. Journal of Psychosomatic Research, 59(1), 1-6. http://doi.org/10.1016/j.jpsychores.2005.03.007

Clandinin, D. J., \& Connelly, F. M. (2000). Narrative inquiry: Experience and story in 
qualitative research. San Francisco: Jossey-Bass.

Clukey, L. (2007). "Just be there”: Hospice caregivers' anticipatory mourning experience. Journal of Hospice and Palliative Care, 9(3), 150-158. http://doi.org/10.1097/01.NJH.0000269992.13625.00

Creswell, J. W. (2013). Qualitative Inquiry And Research Design: (3rd. ed.). London: Sage Publications.

Cystic Fibrosis Canada. (2011). Cystic fibrosis and lung transplantation. Retrieved from http://www.cysticfibrosis.ca/wp-content/uploads/2013/10/cflungtransplantationE.pdf

Dearnley, C. (2005). A reflection on the use of semi-structured interviews. Nurse Researcher, 13(1), 19-28. http://doi.org/10.7748/nr2005.07.13.1.19.c5997

Dellon, E. P., Shores, M. D., Nelson, K. I., Wolfe, J., Noah, T. L., \& Hanson, L. C. (2009). Caregivers' perspectives on decision making about lung transplantation in cystic fibrosis. Progress in Transplantation, 19(4), 318-325. http://doi.org/10.7182/prtr.19.4.81151027368g8347

Duggleby, W., Williams, A., Holtslander, L., Cunningham, S., \& Wright, K. (2011). The chaos of caregiving and hope. Qualitative Social Work, 11(5), 459-469. http://doi.org/10.1177/1473325011404622

Eliot, T. S. (1940). East Coker, Four Quartets.

Eneanya, N. D., Goff, S. L., Martinez, T., Gutierrez, N., Klingensmith, J., Griffith, J. L., ... Cohen, L. M. (2015). Shared decision-making in end-stage renal disease: A protocol for a multi-center study of a communication intervention to improve end-of-life care for dialysis patients. BMC Palliative Care, 14(1), 30. http://doi.org/10.1186/s12904-015$0027-\mathrm{x}$ 
Etemadifar, S., Bahrami, M., Shahriari, M., \& Khosravi Farsani, A. (2014). The effectiveness of a supportive educative group intervention on family caregiver burden of patients with heart failure. Iranian Journal of Nursing \& Midwifery Research, 19(3), 217-223.

Evon, D. M., Burker, E. J., Galanko, J. A., Dedert, E., \& Egan, T. M. (2010). Depressive symptoms and mortality in lung transplant. Clinical Transplantation, 24, E201-206. http://doi.org/10.1111/j.1399-0012.2010.01236.x

Fogarty, C., \& Cronin, P. (2008). Waiting for healthcare: A concept analysis. Journal of Advanced Nursing, 61(4), 463-471. http://doi.org/10.1111/j.1365-2648.2007.04507.x

Freeman, M. (2007). Narrative and relation: The place of the other in the story of the self. In D. P. R. Josselson, A.Lieblich, D.P. McAdams (Ed.), The meaning of others: Narrative studies of relationships (pp. 11-19). Washington, D.C.: American Psychological Association.

Gibbons, S. W., Ross, A., \& Bevans, M. (2014). Liminality as a conceptual frame for understanding the family caregiving rite of passage: An integrative review. Research in Nursing \& Health. http://doi.org/10.1002/nur.21622

Gleichgerrcht, E., \& Decety, J. (2014). The relationship between different facets of empathy, pain perception and compassion fatigue among physicians. Frontiers in Behavioral Neuroscience, 8, 1-9. http://doi.org/10.3389/fnbeh.2014.00243

Goetzinger, A. M., Blumenthal, J. A., O’Hayer, C. V., Babyak, M. A., Hoffman, B. M., Ong, L., ... Palmer, S. M. (2012). Stress and coping in caregivers of patients awaiting solid organ transplantation. Clinical, 26, 97-104. http://doi.org/10.1111/j.13990012.2011.01431.x

Granek, L., \& Fergus, K. (2012). Resistance, agency, and liminality in women's accounts of symptom appraisal and help-seeking upon discovery of a breast irregularity. Social 
Science \& Medicine, 75(10), 1753-1761. http://doi.org/10.1016/j.socscimed.2012.07.016

Guba, E. G., \& Lincoln, Y. S. (1994). Competing Paradigms in Qualitative Research. In N. K. Denzin \& Y. S. Lincoln (Eds.), Handbook of qualitative research (pp. pp. 105-117). Thousand Oaks: Sage Publications.

Hartrick Doane, G., \& Varcoe, C. (2015). How to nurse: Relational inquiry with individuals and families in changing health and health care contexts. Philadelphia: Lippincott, Williams \& Wilkins.

Hollander, M. J., Liu, G., \& Chappell, N. L. (2009). Who cares and how much? Healthcare Quarterly, 12(2), 42-49. http://doi.org/10.12927/hcq.2009.20660

Holloway, I., \& Freshwater, D. (2007). Narrative research in nursing. Oxford: Blackwell Publishing Ltd.

Hoppes, S. (2005). Meanings and purposes of caring for a family member: An autoethnography. American Journal of Occupational Therapy, 59(3), 262-272.

Hulme, K. (1984). The bone people. New Zealand: Spiral Press.

Irvin, S. K. (2001). Waiting: Concept Analysis.

Ivarsson, B. (2012). Heart or lung transplanted patients ' retrospective views on information and support while waiting for transplantation, 1620-1628. http://doi.org/10.1111/j.13652702.2012.04284.x

Ivarsson, B., Ekmehag, B., \& Sjöberg, T. (2014). Waiting for a heart or lung transplant: Relatives' experience of information and support. Intensive and Critical Care Nursing, 30(4), 188-195. http://doi.org/10.1016/j.iccn.2014.03.003

Jacelon, C. S., \& Imperio, K. (2005). Participant diaries as a source of data in research with older adults. Qualitative Health Research, 15(7), 991-997. 
http://doi.org/10.1177/1049732305278603

Jordan, J., Price, J., \& Prior, L. (2015). Disorder and disconnection: Parent experiences of liminality when caring for their dying child. Sociology of Health \& Illness, 37(6), 839855. http://doi.org/10.1111/1467-9566.12235

Josselson, R., Lieblich, A., \& McAdams, D. P. (2003). Up close and personal: The teaching and learning of narrative research. Washington, D.C.: American Psychological Association.

Kaiser, K. (2009). Protecting respondent confidentiality in qualitative research. Qualitative Health Research, 19(11), 1632-1641. http://doi.org/10.1177/1049732309350879

Keefe, J., \& Rajnovich, B. (2007). To pay or not to pay: Examining underlying principles in the debate on financial support for family caregivers. Canadian Journal on Aging, 26(S1), 103-115. http://doi.org/10.3138/cja.26.suppl

Kelly, A. (2008). Living loss: An exploration of the internal space of liminality. Mortality, 13(4), 335-350. http://doi.org/10.1080/13576270802383915

Klodnicka Kouri, K., Ducharme, F. C., \& Giroux, F. (2011). A psycho-educational intervention focused on communication for caregivers of a family member in the early stage of Alzheimer's disease: Results of an experimental study. Dementia, 10(3), 435-453. http://doi.org/10.1177/1471301211408124

Kruse, B. G. (2006). The meaning of perseverance: Caregiver stories of courage during recent hurricanes. Journal of Hospice and Palliative Care, 8(6), 338-345. Retrieved from www.jhpn.com/

Kurz, J. M. (2002). Vulnerability of well spouses involved in lung transplantation. Journal of Family Nursing, 8(4), 353-370. http://doi.org/10.1177/107484002237512

Kurz, J. M., \& Cavanaugh, J. C. (2001). A qualitative study of stress and coping strategies used 
by well spouses of lung transplant candidates. Family Systems \& Health, 19(2), 181-197. http://doi.org/10.1037/h0089448

Lai, C. K. (2010). Narrative and narrative enquiry in health and social sciences. Nurse Researcher, 17(3), 72-84. http://doi.org/10.7748/nr2010.04.17.3.72.c7748

Lapum, J. L. (2008). The performative manifestation of a research identity: Storying the journey through poetry. Forum: Qualitative Social Research, 9(2).

Ledoux, K. (2015). Understanding compassion fatigue: Understanding compassion. Journal of Advanced Nursing, 71(9), 2041-2050. http://doi.org/10.1111/jan.12686

Lefaiver, C. A., Keough, V. A., Letizia, M., \& Lanuza, D. M. (2009). Quality of life in caregivers providing care for lung transplant candidates. Progress in Transplantation, 19(2), 142-152. http://doi.org/10.7182/prtr.19.2.g226182714730n07

Leung, D., \& Lapum, J. (2005). A poetical journey: The evolution of a research question. International Journal of Qualitative Methods, 4(3), 63-82. Retrieved from https://ejournals.library.ualberta.ca/index.php/IJQM/index

Lieblich, A., Tuval-mashiach, R., \& Zilber, T. (1998). Narrative Research: Reading, Analysis, and Interpretation. Narrative research: reading, analysis and interpretation. Thousand Oaks: Sage Publications. http://doi.org/10.4135/9781412985253

Little, M., Jordens, C. F. C., Paul, K., Montgomery, K., \& Philipson, B. (1998). Liminality: A major category of the experience of cancer illness. Social Science and Medicine, 47(10), 1485-1494. http://doi.org/10.1016/S0277-9536(98)00248-2

Lynch, S. H., \& Lobo, M. L. (2012). Compassion fatigue in family caregivers: A Wilsonian concept analysis. Journal of Advanced Nursing, 68(9), 2125-2134. http://doi.org/10.1111/j.1365-2648.2012.05985.x 
Macdonald, K. (2006). Living in limbo-patients with cystic fibrosis waiting for transplant. British Journal of Nursing, 15(10), 567-572. http://doi.org/http://dx.doi.org/10.12968/bjon.2006.15.10.21134

Mahon-Daly, P., \& Andrews, G. J. (2002). Liminality and breastfeeding: Women negotiating space and two bodies. Health and Place, 8, 61-76. http://doi.org/10.1016/S13538292(01)00026-0

McGuire, S., \& Georges, J. (2003). Undocumentedness and liminality as health variables. Advances in Nursing Science, 26(3), 185-195.

Meltzer, L. J., \& Rodrigue, J. R. (2001). Psychological distress in caregivers of liver and lung transplant candidates. Journal of Clinical Psychology, 8(3), 173-180.

Mishel, M. H. (1988). Uncertainty in Illness. Journal of Nursing Scholarship, 20(4), 225-232. http://doi.org/10.1111/j.1547-5069.1988.tb00082.x

Mittelman, M. S., Roth, D. L., Coon, D. W., \& Haley, W. E. (2004). Sustained Benefit of Supportive Intervention for Depressive Symptoms in Caregivers of Patients with Alzheimer's Disease. American Journal of Psychiatry, 161(5), 850-856. http://doi.org/10.1176/appi.ajp.161.5.850

Monterosso, L., Young, J., \& Morey, S. (2003). Relocation information needs of lung transplant recipients and carers. Transplant Nurses Journal, 12(2), 16-22. Retrieved from http://www.tna.asn.au/tja-journal/about-the-journal/

Murakami, H. (1998). South of the border, west of the sun. New York: Random House Inc.

Myaskovsky, L., Dew, M. A., Switzer, G. E., McNulty, M. L., DiMartini, A. F., \& McCurry, K. R. (2005). Quality of life and coping strategies among lung transplant candidates and their family caregivers. Social Science \& Medicine, 60(10), 2321-32. 
http://doi.org/10.1016/j.socscimed.2004.10.001

Naef, R., \& Bournes, D. A. (2009). The lived experience of waiting: A Parse method study. Nursing Science Quarterly, 22(2), 141-153. http://doi.org/10.1177/0894318409331932

Nazarian, V. (2002). Dreams of the compass rose. Maryland: Wildside Press.

Oudhoff, J. P., Timmermans, D. R. M., Bijnen, A. B., \& van der Wal, G. (2004). Waiting for elective general surgery: Physical, psychological and social consequences. ANZ Journal of Surgery, 74(5), 361-367. http://doi.org/10.1111/j.1445-1433.2004.02998.x

Pailler, M. E., Johnson, T. M., Zevon, M. a., Kuszczak, S., Griffiths, E., Thompson, J., ... Wetzler, M. (2015). Acceptability, Feasibility, and Efficacy of a Supportive Group Intervention for Caregivers of Newly Diagnosed Leukemia Patients. Journal of Psychosocial Oncology, 33(2), 163-177. http://doi.org/10.1080/07347332.2014.992086

Paterson, B. L. (2001). The shifting perspectives model of chronic illness. Journal of Nursing Scholarship, 33(1), 21-6. http://doi.org/10.1111/j.1547-5069.2001.00021.x

Pereira, H. R., Anto, M., \& Botelho, R. (2011). Sudden informal caregivers: the lived experience of informal caregivers after an unexpected event. Journal of Clinical Nursing, 20, 24482457. http://doi.org/10.1111/j.1365-2702.2010.03644.x

Perry, B., Dalton, J. E., \& Edwards, M. (2010). Family caregivers' compassion fatigue in longterm facilities. Nursing Older People, 22(4), 26-31. http://doi.org/10.7748/nop2010.05.22.4.26.c7734

Phillips, K. M., Burker, E. J., \& White, H. C. (2011). The roles of social support and psychological distress in lung transplant candidacy. Progress in Transplantation, 21(3), 200-206. http://doi.org/10.7182/prtr.21.3.48q4vw7428q2786u

Picoult, J. (2013). The Storyteller. New York: Emily Bestler Books/Washington Square Press. 
Plank, A., Mazzoni, V., \& Cavada, L. (2012). Becoming a caregiver: New family carers' experience during the transition from hospital to home. Journal of Clinical Nursing, 21, 2072-2082. http://doi.org/10.1111/j.1365-2702.2011.04025.x

Polkinghorne, D. E. (1988). Narrative knowing and the human sciences. New York: State University Press.

Poole, K. (1997). The emergence of the "waiting game": A critical examination of the psychosocial issues in diagnosing breast cancer. Journal of Advanced Nursing, 25(2), 273-281. http://doi.org/10.1046/j.1365-2648.1997.1997025273.x

Retta, B. (2011). From "reel" to "real" - Embodied responses to rape (Master's thesis). Retrieved from ProQuest Dissertations Publishing. (MR93406)

Rickman, J., \& Roberts, J. A. (2001). Education and debate. British Medicial Journal, 323, 293295. http://doi.org/10.1136/bmj.322.7281.293

Rodrigue, J. R., \& Baz, M. A. (2007). Waiting for lung transplantation: Quality of life, mood, caregiving strain and benefit, and social intimacy of spouses. Clinical Transplantation, 21(6), 722-727. http://doi.org/10.1111/j.1399-0012.2007.00729.x

Rodrigue, J. R., Widows, M. R., \& Baz, M. A. (2006). Caregivers of lung transplant candidates: Do they benefit when the patient is receiving psychological services? Progress in Transplantation, 16(4), 336-342. http://doi.org/10.7182/prtr.16.4.18454p20831u7x7u

Sabo, B. (2014). Waiting and Liminality: A phenomenon of spousal caregiving? Cancer Nursing, 37(3), 184-188. http://doi.org/10.1097/NCC.0b013e31828ee266

Silva-Smith, A. L. (2007). Restructuring life: Preparing for and beginning a new caregiving role. Journal of Family Nursing, 13(1), 99-116. http://doi.org/10.1177/1074840706297425

Simich, L., Maiter, S., \& Ochocka, J. (2009). From social liminality to cultural negotiation: 
Transformative processes in immigrant mental wellbeing. Anthropology \& Medicine, 16(3), 253-266. http://doi.org/10.1080/13648470903249296

Streubert, H. J., \& Carpenter, D. R. (2011). Qualitative research in nursing: Advancing the humanistic imperative (5th Ed.). Philadelphia: Lippincott, Williams \& Wilkins.

Stubblefield, C., \& Murray, R. L. (2002). Waiting for lung transplantation: Family experiences of relocation. Pediatric Nursing, 28(5), 501-504. Retrieved from http://www.pediatricnursing.net/

Thabut, G., Christie, J. D., Mal, H., Fournier, M., Brugière, O., Leseche, G., ... Rizopoulos, D. (2013). Survival benefit of lung transplant for cystic fibrosis since lung allocation score implementation. American Journal of Respiratory and Critical Care Medicine, 187(12), 1335-1340. http://doi.org/10.1164/rccm.201303-0429OC

The Lung Association Alberta \& NWT. (2009). Lung transplant: Information for Alberta \& NWT residents. Retrieved from http://www.ab.lung.ca/sitewyze/files/LungTransplant.pdf

Thompson, K. (2007). Liminality as a descriptor for the cancer experience. Illness, Crisis \& Loss, 15(4), 333-351. http://doi.org/10.2190/IL.15.4.d

Trillium Gift of Life. (2015). Statistics. Retrieved November 9, 2015, from http://www.giftoflife.on.ca/en/publicreporting.htm\#waitinglistbyage

Turcotte, M. (2013). Family caregiving: What are the consequences? Statistics Canada, 1-16. Retrieved from http://www.statcan.gc.ca/pub/75-006-x/2013001/article/11858-eng.htm Turner, V. (1967). The forest of symbols. The Forest of Symbols. New York City: Cornell University Press.

Turner, V. (1969). The ritual process: Structure and anti-structure. Ithaca: Cornell University Press. 
Turner, V. (1979). Process, performance and pilgrimage. New Delhi: Concept Publishing Company.

University Health Network. (2010). Lung transplant patient manual. Retrieved from http://www.uhn.ca/MOT/PatientsFamilies/Clinics_Tests/Lung_Transplant/Documents/lu ng transplants.pdf

van Gennep, A. (1960). Initiation Rites. In Rites of Passage. London: Compton Printing Works. http://doi.org/10.1007/s13398-014-0173-7.2

Walker, L. O., \& Avant, K. C. (1995). Strategies for theory construction in nursing. Norwalk: Appleton \& Lange.

Ward-Griffin, C., St-Amant, O., \& Belle Brown, J. (2011). Compassion fatigue within double duty caregiving: Nurse-daughters caring for elderly parents. The Online Journal Issues in Nursing. http://doi.org/10.3912/OJIN.Vol16No01Man04

Warner, J., \& Gabe, J. (2004). Risk and liminality in mental health social work. Health, Risk \& Society, 6(4), 387-399. http://doi.org/10.1080/13698570412331323261

Watson, G. (2011). Parental liminality: A way of understanding the early experiences of parents who have a very preterm infant. Journal of Clinical Nursing, 20(9-10), 1462-1471. http://doi.org/10.1111/j.1365-2702.2010.03311.x

Weaver, K., \& Mitcham, C. (2008). Nursing concept analysis in North America: State of the art. Nursing Philosophy: An International Journal for Healthcare Professionals, 9(3), 180194. http://doi.org/10.1111/j.1466-769X.2008.00359.x

White, S., \& Keefe, J. (2005). Paying caregivers: A briefing paper. Canadian Caregiving Coalition. Retrieved from http://www.ccc-ccan.ca/media.php?mid=55

Whiting, L. S. (2008). Semi-structured interviews: Guidance for novice researchers. Nursing 
Standard, 22(23), 35-40. http://doi.org/10.7748/ns2008.02.22.23.35.c6420

Whytehead, C. J. (2006). The burdens experienced by caregivers of candidates waiting for lung transplant. Retrieved from ProQuest Dissertations Publishing. (1433261)

Whytehead, C. J., Davies, M., \& Bolden, T. (2012). Catch your breath! A guide to lung transplant for families and support people. Retrieved from http://www.uhn.ca/MOT/PatientsFamilies/Clinics_Tests/Lung_Transplant/Documents/Lu ngTransplant_GuideSupportPeople_2012.pdf

Yelle, M. T., Stevens, P. E., \& Lanuza, D. M. (2013). Waiting narratives of lung transplant candidates. Nursing Research and Practice, 2013, 1-10. http://doi.org/http://dx.doi.org/10.1155/2013/794698

Yorke, J., \& Cameron-Traub, E. (2008). Patients' perceived care needs whilst waiting for a heart or lung transplant. Journal of Clinical Nursing, 17(5a), 78-87. http://doi.org/10.1111/j.1365-2702.2007.02078.x

Zeidner, M., Hadar, D., Matthews, G., \& Roberts, R. D. (2013). Personal factors related to compassion fatigue in health professionals. Anxiety, Stress, and Coping, 26(6), 595-609. http://doi.org/10.1080/10615806.2013.777045

Zulman, D. M., Schafenacker, A., Barr, K. L., Moore, I. T., Fisher, J., McCurdy, K., ... Northouse, L. (2012). Adapting an in-person patient-caregiver communication intervention to a tailored web-based format. Psycho-Oncology, 21(3), 336-341. http://doi.org/10.1002/pon.1900 